\title{
The California Greenhouse Gas Initiative and its Implications to the Automotive Industry
}

prepared by

Center for Automotive Research

Ann Arbor, MI 


\section{About Argonne National Laboratory}

Argonne is managed by The University of Chicago for the U.S. Department of Energy under contract W-31-109-Eng-38. The Laboratory's main facility is outside Chicago, at 9700 South Cass Avenue, Argonne, Illinois 60439. For information about Argonne and its pioneering science and technology programs, see www.anl.gov.

\section{Availability of This Report}

This report is available, at no cost, at http://www.osti.gov/bridge. It is also available

on paper to the U.S. Department of Energy and its contractors, for a processing fee, from:

U.S. Department of Energy

Office of Scientific and Technical Information

P.O. Box 62

Oak Ridge, TN 37831-0062

phone (865) 576-8401

fax (865) 576-5728

reports@adonis.osti.gov

\section{Disclaimer}

This report was prepared as an account of work sponsored by an agency of the United States Government. Neither the United States Government nor any agency thereof, nor The University of Chicago, nor any of their employees or officers, makes any warranty, express or implied, or assumes any legal liability or responsibility for the accuracy, completeness, or usefulness of any information, apparatus, product, or process disclosed, or represents that its use would not infringe privately owned rights. Reference herein to any specific commercial product, process, or service by trade name, trademark, manufacturer, or otherwise, does not necessarily constitute or imply its endorsement, recommendation, or favoring by the United States Government or any agency thereof. The views and opinions of document authors expressed herein do not necessarily state or reflect those of the United States Government or any agency thereof, Argonne National Laboratory, or The University of Chicago. 


\section{The California Greenhouse Gas Initiative and its Implications to the Automotive Industry}

by

Center for Automotive Research

for

The Center for Transportation Research, Argonne National Laboratory

and the

United States Department of Energy

September 2005

Project Managers:

Center for Automotive Research: B. Smith

Argonne National Laboratory Center for Transportation Research: D.J. Santini
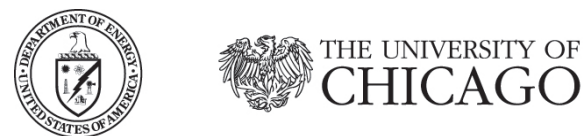

CAR CENTER FOR AUTOMOTIVE RESEARCH

Argonne National Laboratory is managed by 


\section{Acknowledgements}

As with any project, this report is the result of many people contributing in many ways. The authors of this report would like to thank Karen Esper and Diana Douglass, who contributed greatly by creating and formatting the document. Their expertise and patience were critical to the project's success. Chris Gulis and Emilio Brahmst spent many long hours researching, documenting and detailing powertrain technologies and manufacturing processes.

Dr Richard Gerth created, applied, and wrote analysis for the single and multiple Logit statistical models used for forecasting. Dr. Gerth also served as an advisor for the regression modeling, and overall statistical analysis. Jillian Lindsay Gauthier contributed by assisting with the statistical modeling and overall document review. Chris Powers also added document review support.

Finally, we would like to thank those in the automotive industry that took time to guide the authors. This topic presents many challenges, not the least of which being the political risks involved in participating in any discussion. The arena of advanced powertrain technology-is a highly controversial and emotional issue. Several industry experts were willing to rise above the fray and offer their time and highly knowledgeable insight into the many challenges of advanced powertrain technology. For this, CAR is greatly appreciative.

Brett C. Smith,

Assistant Director, Manufacturing Engineering and Technology

Raymond T. Miller,

Research Assistant 


\section{Table of Contents}

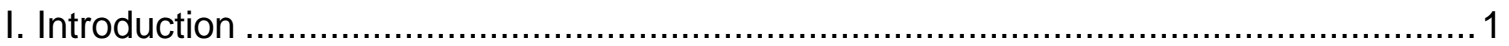

II. Pathways to Meeting Regulation Created Low Volume Market Requirements............. 3

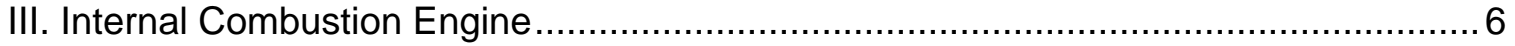

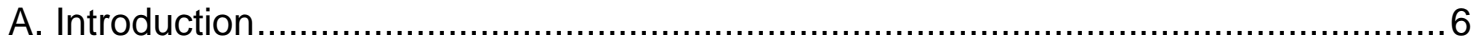

B. Internal Combustion Engine Manufacturing Processes........................................ 6

C. Internal Combustion Engine Manufacturing Investment and Flexibility.................. 10

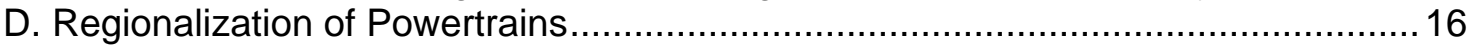

E. Internal Combustion Engine Component Cost Modeling ................................... 17

F. Internal Combustion Engine Component Cost and Fuel Economy Forecasts......... 19

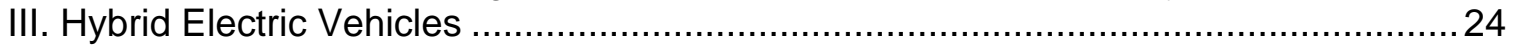

A. Hybrid Electric Vehicle Architecture and Technology....................................... 24

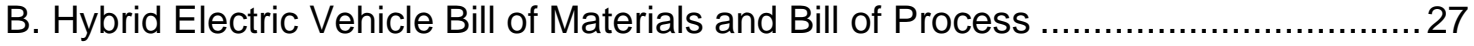

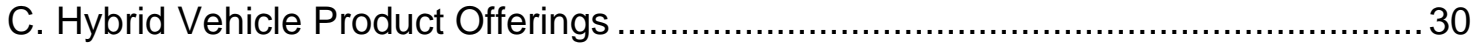

D. Manufacturer Hybrid Vehicle Product Plans...................................................... 31

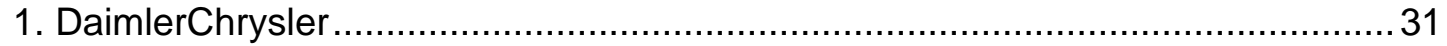

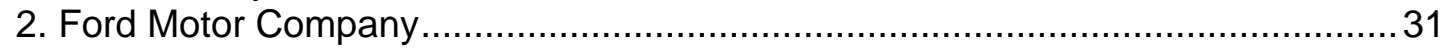

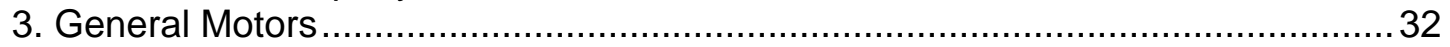

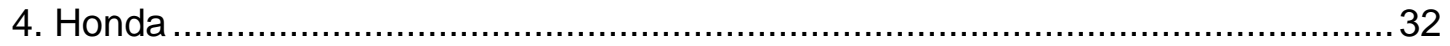

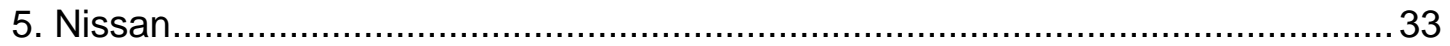

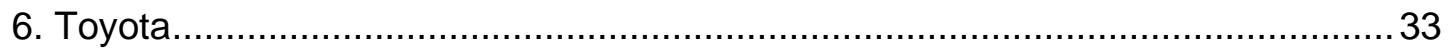

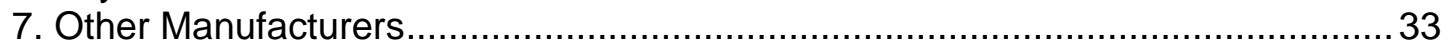

E. Pathways to Scale Economy for Hybrid Electric Vehicles ................................... 35

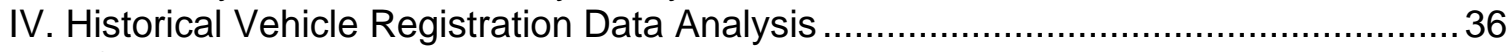

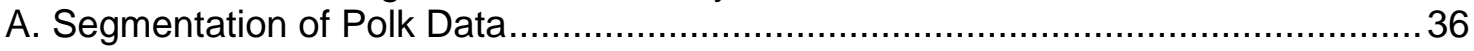

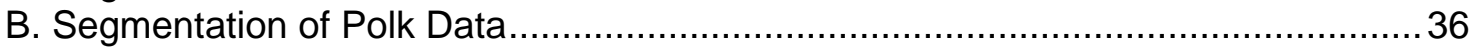

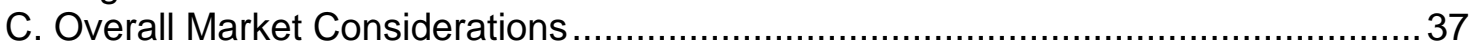

D. PCLDT1 Passenger Cars and Light Duty Trucks 1 (equal to or less than 3750

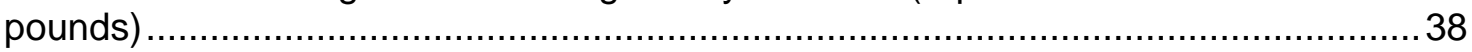

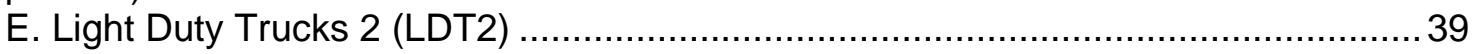

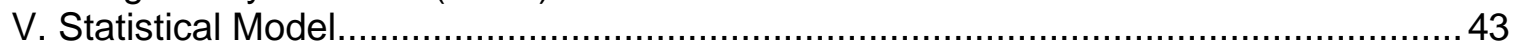

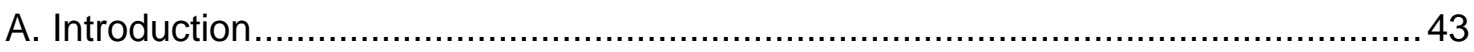

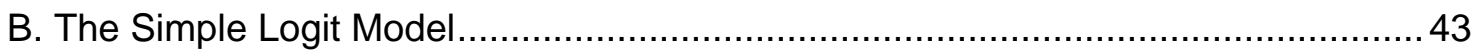

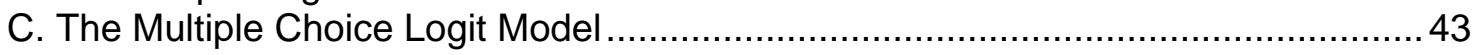

D. Application of the Logit Model to the Drivetrain Data ..................................... 45

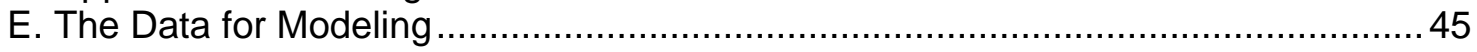

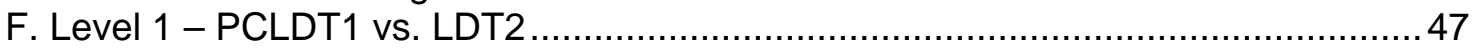

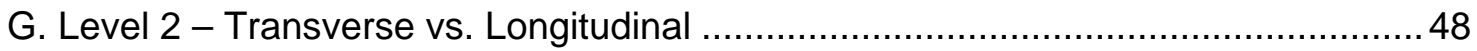

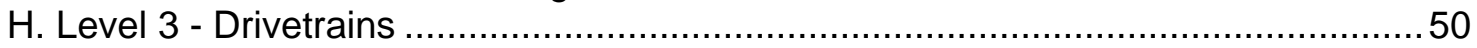

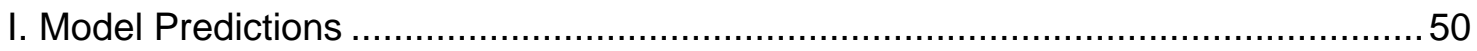

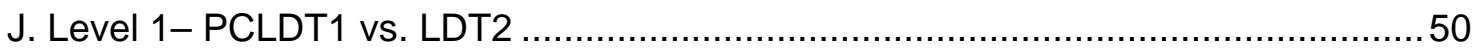

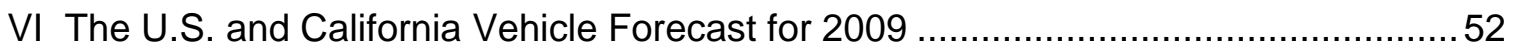

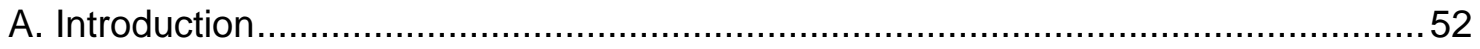

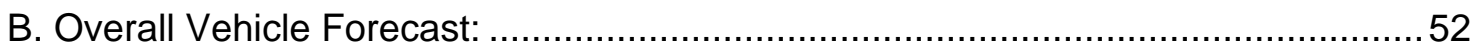

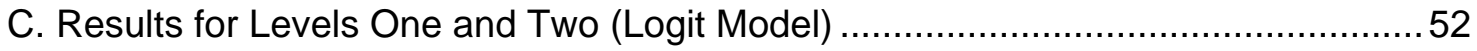

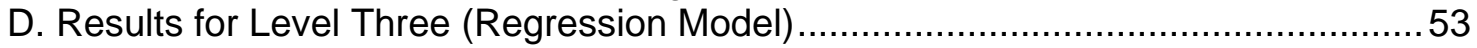

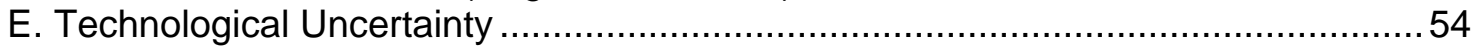

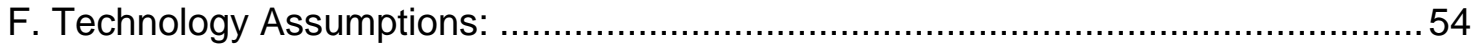




\section{Table of Tables}

Table 1 - Domestic Lt.-Vehicle Production Summary by Engine............................... 11

Table 2 - Engine Plant Conversion....................................................................... 15

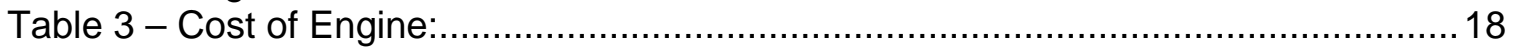

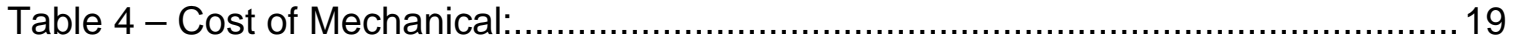

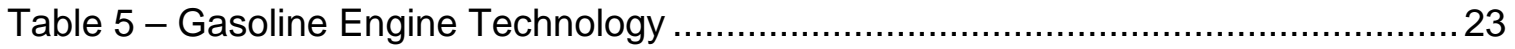

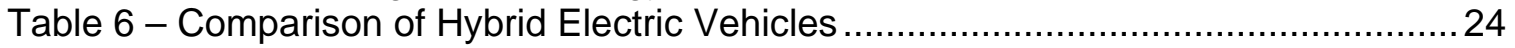

Table 7 - Weight Comparison of Hybrid Vehicle with Non-Hybrid Model .......................25

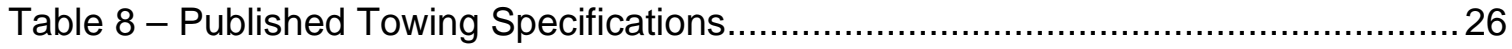

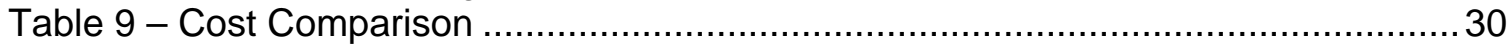

Table 10 - Light Vehicle Hybrid Electric Vehicles in the U.S. Market ........................... 34

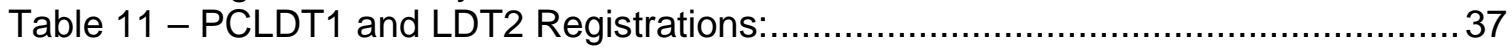

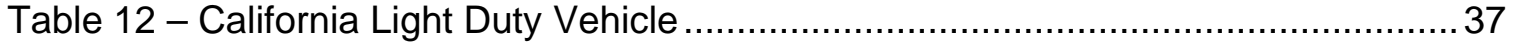

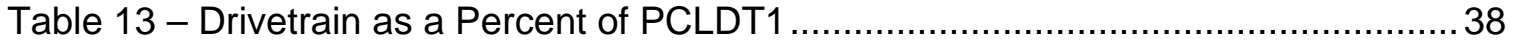

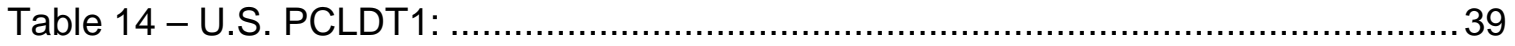

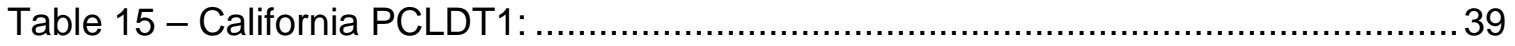

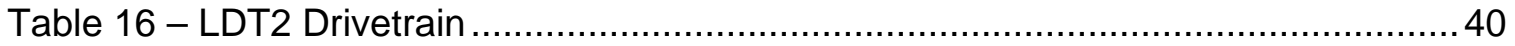

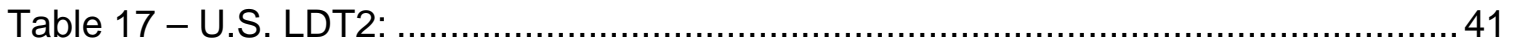

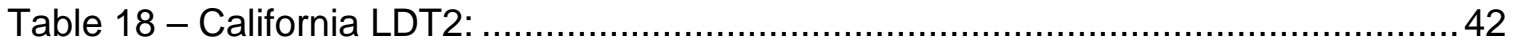

Table 19 - Percent of PCLDT1 Transverse Drivetrains Sold in the U.S. and in CA from

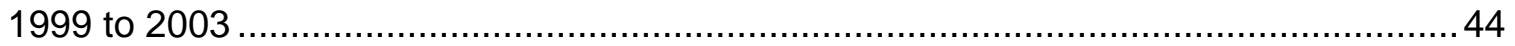

Table 20 - Vehicle Segmentation of Vehicle Registration ..................................... 46

Table 21 - LSE Regression Results for the PCLDT1 Model ....................................4 47

Table 22 - LSE Regression Results for the PCLDT1 Model ....................................49

Table 23 - Model Table for PCLDT1 ................................................................. 51

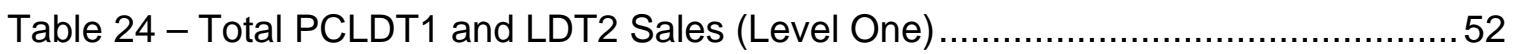

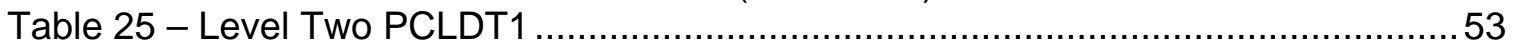

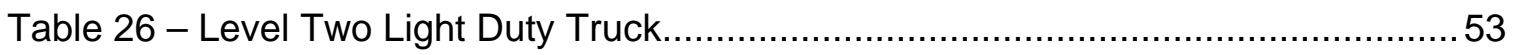

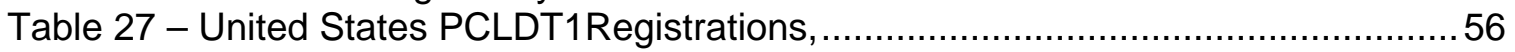

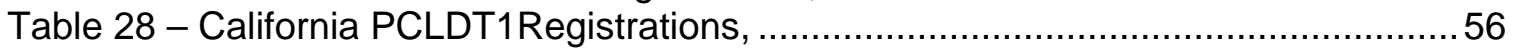

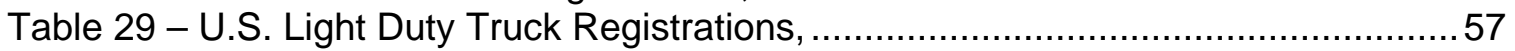

Table 30 - California Light Duty Truck Registrations, ........................................... 57

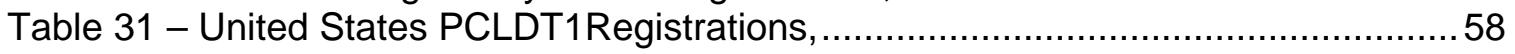

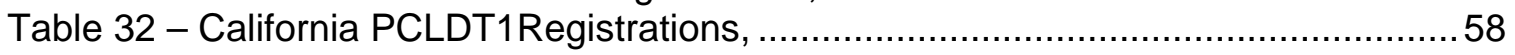

Table 33 - U.S. Light Duty Truck Registrations, ............................................. 59

Table 34 - California Light Duty Truck Registrations, ......................................... 60 


\section{Table of Figures}

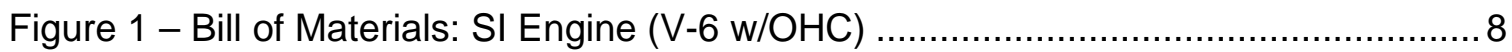

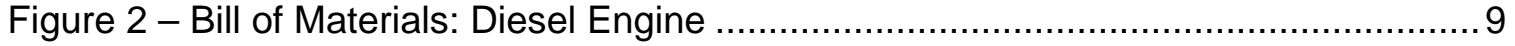

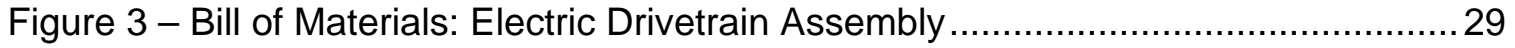

Figure 4 - Predicted and Actual Percentages........................................................ 51 


\section{List of Appendices}

Appendix I Hybrid Electric Vehicle Layout: Selected Vehicles Available in the U.S. Vehicle Market 58

Appendix II The Honda IMA System-Converting ICE to HEV ................................ 61

Appendix III Logit Model Results.

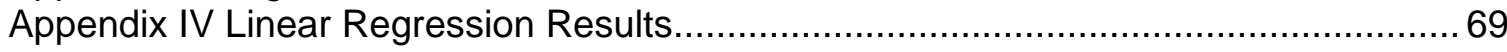

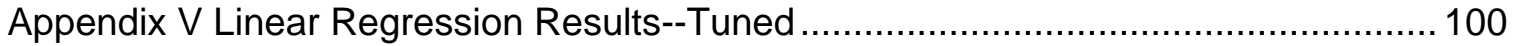

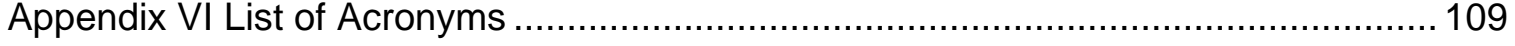




\section{Executive Summary}

\section{Introduction}

CAR undertook this investigation to better understand the costs and challenges of a local (state) regulation necessitating the implementation of alternative or advanced powertrain technology. CAR will attempt to add insight into the challenges that local regulations present to the automotive industry, and to contribute further to the discussion of how advanced powertrain technology may be used to meet such regulation.

Any local law that (directly or indirectly) affects light duty motor vehicle fuel economy creates what in effect is a specialty market for powertrain technology. As such these small markets present significant challenges for automotive manufacturers. First, a small market with unique standards presents significant challenges to an industry that has sustained growth by relying on large volumes to achieve scale economies and deliver products at a cost acceptable to the consumer. Further, the challenges of the additional technology make it likely that any powertrain capable of meeting the stringent emissions standards will include costly additional components, and thus will be more costly to manufacture. It is likely that manufacturers would consider the following actions as steps to deliver products to meet the pending California regulatory requirements anticipated as a result of prior California legislation:

1. Substituting more fuel efficient vehicles: Bring in more efficient vehicles from global operations, while likely dropping existing domestic products.

2. Substituting powertrains: Add existing downsized engines (i.e. turbocharged versions, etc.) into California market-bound vehicles.

3. Powertrain enhancements: Add technology to current engine and transmission offerings to improve efficiency and reduce emissions.

4. Incorporating alternative powertrains into existing vehicle platforms: Develop a hybrid or other type of powertrain for an existing vehicle.

5. New powertrains and new platforms: Develop vehicles specifically intended to incorporate new powertrain technologies, materials and/or design (e.g. the General Motors EV1 or the Toyota Prius).

These five actions represent the gamut from the least complicated solution to the most complex. They also generally represent the least expensive response to the most expensive. It is possible that the least expensive responses may be least likely to meet market demands while achieving required GHG emission limits. At the same time, the most expensive option may produce a vehicle that satisfies the GHG reduction requirements and meets some consumer requirements, but is far too costly to manufacture and sell profitably. The response of a manufacturer would certainly have to take market size, consumer acceptance, technology implication and cost, as well as internal capacities and constraints, into consideration. It is important to understand that individual companies may respond differently in the short term. However, it is probable that there would be a more consistent industry-wide response in the longer term.

Options 1 and 2 present the simplest responses. A company may reach into its global portfolio to deliver vehicles that are more fuel-efficient. These vehicles are usually much smaller and significantly less powerful than current U.S. offerings. Industry respondents indicated that such a strategy may be possible but would likely be met with less than positive reaction from the buying public. A general estimate for the cost to homologize a vehicle-that is, to prepare an existing vehicle for entry into the United States provided 
all business conditions were met (reasonable product, capacity availability, etc.), would be approximately $\$ 50$ million. Assuming an estimated cost for homologation to meet U.S. standards of $\$ 50$ million and a 20,000 vehicle per year sales volume in California, the company would then incur a $\$ 2,500$ per-vehicle cost to bring them into the market. A manufacturer may also choose to incorporate a more efficient powertrain into a vehicle already sold in the market. The costs associated with such a strategy would include reengineering the vehicle engine compartment to accept the new powertrain, and developing, engineering and manufacturing those parts unique to the vehicle. Costs would also be incurred to achieve emission certification. Total costs per vehicle, if sold only in California would be similar to nationally averaged costs per vehicle when bringing a new vehicle into the national market.

While companies may consider the importation of a more fuel-efficient vehicle from their current global portfolio, or the addition of a powertrain from another market, it is likely that these would be seen as stop-gap responses to the legislation. Many of the candidate vehicles and powertrains would likely not meet California consumer expectations, and may not provide enough fuel savings to achieve more severe emission regulations, thus offering only a step toward any solution.

\section{Internal Combustion Engine Manufacturing Investment and Flexibility}

A major concern for any manufacturer is uncertainty in future markets. In few areas of the automotive business is this more noticeable than the engine plant. Designed to take advantage of high-volume scale economies, engine facilities have evolved into highly efficient, but relatively inflexible, operations. Flexibility at engine plants has traditionally been limited to engines of similar cylinder number, with similar geometry. Thus, any rapid change in product mix (i.e., 4-cylinder, 6-cylinder, 8-cylinder, gasoline, diesel, etc. or even a change in head or block design) presents a threat to most manufacturers. By comparing three separate estimates, CAR was able to develop a reasonable target cost for investing in new tooling for an existing engine facility. We estimate the approximate cost to be $\$ 170$ to $\$ 185$ million dollars of investment for a six-cylinder $V$-configuration gasoline engine at a volume of 300,000 per year (production lost to downtime). Any change in engine configuration-or the inclusion of a low-volume version of an engine (as in the case of a 'high mileage' variant)-would present several cost hurdles. The addition or substitution of technologies to existing engine programs would likely require change to the manufacturing system, and thus additional cost.

Traditional engine head and block machining lines have used highly fixed transfer lines. The transfer line, while offering high-volume scale economies, requires significant rework (possibly requiring as much as 24 months for changeover, including 6 months of tool design change preceding an actual down time as high as 18 months) for the addition of a new product. Increasingly manufacturers have been incorporating computer numerically controlled (CNC) machinery as a means to gain flexibility. CNC machines offer increased flexibility, but at a higher up-front investment cost. CAR estimates that it would require investment of between $\$ 675$ million and $\$ 1.1$ billion for the automotive industry to re-tool engine facilities to create a series of significantly more fuel efficient internal combustion engines in order to provide adequate reductions in carbon dioxide emissions.

The cost of product development must also be considered when investigating the costs of adaptation. While the cost of developing an engine program varies drastically, it is 
possible to make some assumptions based on published estimates. CAR estimates that the development cost of high volume 6-cylinder $V$ configuration engine is approximately $\$ 69$ per engine, and \$333 per-unit cost for a low volume derivative.

\section{Internal Combustion Engine Component Cost Modeling}

CAR used an internally developed engine cost model to estimate component costs for this project. CAR has used the model for previous internal and external projects. It is intended to represent a stylized cost model for the complete vehicle, divided into basic systems. For this project, CAR used input from several sources to further tune the model. The model includes engine mechanical, fuel delivery, engine electrical and exhaust. The model assumes a single overhead cam engine configuration and is closely matched to the NAICS codes. These are stylized costs assuming a scale volume manufacturing scenario. This model does not attempt to capture the component development costs, nor other various overhead costs. Table 1 shows the cost estimates for each of the four engine modules as derived from the model.

Exec Sum Table 1 - Cost of Engine:

Stylized Cost of ICE Engines; Inline 4, V6, Inline 6 Diesel (CIDI), and V8 Configurations

\begin{tabular}{|l|c|c|c|c|}
\hline $\begin{array}{l}\text { Engine Module } \\
\text { as a Percent of } \\
\text { Total }\end{array}$ & $\begin{array}{c}\text { 4-Cylinder SI } \\
\text { Inline } \\
\text { Configuration } \\
\text { (dollars) }\end{array}$ & $\begin{array}{c}\text { 6-Cylinder SI } \\
\text { V } \\
\text { Configuration } \\
\text { (dollars) }\end{array}$ & $\begin{array}{c}\text { 6-Cylinder CIDI } \\
\text { Inline } \\
\text { Configuration } \\
\text { (dollars) }\end{array}$ & $\begin{array}{c}\text { 8-Cylinder SI } \\
\text { V } \\
\text { Configuration } \\
\text { (dollars) }\end{array}$ \\
\hline $\begin{array}{l}\text { Engine } \\
\text { Mechanicals }\end{array}$ & $\$ 816$ & $\$ 1,225$ & $\$ 1,932$ & $\$ 1,523$ \\
\hline Fuel Delivery & $\$ 374$ & $\$ 509$ & $\$ 1,176$ & $\$ 609$ \\
\hline $\begin{array}{l}\text { Engine } \\
\text { Electrical }\end{array}$ & $\$ 321$ & $\$ 452$ & $\$ 420$ & $\$ 479$ \\
\hline Exhaust & $\$ 189$ & $\$ 264$ & $\$ 560$ & $\$ 276$ \\
\hline $\begin{array}{l}\text { Additional } \\
\text { Exhaust } \\
\text { Technology }\end{array}$ & N/A & N/A & $\$ 1,500$ & N/A \\
\hline $\begin{array}{l}\text { Total Stylized } \\
\text { Cost }\end{array}$ & $\$ 1,700$ & $\$ 2,450$ & $\$ 5,588$ & $\$ 2,886$ \\
\hline
\end{tabular}

The after-treatment for diesel engines presents a great challenge for the industry. There was some belief by the sources that that lean $\mathrm{NO}_{\mathrm{x}}$ catalysts or $\mathrm{NO}_{\mathrm{x}}$ absorbers and selective catalytic reduction (SCR) are likely to be technologically viable methods of meeting Tier 2 Bin 5 for $\mathrm{NO}_{\mathrm{x}}$ reduction. Yet, there was also strong concern expressed that these technologies were not yet able to meet high mileage durability standards, and may be too costly in their final form. Several companies are also focusing on selective catalytic reduction (SCR) technology for $\mathrm{NO}_{\mathrm{x}}$ reduction. A common strategy for SCR is to periodically inject urea into the exhaust, thus neutralizing $\mathrm{NO}_{\mathrm{x}}$. However, this strategy relies on the user - the driver - to be responsible for assuring that there is adequate urea in the canister. Initially there was great doubt that the technology would be a viable option for the U.S. market. Many felt that the E.P.A. would only cautiously consider the implications of shifting responsibility from the manufacturer to the driver. However, 
given recent discussions with industry sources, SCR appears to be considered an increasingly viable option going forward.

Internal Combustion Engine Component Cost and Fuel Economy Estimates

An important element of any vehicle sales forecast for 2009 is whether or not the technology is likely to be used on those vehicles. Given lead time required by the automotive industry to incorporate new technology into their products, the technology choices for 2009 are relatively limited. This report will address (and attempt to quantify) possible near-term technologies, and also briefly investigate those technologies that appear to be possible long-term options. Through literature searches CAR collected a list of potential technologies that served as a foundation. CAR then discussed the technology options with more than 25 individuals (stakeholders from various segments of the industry).

The estimates for carbon dioxide reduction ${ }^{1}$ and cost (Table 2) are presented as averages of the responses given by the experts. However, CAR wishes to include the 'it depends' variable in the discussion. That is, invariably, the experts would estimate a cost and efficiency gain for the technology and then comment that their response depended greatly on a wide variety of factors. Some of these variables were controllable-such as base engine, vehicle segment, etc. However, there were others that were far more qualitative. For example, there is a wide range of current expertise among companies in core engine engineering; it is possible for a top performer to get significantly better efficiency gains from a given technology than a company with lesser engineering expertise. Conversely, it is also possible that a poor performer may be able to get more out of a technology because there is, "room for improvement." Several panelists were impressed with (and generally accepted) recent reports that performed modeling on various vehicle segments. However, they indicated that much variance for a 'real world' application should still be expected. They also believed that variance may tend to be downward biased-that is, real world performance would be less than modeled.

\footnotetext{
${ }^{1}$ The respondents provided estimates of fuel economy benefits, which CAR converted in the report to carbon dioxide reduction estimates.
} 
Exec Sum Table 2 - Gasoline Engine Technology

\begin{tabular}{|c|c|c|}
\hline & $\begin{array}{c}\text { Incremental } \\
\text { Cost }\end{array}$ & $\begin{array}{l}\mathrm{CO}_{2} \text { Emissions } \\
\text { Reduction }\end{array}$ \\
\hline \multicolumn{3}{|l|}{ Valvetrain Technologies } \\
\hline Intake Cam Phasing & $\$ 85$ & 4 \\
\hline Exhaust Cam Phasing & $\$ 90$ & 2 \\
\hline Dual Equal Cam Phasing & $\$ 150$ & 4 \\
\hline Mechanical Variable Valve Lift and Duration & $\$ 350$ & 7 \\
\hline${ }^{\star}$ Electromagnetic Actuation & $\$ 600$ & 9 \\
\hline${ }^{\star}$ Electrohydraulic Actuation & $\$ 700$ & 9 \\
\hline Cylinder Deactivation & $\$ 150$ & 7 \\
\hline \multicolumn{3}{|l|}{ Combustion Chamber } \\
\hline Variable Compression Ratio & $\$ 350$ & 5 \\
\hline GDI-Stoichiometric & $\$ 225$ & 6 \\
\hline${ }^{\star} \mathrm{GDI}$ - Lean Burn Stratified Charge & $\$ 500$ & 11 \\
\hline *Gasoline $\mathrm{HCCl}$ & $\$ 700$ & 12 \\
\hline \multicolumn{3}{|l|}{ Transmission Technologies } \\
\hline 6-Speed Automatic Transmission & $\$ 100$ & 6 percent \\
\hline Continuously Variable Transmission (CVT) & $\$ 50$ & 8 percent \\
\hline${ }^{\star \star A}$ Automated Manual Transmission (5/6 sp) & $\begin{array}{c}\text {-\$140 to - } \\
\$ 80^{\star *}\end{array}$ & 6-7 percent over $(A / T)$ \\
\hline
\end{tabular}

\section{Hybrid Electric Technology}

Currently two formats of hybrid, with several variations, are considered the likely candidates to gain market acceptance. Honda has chosen to use the integrated motor assist (IMA) layout for their initial entries, while Toyota and Ford offer products using Parallel-series HEV technology. For this report (specifically the 2009 forecast), CAR will only consider vehicles that use electric power for motive purposes. Thus, the General Motors Sierra and Silverado pick-up trucks are not considered for this report. CAR spent time discussing each of the systems with several industry sources. The general theme of their responses confirmed the belief that the IMA offered a more attractive cost hurdle, while the parallel systems might offer more efficiency. Those familiar with HEV design were strongly convinced of two things. First, they believed there is a wide range of performance and efficiency gains possible from both systems. Thus, the ability to 'tune' similar systems differently made it nearly impossible to rule out any efficiency estimates, nor confirm that there was any one best approach. In essence, what they said was that at this point there are too many variables to choose the one right path to hybridization. Second, many suggested that the modeling done to test these vehicles was not yet as precise as needed. The ability to predict real world performance is, for obvious reasons, not as advanced as that of the internal combustion engine. Several sources indicated that these challenges should not be viewed as reasons to forgo discussion on the subject, but instead to treat all results with great care.

Given those challenges, CAR attempted to gain insight into the cost of hybrid electric vehicle component technology. Most respondents were not able to present specific cost estimates, relying instead on likely cost ranges. Many of the sources indicated that there 
are numerous approaches to hybridization, thus creating vast differences in component performance requirements

Table 3 shows the range of component cost estimates for a 4-cylinder DOHC compact passenger car. It was assumed that the vehicle would achieve equivalent performance, with a 23 to 26 percent reduction in carbon dioxide emissions. We present these cost estimates with several caveats. First, the estimates were for an assumed volume of 100,000 components per year-levels that have yet to be achieved by any single manufacturer. Realistically, scale economies for such technologies will be achieved at much higher volumes - as one respondent noted; "The Auto supplier industry doesn't do anything in volumes of 100,000-and make money at it." Second, as indicated, all of the individuals interviewed were hesitant to discuss costs. All agreed there is great uncertainty regarding the cost structure. Finally, there are some who believe the initial current costs are significantly higher, and specifically with regard to batteries, may be difficult to reduce even with added volumes.

Exec Sum Table 3 - Cost Comparison Parallel and Integrated Starter Layouts

\begin{tabular}{|c|c|c|}
\hline Parallel & Component & $\begin{array}{c}\text { Integrated Starter } \\
\text { Generator }\end{array}$ \\
\hline$\$ 1,800-\$ 2,200$ & Battery (NiMH) & $\$ 1,500-\$ 1,800$ \\
\hline$\$ 600-\$ 680$ & $\begin{array}{c}\text { Inverter (power } \\
\text { conditioning) }\end{array}$ & $\$ 500-\$ 550$ \\
\hline$\$ 850-\$ 900$ & Power Control Unit & $\$ 600-\$ 800$ \\
\hline$\$ 500-\$ 600$ & Electric Motor & $\$ 700-\$ 800$ \\
\hline$\$ 350-\$ 500$ & Generator & Not applicable \\
\hline$\$ 50-\$ 100$ & $\begin{array}{c}\text { Transaxle/power } \\
\text { conversion* }\end{array}$ & Not applicable \\
\hline$\$ 4,150-\$ 4,890$ & Total Target Cost & $\$ 3,300-\$ 3,950$ \\
\hline *Increase over replaced transaxle
\end{tabular}

Finally, it has been common to assume that a portion of the added cost of hybrid technology would be offset by the use of a smaller engine. For such cost adjustment, one could use engine cost estimates presented earlier in this report to estimate a cost savings. However, at least three recent HEV entries have used the same-or even more complex engines than their non hybridized variant-thus eliminating any cost benefits from engine downsizing—but offering performance improvements.

\section{U.S. and California Market Segmentation Forecast}

The Center for Automotive Research acquired (through a partnership with R.L. Polk) U.S. and California vehicle registration data for the years 1999-2003. All passenger cars and the portion of LTD1s equal to or less than $3750 \mathrm{lbs}$. (loaded vehicle weight) were grouped together (hereafter referred to as PCLDT1). All LDT2s and the portion of LDT1s $3751 \mathrm{lbs}$. and greater were also grouped together (LDT2). ${ }^{2}$ The LDT2 also

\footnotetext{
${ }^{2}$ The vehicle weights were taken from Wards 2003 Annual Report. There are a number of vehicles counted that were discontinued before 2003. For these vehicles, the appropriate yearbook was used. There were several models (such as the Chevrolet Colorado) which had trim levels both above and below the 3750 mark. Since trim level is not found in the Polk data we differentiated by drivetrain (i.e. the heavier $4 \times 4$ models were separated from the lighter $2 \times 4$ models). CAR also made some alterations to Conversion
} 
includes vehicles with a GVRW of over 8,500 lbs., but a less than 10,000 loaded vehicle weight. Once vehicles were segmented into PCLDT1 and LDT2, CAR then separated the data by transverse (FWD) and longitudinal (RWD), and then two-wheel-drive (2WD), all-wheel-drive (AWD), and four-wheel-drive (4WD). The data was further divided by cylinders ( 3 and 4,5 and 6, 8, and 10 and 12 cylinders), and fuel/powertrain type (gasoline, diesel, HEV, etc.).

The orientation of the engine is essential to the differentiation of FWD/RWD vehicles. The transverse mounted engine is the predominant orientation of FWD, while RWD vehicles have longitudinally mounted engines. This engine orientation is important because it is a possible differentiator for hybrid drivetrain component technology. Those vehicles offered only in AWD were placed into FWD or RWD depending on engine orientation.

Finally, it is important to note that the California data was included in the total U.S. data to represent the current light vehicle market-that is, a representation of current national market segmentation. This was done to compare the status quo, with the California market as a unique entity.

The data shows the U.S. market has seen an increase in LDT2s as a percent of the total market during the years 1999 through 2003. The California market has seen a similarif not more pronounced-shift during the same period. It is important to note that this change represents a significant continued shift in consumer vehicle preference that has taken place for over a decade, and has greatly affected vehicle fuel economy and concomitant emissions. However, there are some indications that the light-duty truck boom' of the last decade may be quickly fading. The State of California represented approximately 11.1 percent of the U.S. light duty vehicle market in 1999. However, that percentage grew to 12.1 percent by 2003 . Importantly, the California market represents a somewhat different vehicle mix than the overall U.S. market. The California market includes a higher percentage of PCLDT1, and, a smaller percent of LDT2s weighing 3751 pounds (loaded weight) or greater.

CAR relied on two prominent industry forecasts to estimate total sales for 2009 . These two estimates were averaged to present a consensus forecast of vehicle sales. It is important to note that the R.L. Polk data used to estimate market segmentation was derived from registration; the consensus vehicle forecast for 2009 is presented as vehicle sales. There were instances were registrations did not necessarily match with reported sales. For example, the Polk data somewhat under-represents reported hybrid sales for the time period covered by the registration period. However, it is generally agreed that registrations represent a strong proxy for sales. Thus, CAR believes that basing the sales forecast on registration data presents a reasonable solution.

CAR used a logit model to create a forecast for the California and U.S. markets and the split between longitudinal and transverse drivetrains for the years 2004 through 2009 . Tables $4-6$ show the forecast for the 2004-2009 model years for total sales, and longitudinal and transverse drivetrains for the U.S. and California markets. The model forecasts further growth of the California market as a percent of the total U.S. market (12.1 percent in 2004 to 12.3 percent in 2009). Although this rate of change is less than

vehicles (i.e. those vehicles that were designed to be converted to run off CNG). These were divided as "gasoline" or "natural gas" powered vehicles per CAR's estimates of vehicles actually converted. 
in the period during which the historical data was examined, it is important to note that California as a percent of U.S. registrations actually decreased from 2002 (12.3) to 2003 (12.1). California has a lower proportion of LDT2s than the U.S. as a whole. The model forecasts a shift from PCLDT1 to LDT2s during the period. By 2009, the model estimates that 50.9 percent of California and 53.1 percent U.S. vehicles sales will be LDT2s as defined here. These are up from 2004 values of 42.8 and $46.8 \%$ respectively.

\section{Exec Sum Table 4 - Total PCLDT1 and LDT2 Sales} Forecast 2004-2009 Results (in units)

\begin{tabular}{|c|c|c|r|r|r|c|}
\hline & \multicolumn{2}{|c|}{ Total Market } & \multicolumn{2}{c|}{ PCLDT1 } & \multicolumn{2}{c|}{ LDT2 } \\
\hline Year & California & U.S. & California & U.S. & \multicolumn{1}{c|}{ California } & U.S. \\
\hline 2004 & $2,050,950$ & $16,925,000$ & $1,173,557$ & $9,007,272$ & 877,393 & $7,917,728$ \\
\hline 2005 & $2,075,150$ & $17,150,000$ & $1,161,515$ & $8,909,846$ & 913,635 & $8,240,154$ \\
\hline 2006 & $2,105,400$ & $17,400,000$ & 1,152020 & $8,818,956$ & 953,379 & $8,581,044$ \\
\hline 2007 & $2,159,400$ & $17,700,000$ & $1,154,333$ & $8,746,274$ & $1,005,066$ & $8,953,726$ \\
\hline 2008 & $2,171,600$ & $17,800,000$ & $1,133,371$ & $8,569,819$ & $1,038,229$ & $9,230,181$ \\
\hline 2009 & $2,201,700$ & $17,850,000$ & $1,121,152$ & $8,367,815$ & $1,080,547$ & $9,482,185$ \\
\hline
\end{tabular}

The PCLDT1 segment is forecast to have a slight decrease in longitudinal-or rearwheel-drive share. Although some manufactures are returning a portion of their portfolio to rear-wheel-drive layout, we also expect to see an increase in front-wheel-drive crossover vehicles. However, it various parties within the industry believe that technology development (i.e. traction and stability control) will be capable of offsetting the traditionally poor bad-weather handling characteristics of rear-wheel-drive vehicles, which could change this forecast.

Exec Sum Table 5 - PCLDT1: Transverse and Longitudinal Sales Forecast 2004-2009 Results (in units)

\begin{tabular}{|r|r|r|r|r|}
\hline & \multicolumn{2}{|c|}{ California } & \multicolumn{2}{c|}{ U.S. } \\
\hline Year & Transverse & Longitudinal & \multicolumn{1}{c|}{ Transverse } & \multicolumn{1}{c|}{ Longitudinal } \\
\hline $\mathbf{2 0 0 4}$ & 899,425 & 274,132 & $7,204,211$ & $1,803,062$ \\
\hline $\mathbf{2 0 0 5}$ & 896,337 & 265,178 & $7,168,376$ & $1,741,470$ \\
\hline $\mathbf{2 0 0 6}$ & 895,004 & 257,017 & $7,136,162$ & $1,682,794$ \\
\hline $\mathbf{2 0 0 7}$ & 902,708 & 251,626 & $7,117,182$ & $1,629,092$ \\
\hline $\mathbf{2 0 0 8}$ & 892,018 & 241,353 & $7,011,902$ & $1,557,917$ \\
\hline $\mathbf{2 0 0 9}$ & 887,948 & 233,205 & $6,883,323$ & $1,484,492$ \\
\hline
\end{tabular}




\section{Exec Sum Table 6 - LDT2 Transverse and Longitudinal}

Sales Forecast 2004-2009 Results (in units)

\begin{tabular}{|r|r|r|r|r|}
\hline & \multicolumn{2}{|c|}{ California } & \multicolumn{2}{c|}{ U.S. } \\
\hline Year & Transverse & \multicolumn{1}{c|}{ Longitudinal } & \multicolumn{1}{c|}{ Transverse } & \multicolumn{1}{c|}{ Longitudinal } \\
\hline $\mathbf{2 0 0 4}$ & 208,351 & 669,042 & $1,880,190$ & $6,037,537$ \\
\hline $\mathbf{2 0 0 5}$ & 227,251 & 686,383 & $2,049,601$ & $6,190,552$ \\
\hline $\mathbf{2 0 0 6}$ & 248,215 & 705,164 & $2,234,100$ & $6,346,943$ \\
\hline $\mathbf{2 0 0 7}$ & 273,698 & 731,368 & $2,438,266$ & $6,515,460$ \\
\hline $\mathbf{2 0 0 8}$ & 295,503 & 742,726 & $2,627,118$ & $6,603,063$ \\
\hline $\mathbf{2 0 0 9}$ & 321,198 & 759,349 & $2,818,630$ & $6,663,555$ \\
\hline
\end{tabular}

In contrast to the PCLDT1 segment, CAR forecasts transverse drivetrains to see an increased percentage of the LDT2 segment. This increase is driven by the rapid introduction in recent years of car-based utility vehicles, or CUVs. These vehicles have begun to take share from the traditional rear-wheel drive sport utility segment. Given future product plans, it is highly likely the CUV segment will be a growth segment in the coming years, it is reasonable to expect this trend to continue for several years.

CAR used the results of the Logit model as the basis for the final forecast. However, because the model used only five years of historical data, it failed to realistically predict future sales when applied to several individual powertrain options. Therefore, CAR applied the logit model to the split between PCLDT1 and LDT2, and to transverse and longitudinal drivetrains within the PCLDT1 and LDT2 segments. Using those results, CAR then applied linear regression to each of the powertrain segments, and made use of regression models in most cases to construct forecasts. When regression results were inconclusive, illogical, or not applicable to a powertrain type, CAR staff judgment was used. Selected segments are presented in Table 7. Full results are presented in appendix IV. 
Exec Sum Table 7 - 2009 Forecast: Selected Segments

\begin{tabular}{|c|c|c|c|c|}
\hline & \multicolumn{2}{|c|}{ U.S. } & \multicolumn{2}{|c|}{ California } \\
\hline & 1999 & 2009 & 1999 & 2009 \\
\hline \multicolumn{5}{|l|}{ PCLDT1 Transverse } \\
\hline FWD/3-4cyl/Gas & $52.8 \%$ & $53.8 \%$ & $60.4 \%$ & $55.8 \%$ \\
\hline FWD/5-6cyl/Gas & $42.1 \%$ & $27.6 \%$ & $35.5 \%$ & $19.9 \%$ \\
\hline FWD/6cyl/Flex & $0.1 \%$ & $0.9 \%$ & $0.0 \%$ & $0.9 \%$ \\
\hline FWD/4cyl/Diesel & $0.2 \%$ & $0.3 \%$ & $0.1 \%$ & $0.8 \%$ \\
\hline $\begin{array}{l}\text { FWD/3-4cyl/Gas-Elec } \\
\mathrm{HEV}\end{array}$ & $0.0 \%$ & $6.0 \%$ & $0.0 \%$ & $12.0 \%$ \\
\hline FWD5/6Gas-Elec HEV & N/A & $1.6 \%$ & N/A & $2.0 \%$ \\
\hline$A W D$ and $4 W D, 4-8 \mathrm{cyl}$ & $2.2 \%$ & $9.2 \%$ & $2.1 \%$ & $8.5 \%$ \\
\hline Share represented & $97.4 \%$ & $99.4 \%$ & $98.1 \%$ & $99.7 \%$ \\
\hline \multicolumn{5}{|l|}{ LDT2 Transverse } \\
\hline FWD/3-4cyl/Gas & $4.9 \%$ & $2.8 \%$ & $6.9 \%$ & $2.8 \%$ \\
\hline FWD/5-6cyl/Gas & $73.4 \%$ & $44.7 \%$ & $84.8 \%$ & $44.7 \%$ \\
\hline FWD/6cyl/Flex & $16.7 \%$ & $5.0 \%$ & $0.3 \%$ & $5.0 \%$ \\
\hline Diesel (any) & $0.0 \%$ & $0.0 \%$ & $0.0 \%$ & $0.0 \%$ \\
\hline $\begin{array}{l}\text { 4WD \& FWD//3- } \\
\text { 4cyl/Gas-Elec HEV }\end{array}$ & NA & $6.0 \%$ & NA & $6.0 \%$ \\
\hline $\begin{array}{l}\text { 4WD \& FWD5/6Gas- } \\
\text { Elec HEV }\end{array}$ & NA & $6.0 \%$ & NA & $6.0 \%$ \\
\hline AWD+4WD/4 cyl/Gas & $0.0 \%$ & $4.9 \%$ & $0.0 \%$ & $4.9 \%$ \\
\hline AWD 5-6cyl/Gas & $5.1 \%$ & $15.0 \%$ & $8.0 \%$ & $15.0 \%$ \\
\hline 4WD+FWD 5-6cyl/Gas & $0 \%$ & $15.6 \%$ & $0 \%$ & $15.6 \%$ \\
\hline Share represented & $100.1 \%$ & $100.0 \%$ & $100 \%$ & $100.0 \%$ \\
\hline \multicolumn{5}{|l|}{ PCLDT1 Longitudinal } \\
\hline RWD/4cyl/Gas & $19.9 \%$ & $11.6 \%$ & $21.2 \%$ & $13.0 \%$ \\
\hline RWD/5-6cyl/Gas & $25.1 \%$ & $41.0 \%$ & $37.7 \%$ & $53.1 \%$ \\
\hline RWD/8cyl/Gas & $25.8 \%$ & $25.8 \%$ & $23.3 \%$ & $20.0 \%$ \\
\hline RWD/4-6 cyl flex & $5.9 \%$ & $2.0 \%$ & $6.5 \%$ & $0.2 \%$ \\
\hline RWD/6cyl/Diesel & $0.2 \%$ & $0.3 \%$ & $0.1 \%$ & $0.2 \%$ \\
\hline HEV (any) & $0.0 \%$ & $0.0 \%$ & $0.0 \%$ & $0.0 \%$ \\
\hline AWD + 4WD 4-6 cyl & $22.9 \%$ & $15.7 \%$ & $10.8 \%$ & $8.8 \%$ \\
\hline AWD + 4WD 8-12 cyl & $0.1 \%$ & $2.8 \%$ & $0.1 \%$ & $1.8 \%$ \\
\hline Share represented & $99.9 \%$ & $99.2 \%$ & $99.7 \%$ & $97.1 \%$ \\
\hline \multicolumn{5}{|l|}{ LDT2 Longitudinal } \\
\hline RWD/4cyl/Gas & $1.5 \%$ & $0.1 \%$ & $3.1 \%$ & $0.2 \%$ \\
\hline RWD/6cyl/Gas & $17.8 \%$ & $11.6 \%$ & $25.8 \%$ & $13.5 \%$ \\
\hline RWD/8-10cyl/Gas & $22.6 \%$ & $19.6 \%$ & $31.1 \%$ & $38.9 \%$ \\
\hline All/6\&8cyl/Flex & $1.2 \%$ & $6.8 \%$ & $0.5 \%$ & $3.2 \%$ \\
\hline All 4-6 cyl/Diesel & $1.1 \%$ & $3.2 \%$ & $1.0 \%$ & $1.3 \%$ \\
\hline RWD/8cyl/Diesel & $1.4 \%$ & $1.5 \%$ & $1.2 \%$ & $1.3 \%$ \\
\hline 4WD/8cyl/Diesel & $2.5 \%$ & $7.4 \%$ & $1.4 \%$ & $5.5 \%$ \\
\hline AWD+4WD/4-6cyl/Gas & $21.2 \%$ & $19.3 \%$ & $14.0 \%$ & $11.4 \%$ \\
\hline AWD+4WD/8-10cyl/Gas & $30.7 \%$ & $29.4 \%$ & $21.8 \%$ & $22.4 \%$ \\
\hline 4WD/8cyl/HEV/Gas & NA & $1.0 \%$ & NA & $2.0 \%$ \\
\hline Share represented & $100.0 \%$ & $99.9 \%$ & $99.9 \%$ & $99.7 \%$ \\
\hline
\end{tabular}


There were segments that were not realistically modeled by the linear regressions. For these segments, CAR relied upon its knowledge of industry trends and future product plans to 'tune the results' and better indicate likely future sales trends. The changes (and the explanation for those changes) to the linear regression models can be found in Appendix V.

CAR believes this forecast represents a reasonable estimate of the 2009 U.S. and California markets. However, it is important to note that, as with any prediction, there are many variables that can affect the actual numbers. With regard to powertrain technology, this is one of the most uncertain times since the early years of the industry.

Currently, the automotive industry is struggling to understand the developing advanced powertrain paradigm. There are several competing technologies that may offer increased fuel efficiency and reduced emissions-albeit at an increased cost. The hybrid electric vehicle presents opportunity for significant decreases in carbon dioxide emissions when driven in congested areas; but may not deliver similar gains when used in less congested areas; and may suffer from poor battery performance in cold weather climates. Conversely, the diesel engine offers potential efficiency gains over the current spark-ignited gasoline engine (and maybe the HEV in some driving cycles) but suffers from cost and emissions challenges. The spark-ignited gasoline engine may also offer increased efficiency but at a cost. It is wholly possible that each of these powertrains could gain acceptance. It is also possible-although unlikely-that each of these technologies could fail to meet consumer requirements, and vanish from the marketplace in the coming years.

In addition to technological uncertainty, we must consider the ongoing public policy discussions regarding fuel economy and vehicle emissions. To complete this model, CAR has made several assumptions regarding technology and policy issues. We believe these assumptions to be reasonable-albeit, highly debatable. The following is a review of market factors we believe add increased variability to the powertrain segmentation.

1. Hybrid Technology: The CAR forecast calls for what we would describe as a strong growth in hybrid penetration. However, there will most certainly be critics that the market will be either significantly lower-or higher-than the CAR estimates. Although there are indications that hybrid technology is becoming a viable option for a portion of the light vehicle market, the extent and duration of that market is still uncertain. Cost will remain an issue; appropriateness for the driving cycle of several segments is also uncertain. CAR relied on announced plans and discussions with various industry sources to develop an estimate for HEV penetration for 2009.

We believe, given our cost and efficiency gains estimates and a reasonable continuation current fuel prices, the HEV will not be an economically attractive choice within the forecast timeframe. Thus, the forecast for HEVs may seem strangely optimistic. We suggest that the technology may be enticing to some consumers for reasons other than fuel savings. It is likely that there are an increasing number of purchasers that value environmental status offered by the purchase of such technology. It is very difficult to estimate the size of this market.

2. Diesel Technology: The forecast calls for a modest increase in diesel application in PCLDT1 and a slightly more aggressive increase in LDT2 (although some of the growth 
in trucks is due to the inclusion of GVW over 8,500 lbs.). Most experts interviewed by CAR believed there will be positive resolution regarding the environmental acceptability (i.e. at a minimum, the ability to meet Tier 2 Bin 5) of the diesel engine within the next five years. The diesel engine, especially diesel aftertreatment technology, represents a variable which could be considered highly uncertain. As such, developments in diesel technology could change the forecast markedly.

3. All-Wheel-Drive in the Passenger Car Market: While this technology does not present the high visibility of the other technology choices, it does present unique difficulty in forecasting. Several manufacturers have recently, or will soon, introduce all-wheel-drive as an option on high-volume models. Many of these vehicles are being positioned as an alternative to the perceived safety advantages offered by all-wheel-drive SUV and CUV offerings. However, some of these all-wheel-drive vehicles are being positioned as performance vehicles. This has important implications for the California market, where the poor weather performance attributes of all-wheel-drive are not a strong market driver, but where a higher mix of performance type rear-wheel-drive passenger cars are sold.

4. Flex Fuel Vehicles: The inclusion of flex fuel vehicles in the forecast presents opportunity for a significant amount of variability. The offering of a flex fuel option is highly variable and is often driven by many factors including, but not limited to, government encouragement, corporate policy and emissions, and even corporate public relations. The conversion of an existing gasoline engine to a flex fuel capable engine is a relatively low cost $^{3}$ method of gaining credits toward emission standards, or even gaining public relations benefits. Therefore it is difficult to forecast the total number of products available to the market-and even more difficult to estimate by powertrain segment. CAR has been very cautious with the forecast for flex fuel or other alternative fueled vehicles (note that CNG and propane were significant enough to be included only in LDT2 longitudinal segment). This caution should not be read as doubt for the given technologies. Their benefits and costs are rather well understood. Instead, it can be attributed to the fact that these technologies are driven by policy, and do not necessarily reflect a 'normal' business strategy. The Alternative Motor Fuel Act of 1988 (and its recent extension) will assure that the manufacturers continue to consider flex-fuel and dedicated alternative fuel vehicles. At least one Midwest state continues to contemplate legislation that would require increased availability of ethanol capable vehicles. Conversely, other states have indicated some concern as to the actual number of flex fueled vehicles that ever use alternative fuels.

\footnotetext{
${ }^{3}$ Manufacturers will understandably have difficulties with the term 'relatively' low cost. However, their actions suggest that the use of flex fuel vehicles to gain emission credits is at least to some extent, a cost effective measure.
} 


\section{Introduction}

CAR undertook this investigation to reveal the costs and challenges of a local (state) regulation necessitating the implementation of alternative or advanced powertrain technology. This report will not address the legality of such regulations, for that will be appropriately addressed in the judicial system. Nor will this report address the value of pursuing a strategy that promotes greater conservation over free market action. Finally, CAR will not enter the fray surrounding Global Warming-for such a topic is far beyond the scope of this effort. Instead, CAR will attempt to add insight into the challenges that local regulations present to the automotive industry, and to contribute further to the discussion of advanced powertrain technology.

Any local law that (directly or indirectly) affects fuel economy creates what in effect is a specialty market for powertrain technology. As such these small markets present significant challenges to automotive manufacturers. First, a small market with unique standards presents a significant challenge to an industry that has sustained growth by relying on large volumes to achieve scale economies and deliver products at a cost acceptable to the consumer. Further, the challenges of the additional technology make it likely that any powertrain capable of meeting the stringent standards will include costly additional components, and thus will be more costly to manufacture.

The objectives of this study will be to: 1) describe a likely decision-making process framework that the automotive industry can use to determine technology applications and 2) to investigate the technology paths that present opportunity to meet such legislation. There are currently numerous reports investigating costs and efficiencies of the advanced powertrain technologies. CAR wishes not to debate the merits of these studies, but to add further insight to the topic by highlighting areas that may require further consideration. CAR also will not spend a significant portion of this report detailing the various technologies, for this has been done in numerous reports and forums. However, where necessary, CAR will highlight important aspects of technologies. Finally, this report will address cost issues-increasing the depth of understanding of the total cost of the technologies.

As a critical element of this project, CAR will deliver a forecast of vehicle sales for calendar year 2009. This represents the timeframe in which pending regulation would begin to be phased in, with full implementation taking several more years. The time frame of four years does not allow for significant volumes of new technology, specifically some of the more popular choices for gasoline engine development. However, we do expect that there will be significant technologies (i.e., gasoline hybrid vehicles and advanced diesels) gaining market penetration by 2009.

Our base assumption for this forecast is to hold the current California passenger car and light truck market segmentation relatively constant (forecasting a likely product mix, given current and past trends and expected product offerings). As such, our assumption complies with the bill's stipulation that regulations not require any fees or taxes on vehicles, fuels, or vehicle miles traveled (VMT); a ban on sale of any vehicle category; a reduction in vehicle weight; a limitation on (or reduction of) vehicle speed limits; or a limitation on or reduction of VMT. Of course, individual vehicle manufacturers may respond by pulling out of certain segments or other market actions to fulfill the requirements of regulation and individual market plans. However, by keeping the market 
segmentation constant, we assume that consumers will continue to have a variety of vehicle choices.

Another important assumption is the potential vehicle manufacturer options to meet any proposed regulations. Given the uncertainty over the commercialization of fuel cells for light duty vehicle propulsion and the challenge of a hydrogen distribution infrastructure, this scope of work does not include fuel cells as a viable short-term consideration. Five vehicle manufacturer options are considered to be possible: adaptation of current platforms and models, adaptation of current powertrains from other regions, advanced technologies adapted to internal combustion engines (gasoline and diesel) and platforms, new powertrain configurations including hybrids, and all new platform/model and powertrain configurations. 


\section{Pathways to Meeting Regulation Creating Low Volume Market Alternative Powertrain Markets}

A critical challenge for this project is to identify pathways to meet challenges presented by regulation creating low volume alternative powertrain markets, and to better understand the structural implications of such regulations. There are numerous paths available to manufacturers. Certainly, most full-line, global manufacturers have vehicles in their global portfolios that can, or could, be modified to more closely meet the pending standards. However, these vehicles are significantly different (i.e. smaller, less powerful) and may not be accepted by the typical California consumer. These same manufacturers also have technology-albeit mostly still in the development or proof of technology stage-that, given appropriate time, may be capable of meeting and even exceeding the standards, but the cost of these vehicles remains unknown and will likely be greater than the present technology choices. CAR made numerous inquiries to industry sources to determine the actions most likely to be taken to react to such legislation in the short term, and identify how these strategies may change to adapt to a more long-term market.

A pertinent question is then: what might the automotive manufacturers likely short-term reaction be to such regulation-and, what might they do if the California legislation were viewed as a singular market, with little expectation to increase market size for the vehicles beyond the state boundaries (Note, the authors realize that the Northeast states, and possibly other regions, would likely follow the precedent set by California, thereby increasing the market significantly). Such an action would create some differences in the discussion regarding scale economies and market size. However, at least initially, the discussion will treat California as a unique market.

The California standard presents two important challenges to automotive manufacturers. First, a small market with unique standards presents a significant challenge to an industry that has sustained growth by using large volumes to achieve scale economies and deliver products at a cost acceptable to the consumer. Further, the challenges of the additional technology make it likely that any powertrain capable of meeting the stringent standards will include costly additional components, and thus be more costly to manufacture.

The total cost of a component is a function of several variables, including the cost of materials, technology research and development, product development, tooling and equipment, labor, and energy inputs. Much of the published research to date has looked closely at the variable costs of new technologies-costs that are directly proportional to the volume of output produced. While variable cost is important, most previous studies fail to take into account the fixed costs-costs that are fixed for a given period of time and for a given production level range. The automotive industry requires large amounts of fixed assets to develop and manufacture powertrains. Thus, it is important to fully understand key fixed costs associated with the introduction of new technologies, with a focus on how volume might affect cost. It is likely manufacturers would consider the following actions as steps to deliver products to meet the pending legislation ${ }^{4}$ :

\footnotetext{
${ }^{4}$ Initially, manufacturers would also implement powertrain modifications-that is, lower axle ratios, higher compression ratios, and etc. However, it is likely that such actions would be small steps toward the challenge of meeting the stringent requirements. We assume that such actions should be considered part of normal powertrain development.
} 
1. Substituting more fuel efficient vehicles: Bring in more efficient vehicles from global operations to decrease carbon dioxide emissions, while likely dropping existing products.

2. Substituting powertrains: Add existing downsized engines (i.e. turbocharged versions, etc.) into California market-bound vehicles.

3. Powertrain enhancements: Add technology to current engine and transmission offerings to reduce carbon dioxide emissions.

4. Incorporating alternative powertrains into existing vehicle platforms: Develop a hybrid or other type of powertrain for an existing vehicle.

5. New powertrains and new platforms: Develop vehicles specifically intended to incorporate new powertrain technologies, materials and/or design (e.g. the General Motors EV1 or the Toyota Prius).

These five actions represent the gamut from the least complicated solution to the most complex. They also generally represent the least expensive response to the most expensive. It is possible that the least expensive responses may be least likely to meet market demands while achieving required GHG emission limits. At the same time, the most expensive option may produce a vehicle that satisfies the GHG reduction requirements and meets some consumer requirements, but is far too costly to manufacture profitably. The response of a manufacturer would certainly have to take market size, consumer acceptance, technology implication and cost, as well as internal capacities and constraints, into consideration. It is important to understand that individual companies may respond differently in the short term. However, it is probable that there would be a more consistent industry-wide response in the longer term.

Options 1 and 2 present the simplest responses. A company may reach into its global portfolio to deliver vehicles that allow for lower carbon dioxide emissions. These vehicles are usually smaller and significantly less powerful than current US offerings. Industry respondents indicated that such a strategy may be possible but would likely be met with less than positive reaction from the buying public. A general estimate for the cost to homologize a vehicle-that is, to prepare an existing vehicle for entry into the United States provided all business conditions were met (reasonable product, capacity availability, etc.), would be approximately $\$ 50$ million. Consider the following example: a manufacturer determines that a vehicle sold in another market is a viable candidate for sale in California furthering their goal to attain a given regulation. Assume that the manufacturer expects to sell approximately 5,000 vehicles per year in the new market, and sell them for the average product cycle of four years. Assuming an estimated cost for homologation to meet U.S. standards of $\$ 50$ million, the company would then incur a $\$ 2,500$ per-vehicle cost to bring them into the market. Such an estimate should be considered a point estimate, with great variability possible. It also should be noted that most vehicles-especially in the segments likely to be considered-would probably not meet U.S. safety and emissions standards and would thus require significant reengineering, potentially adding greatly to the cost of the importation.

A manufacturer may also choose to incorporate a more efficient powertrain into a vehicle already sold in the market. Such an engine may be a smaller turbo-charged gasoline engine, a diesel engine (assuming additional cost and development for after-treatment devices), and/or a manual or 6-speed automatic transmission offered in other markets. The costs associated with such a strategy would include re-engineering the vehicle engine compartment to accept the new powertrain and developing, engineering and 
manufacturing those parts unique to the vehicle. Costs would also be incurred to achieve emission certification.

An important caveat to consider is that the cost of homologization and 'engine-swapping' may decrease in coming years. Through the increased application of computer-aided tools, manufacturers are rapidly decreasing the time-and cost-required to engineer (or make engineering changes to) vehicles. Also, in response to the uncertainties of alternative powertrain technology, manufacturers are giving more consideration to a wide variety of powertrains when developing new vehicles. While a vehicle may be designed primarily for the traditional gasoline engine, consideration is being given to the possibility of later adding a diesel or hybrid variant to any given vehicle platform. Thus, it is probable that future vehicles will be more flexible with regard to powertrain alternatives

In order to reduce carbon dioxide emissions, companies may consider the importation of a more fuel-efficient vehicle from their current global portfolio, or the addition of a powertrain from another market. It is likely that these would be seen as stop-gap responses to the legislation. Many of the candidate vehicles and powertrains would likely not meet consumer expectations, and may not provide enough fuel savings to achieve the required GHG reduction, thus offering only a step toward any solution. More realistically, manufacturers would need to address any significant GHG reduction via options 3, 4 and 5 . Therefore, this report will focus on only those alternatives that CAR believes represent the most likely long-term alternatives. A sixth option, the increased use of alternative fuels, will also be explored.

When a manufacturer chooses to address a market requirement, the company must consider a wide range of criteria. For this discussion we have divided the criteria into three general areas. The first element is product development. This includes research and development and product design and engineering. The second area includes items associated with manufacturing the product, including manufacturing engineering, materials and labor (i.e., piece cost), and plant and special tooling (i.e. tooling costs). Finally, there are the market considerations including, transportation, parts/service complexity, volume assumptions and consumer acceptance (price, performance, etc.). Certainly these considerations do not exist in a vacuum, with a successful company seamlessly integrating all functions into a flowing process. However, for discussion purposes, we believe this division is reasonable.

As noted, there have been numerous reports which address the market considerations associated with advanced powertrain technologies. CAR believes it is equally important to investigate the upstream portion of the equation. Any market assessment of a technology cannot take place without technical analysis and cost accounting of the product development and manufacture aspects. Unfortunately, there is a tendency for some to assume that, because there is a possible market (at an assumed price) for a given technology, the other fundamentals will merely "fall into place." Therefore, this report will attempt to put into context the rather complex challenge of assessing what it would require to make the pieces "fall into place". 


\section{Internal Combustion Engine}

\section{A. Introduction}

A basic understanding of the current bill of materials (B.O.M) and bill of process (B.O.P.) is fundamental to any discussion regarding the addition of advanced technology for internal combustion engines. Such an understanding serves at least two critical needs. First, it allows a more precise account of the added (and deleted) components of advanced ICE technologies (the B.O.M.). Second, it provides a method to better understand the structural changes required in the manufacturing infrastructure (the B.O.P.).

\section{B. Internal Combustion Engine Manufacturing Processes}

The following is a generic bill of materials for a typical gasoline engine as illustrated in the figure. Using this bill of materials as a starting point will help to clarify the task of technology substitution throughout this report. The cylinder block, along with the crankcase, forms the main body of the engine. The block and crankcase are usually cast en bloc to form a single casting. The block provides the smooth cylinders which guide the pistons. The crankcase supports the crankshaft and camshaft using bearings. An oil pan bolted to the bottom of the crankcase forms a tight covering for the crankshaft and functions as a basin for lubricating oil.

The cylinder head is usually a one-piece casting bolted to the top of the cylinder block. The cylinder head covers the ends of the cylinders to form a combustion chamber, where burning and expansion of gas takes place. Combustion of gases provides a downward force on the piston which is transmitted to the crankshaft through a connecting rod that connects one end of the piston to the crankshaft. The piston is connected to the connecting rod by a piston pin in a configuration that allows the connecting rod to swing back and forth. Piston rings are wrapped around the top of the pistons to maintain a pressure-tight seal within the cylinder. The connecting rod converts the up-and-down motion of the piston to a rotary motion of the crankshaft. The bottom of the connecting rod includes a journal bearing which allows connection to the crankshaft. The crankshaft receives the power from the piston and connecting rod and transmits this power to the drivetrain. Counter weights on the crankshaft, together with a flywheel bolted to one end, provide improved engine smoothness.

Each cylinder typically employs both intake (1 or 2 ) and exhaust (1 or 2 ) valves that allow gases to flow into and out of the cylinder. These valve trains are mounted to the lobes, or cams, of the camshaft. The valves are opened or closed by the camshaft against the tension of a valve spring. Camshafts were originally located in the engine block and connected to a push rod and rocker arm to open and close the valves (i.e., pushrod technology). Alternatively, camshafts (i.e., overhead camshafts) located in the cylinder head open and close the valves using a rocker arm without a need for the push rod. The camshaft is driven by the crankshaft either through timing gears or a timing belt. 
In each cylinder, a spark plug is screwed into an aperture so that one end of the plug is exposed to the combustion chamber. The spark plug introduces the ignition energy into the combustion chamber.

In order for the engine to operate properly, it requires several accessory systems: an air flow/fuel system to supply the fuel and oxygen that is burned in the engine, a cooling system to carry away heat so that excessive temperatures do not occur in engine parts, an electrical/ignition system to provide high-voltage ignition and power electronic devices, and an exhaust system to conduct exhaust gases from the engine and reduce the harmful gases produced by the engine. Each of these is an integral part of the engine.

A bill of materials for the diesel engine is also included. In many respects the diesel is similar to the spark-ignited engine. However, the diesel engine requires a more robust block and head and several different accessories. Since fuel is injected under high pressure directly into the cylinder and must be accurately controlled, no ignition system is required for the diesel engine. The diesel fuel injector has to withstand very high pressures compared to the gasoline spark-ignited engine. A rule of thumb offered by one industry source suggests that currently as much as $75 \%$ of the incremental cost for a diesel engine compared to a spark ignited engine is due to the requirement for a higher pressure fuel delivery system (note this does not include the after-treatment technology that will be required to meet pending regulations). Diesel engine emissions control systems also differ from spark-ignited engines. Because of the need to capture oxides of nitrogen and particulate emissions, the diesel exhaust and after treatment is more complex and costly. The industry source indicated that the cost of the emissions technology required to meet pending regulation would create three equally costly development components for diesel engines; the mechanical system, the fuel delivery system and the exhaust system. 
Figure 1 - Bill of Materials: SI Engine (V-6 w/OHC)

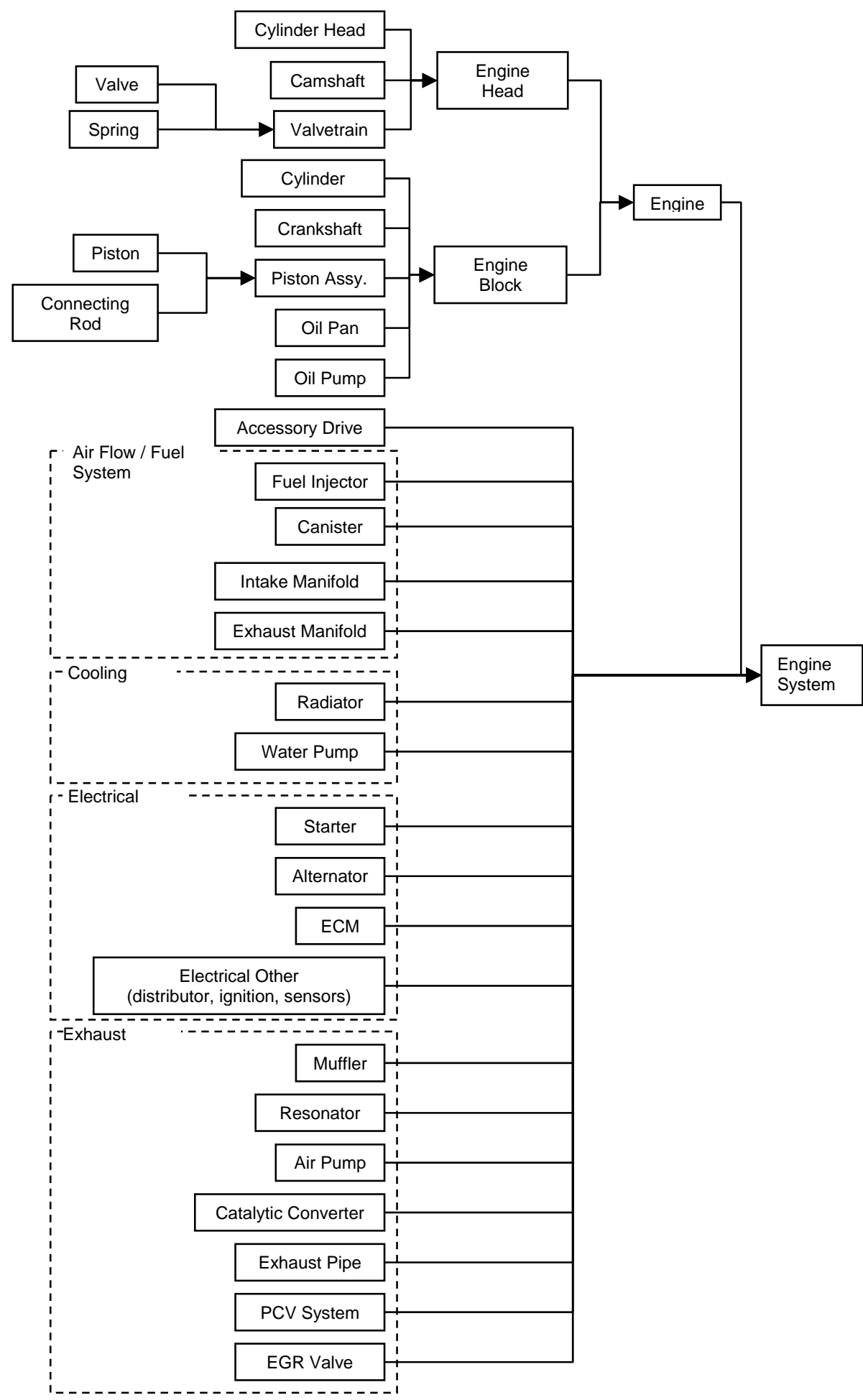


Figure 2 - Bill of Materials: Diesel Engine

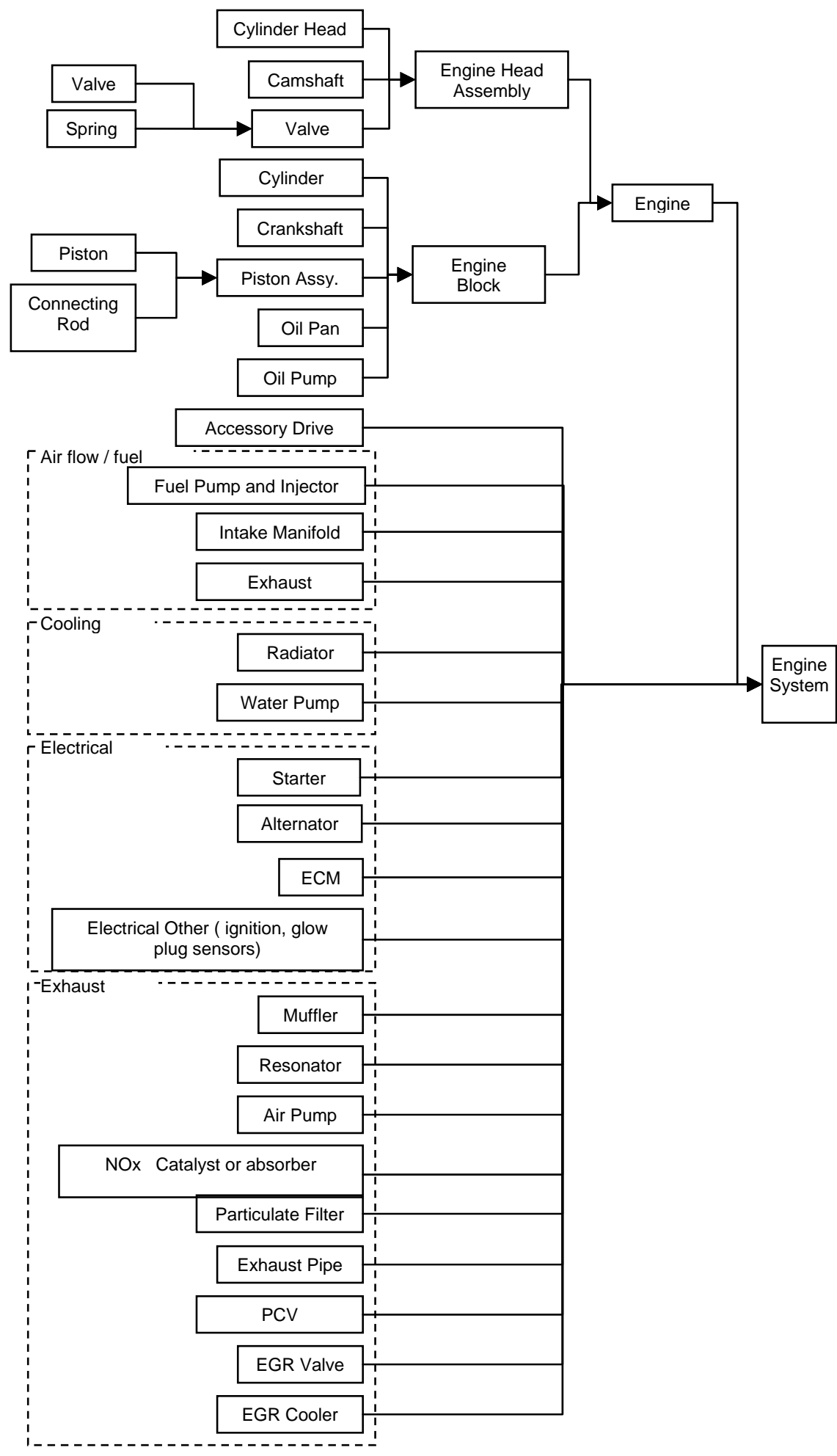


Once a bill of materials has been defined, it is possible to define the bill of process-or how those materials are manufactured into the final product. The manufacture of an engine is a highly complex procedure, consisting of three unique steps; foundry casting, machining, and engine build/dressing. The casting is done in a foundry, while the machining and engine build are done at the engine manufacturing plants.

Historically, North American vehicle manufacturers have cast their own heads and blocks. However, in recent years many manufacturers have disinvested in casting operations. Instead, they have outsourced head and block manufacture to independent suppliers. This outsourcing is partly the result of the conversion of block and head materials from cast iron to aluminum. The cylinder block is cast in one piece from gray iron or aluminum. The block casting contains not only the cylinders, but also the water jackets that surround them. In aluminum blocks, cast-iron cylinder sleeves are usually used.

Manufacturing a cylinder block includes casting as one piece from iron or iron alloy. They are cast by pouring molten iron/aluminum into a mold. There are several methods used for molding a block. Once the block is cast, it must then be machined. The machining processes include drilling holes for attachment of various parts, machining the cylinders, boring the camshaft-bearing holes and other such activities.

Cylinder heads are usually cast in one piece in a manner similar to the way the cylinder block is cast. Again, iron alloyed with various other metals has traditionally been used. However, engine heads are now primarily aluminum alloy. The machining processes are similar to the required activities for the block. The block and head are then ready to be assembled along with the other components.

The final step for engine manufacture is the assembly of the components. These operations include: assembly of head and block, attachment to the block of crankshaft, bearings, and bearing caps, attachment of the oil pan, attachment to the rear of the crankshaft of the flywheel, installation of pistons with rings and connecting rods, and finally attachment of the valvetrain.

\section{Internal Combustion Engine Manufacturing Investment and Flexibility}

A major concern for any manufacturer is uncertainty in future markets. In few areas of the automotive business is this more noticeable than the engine plant. Designed to take advantage of high-volume scale economies, engine facilities have evolved into highly efficient, but relatively inflexible, operations. Although manufacturers have somewhat increased the flexibility of their engine manufacturing facilities in recent years, most remain rather limited. Flexibility at engine plants has traditionally been limited to engines of similar cylinder number, with similar geometry. Thus, any rapid change in product mix (i.e., 4-cylinder, 6-cylinder, 8-cylinder, gasoline, diesel, etc. or even a change in head or block design) presents a threat to most manufacturers. Table 1 shows the trends in engine installation in North American produced vehicles for a ten-year period. It is apparent that, while there are definite trends, the rate of change is relatively slow. Any shock to the market, whether consumer or policy driven, would represent a significant challenge to the traditional engine manufacturing paradigm. 
By comparing three separate estimates, CAR was able to develop a reasonable target cost for investing in new tooling for an existing engine facility. We estimate the approximate cost to be $\$ 170$ to $\$ 185$ million dollars of investment for a six-cylinder $\mathrm{V}$ configuration gasoline engine at a volume of 300,000 per year. Any change in engine configuration-or the inclusion of a low-volume version of an engine (as in the case of a 'high mileage' variant) - would present several cost hurdles. The addition or substitution of technologies to existing engine programs would likely require change to the manufacturing system, and thus additional cost.

\section{Table 1 - Domestic Lt.-Vehicle Production Summary by Engine} (North American Production by Model Year for the U.S. Market)

\begin{tabular}{|c|c|c|c|c|c|c|c|}
\hline & $\begin{array}{c}\text { \% 3- } \\
\text { Cyl. }\end{array}$ & $\begin{array}{l}\text { \% 4- } \\
\text { Cyl. }\end{array}$ & $\begin{array}{c}\% 5- \\
\text { Cyl. }\end{array}$ & $\begin{array}{c}\text { \% 6- } \\
\text { Cyl. }\end{array}$ & $\begin{array}{c}\text { \% 8- } \\
\text { Cyl. }\end{array}$ & $\begin{array}{c}\text { \% 10- } \\
\text { Cyl. }\end{array}$ & $\begin{array}{l}\text { Total } \\
\text { Units }\end{array}$ \\
\hline \multicolumn{8}{|l|}{ Cars } \\
\hline ‘04 & -- & 49.9 & -- & 42.7 & 7.3 & -- & $5,576,846$ \\
\hline ‘03 & -- & 49.1 & -- & 42.8 & 8.1 & -- & $6,319,345$ \\
\hline '02 & -- & 49.0 & -- & 43.0 & 8.1 & -- & $5,904,894$ \\
\hline ‘01 & -- & 48.8 & -- & 42.3 & 8.9 & -- & $6,363,152$ \\
\hline ‘00 & 0.1 & 46.6 & -- & 44.0 & 9.3 & -- & $7,398,129$ \\
\hline ‘99 & 0.1 & 47.7 & -- & 42.8 & 9.4 & -- & $7,087,461$ \\
\hline ‘98 & 0.2 & 52.0 & -- & 38.7 & 9.1 & -- & $6,640,109$ \\
\hline ‘97 & 0.3 & 52.6 & -- & 36.6 & 10.5 & -- & $7,029,944$ \\
\hline ‘96 & 0.4 & 49.3 & -- & 38.6 & 11.7 & -- & $6,810,423$ \\
\hline ‘95 & 0.4 & 44.9 & -- & 41.4 & 13.3 & -- & $7,518,678$ \\
\hline 10-Yr. Avg. & 0.2 & 48.9 & -- & 41.2 & 9.7 & -- & $6,664,898$ \\
\hline \multicolumn{8}{|c|}{ Light Trucks } \\
\hline ‘04 & -- & 4.4 & 1.1 & 44.7 & 49.0 & 0.7 & $8,510,987$ \\
\hline ‘03 & -- & 6.4 & -- & 47.5 & 45.2 & 0.9 & $8,538,668$ \\
\hline ‘02 & -- & 6.4 & -- & 50.8 & 41.9 & 0.9 & $8,146,028$ \\
\hline ‘01 & -- & 7.2 & -- & 48.7 & 42.6 & 1.5 & $6,953,143$ \\
\hline ‘00 & -- & 7.8 & -- & 49.6 & 40.8 & 1.7 & $7,649,829$ \\
\hline ‘99 & -- & 7.5 & -- & 47.2 & 43.6 & 1.7 & $7,384,140$ \\
\hline ‘98 & -- & 10.8 & -- & 51.2 & 37.7 & 0.4 & $6,533,811$ \\
\hline ‘97 & -- & 11.0 & -- & 44.4 & 43.9 & 0.7 & $6,371,749$ \\
\hline ‘96 & -- & 12.9 & -- & 54.1 & 32.7 & 0.3 & $5,612,023$ \\
\hline ‘95 & -- & 12.2 & -- & 52.3 & 35.2 & 0.3 & $5,871,351$ \\
\hline 10-Yr. Avg. & -- & 8.3 & 0.1 & 48.8 & 41.8 & 0.9 & $7,157,173$ \\
\hline \multicolumn{8}{|c|}{ Light Vehicles } \\
\hline ‘04 & -- & 22.4 & 0.7 & 43.9 & 32.5 & 0.4 & $14,087,833$ \\
\hline ‘03 & -- & 24.6 & -- & 45.5 & 29.4 & 0.5 & $14,858,013$ \\
\hline ‘02 & -- & 24.3 & -- & 47.5 & 27.7 & 0.5 & $14,050.922$ \\
\hline ‘01 & -- & 27.1 & -- & 45.6 & 26.5 & 0.8 & $13,316,295$ \\
\hline ‘00 & -- & 26.9 & -- & 46.8 & 25.3 & 0.9 & $15,047,958$ \\
\hline ‘99 & -- & 27.2 & -- & 45.0 & 26.9 & 0.9 & $14,471,601$ \\
\hline ‘98 & 0.1 & 31.6 & -- & 44.9 & 23.3 & 0.2 & $13,173,920$ \\
\hline ‘97 & 0.2 & 32.8 & -- & 40.3 & 26.4 & 0.3 & $13,401,693$ \\
\hline ‘96 & 0.2 & 32.9 & -- & 45.6 & 21.2 & 0.1 & $12,422,446$ \\
\hline ‘95 & 0.2 & 30.6 & -- & 46.2 & 22.9 & 0.1 & $13,390,029$ \\
\hline 10-Yr. Avg. & 0.1 & 27.9 & 0.1 & 45.2 & 26.3 & 0.5 & $13,882.071$ \\
\hline
\end{tabular}

Source: WardsAuto.com, Cars and Light Trucks $<8500$ GVW

Most traditional engine plants would struggle to adapt to the introduction of a lowvolume variant. Based on discussions with industry sources, CAR estimates the cost 
of the engine block machining transfer line for the six-cylinder example to be approximately $\$ 60-\$ 70$ million. The head machining line is estimated to cost approximately $\$ 40$ million.

The desire-or even ability - to increase engine plant flexibility is at least partly necessitated by the financially driven need to reuse portions of the current equipment. It is also a direct function of the value a company places on overall flexibility. Traditional engine head and block machining lines have used highly fixed transfer lines. Such a transfer line, while offering high-volume scale economies, requires significant re-work (possibly requiring as much as 24 months for changeover, including 6 months of tool design change preceding an actual down time as high as 18 months) for the addition of a new product. Increasingly; manufacturers have been incorporating computer numerically controlled (CNC) machinery as a means to gain flexibility. CNC machines offer increased flexibility, but at a higher up-front investment cost.

Diagram 1 shows three stylized engine head machining line layouts. The traditional dedicated head machining layout includes three high-volume transfer lines: one for rough machining, one for product-specific machining, and another for finish machining. Currently, most manufacturers are implementing one of two strategies to increase flexibility. The parallel transfer head line is a combination of high-volume transfer lines for rough and final machining, with two 'low-volume', transfer lines for the product-specific machining operating in parallel. These two lines generally consist of a higher volume line (e.g. 180,000 units per year) and a low volume line (e.g. 30,000 per year). The parallel transfer line presents manufacturers with an opportunity to offer engine variants at lower volumes, while concomitantly maintaining scale economies for rough and final machining. However, because this strategy relies upon traditional transfer line technology, it still requires significant downtime for product changeovers, and does not offer the ability to mix products between the product-specific machining lines. The other option is a transfer line CNC hybrid line. The CNC hybrid line also relies on transfer lines for rough and finish machining but uses multiple parallel cells of CNC machines for product-specific work. This system allows for greater flexibility and reduced downtime but requires more upfront investment. In such a strategy, each group of CNC cells is capable of machining any of the variants. Thus, it is possible to flex the product between individual lines as needed. This is indicated in the diagram by the nesting of lines between each stage. Such flexibility offers manufacturers the opportunity to continue operations if a CNC machine needs maintenance. 


\section{Diagram 1 - CNC: Three Fundamental Engine Head Machining Strategies}
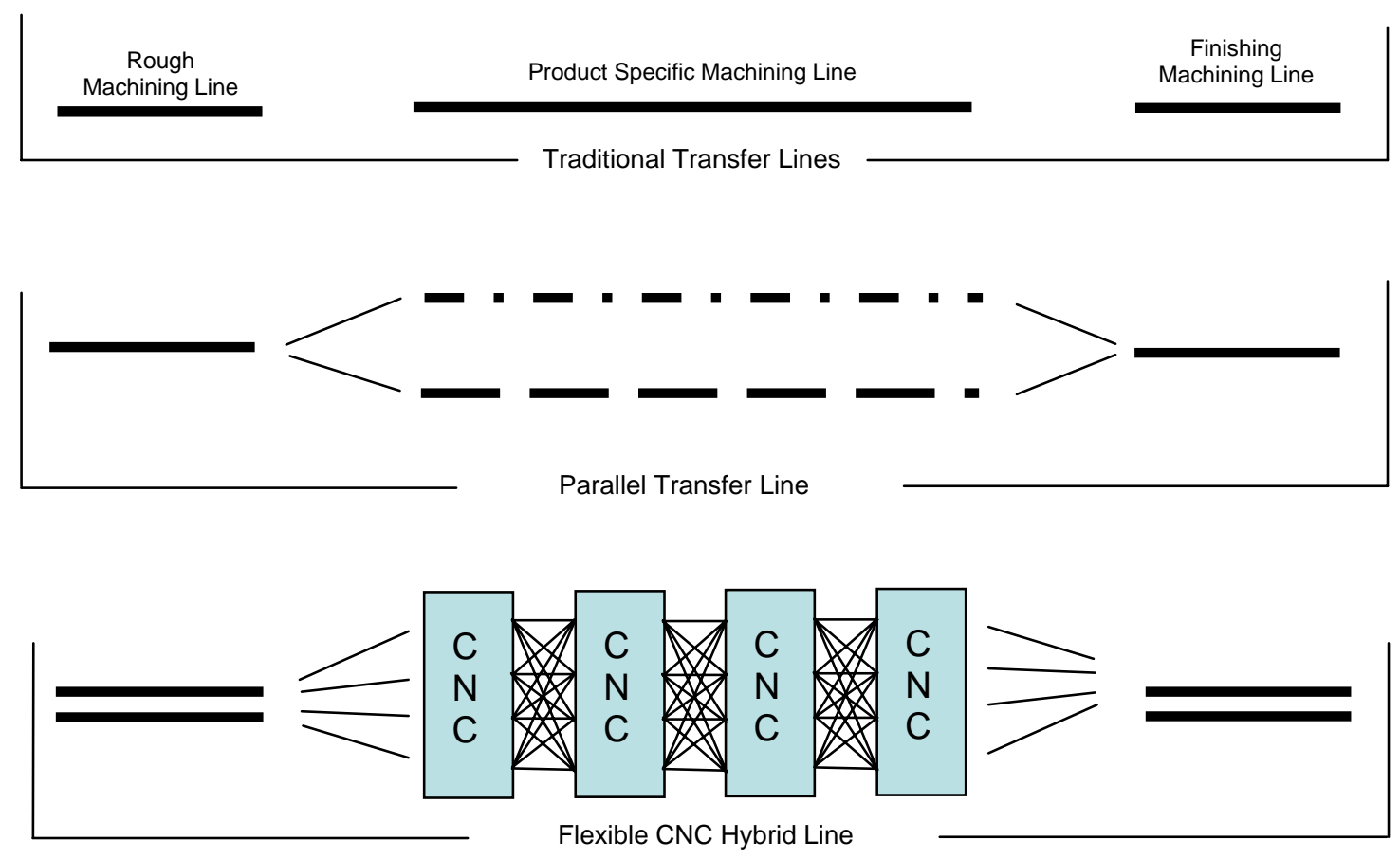

Fixed Transfer Line

Product Specific Transfer Line

It is worth noting that several sources suggested flexibility in the engine plant was driven by a 'top down' focus on preparedness. Companies that value the ability to rapidly respond to market conditions place a much higher value on flexibility. Therefore, they are able to justify increased up-front investment costs associated with the CNC machinery. Conversely, there are also companies that will asses the purchase decision based on the lowest acquisition cost. Those companies have a propensity to choose solutions with lower up-front costs, while accepting the penalty resulting from longer response times to market fluctuations.

The transfer-CNC hybrid machining operations can lead to significantly reduced changeover lead time-and thus a more rapid and less costly response to market conditions. One source indicated that tooling design and facility changeover can be reduced by a half to two-thirds. Further, many of the newer, more flexible systems are also capable of running current production components while the changes are being made for the new block. Interestingly, one source indicated that although such flexibility has been increasingly built into the system, it is likely there would still be some significant costs and hurdles in making such changes. Even though many manufacturers have an increased ability to adjust engine machining mix to market swings, that ability remains relatively untested and uncertain.

CAR presents a potential scenario to illustrate the cost and business strategies that are associated with manufacturing a relatively low-volume, high-mileage engine variation. We present this cost model with several caveats. First, we assume that only 15 engine 
facilities would require the changes_-some facilities are already relatively flexible-and companies would likely choose to target their facility engine and facility portfolio to meet standards. Second, all cost estimates are based on discussions with industry sources other than the manufacturers. And finally, for simplicity, we have averaged the expected cost of 4-, 6- and 8-cylind and equipment supplier's engine facilities.

CAR will focus this discussion on the engine head operations. As described earlier in this report, engine block operations will likely remain relatively inflexible and geared for high-volume. Thus, there is little opportunity to significantly change the block transfer machining process without a complete redesign of the system-an important (and undesirable) cost penalty. Much of the actual change required would likely be to the heads. Therefore, CAR assumes that manufacturers would develop solutions that minimize change to the blocks while taking advantage of the changes available for head design.

We present two options for meeting the challenge. First, a manufacturer may choose to replace a portion of an existing sequential transfer operation. Alternatively, they may decide that increased flexibility presents a strategic advantage, and commit resources to implement a flexible CNC-transfer hybrid line. Table 2 presents the manufacturing costs associated with the two options. The example shows challenges faced by manufacturers. A company can choose to respond to the challenge via the lower initial cost solution (with negative implications for future flexibility) but face a higher per-engine cost or invest in the solution with higher upfront costs (but decreased variable cost and increased flexibility.) Regardless of the decision, the increased investment required to create a low-volume variant presents significant investment for the industry.

Obviously, the investment decision would also be affected by other factors-not the least of which is the current technology in use. For the case of installing CNC machinery, we assume the product specific portion of the current line is considered sunk cost and thus scrapped. Also, we assume that the strategy to add a parallel line would be the replacement of a current low volume product line. ${ }^{5}$ Industry sources indicated that the cost of change to the block line and the engine assembly lines were likely constant with regard to volume.

Also, this example focuses on the cost of converting the line to run a different head design. It is also possible that the manufacturer may choose to reduce the number of cylinders (i.e. from i.e. from eight to six or six to four). Due to the inline-configuration of the 4 cylinder, the conversion of a V6 to an inline 4 cylinder is a much more costly task than from a $\vee 8$ configuration to a $\vee 6$. Because of the similarity of design between the $\vee 6$ and V8, many companies have built some flexibility for such a shift into their systems. However, most engine machining and assembly equipment is not readily converted from manufacturing $\vee$ configuration engines to inline type engines. Thus, the shift from 6 cylinders to 4 cylinder production presents significant cost hurdles. Finally, it is common for manufacturers to offer several different displacements from the same block. It is assumed that a higher efficiency engine would include a displacement reduction within the engine family (i.e. from a 5.7 liter to a 5.3 liter displacement).

\footnotetext{
${ }^{5} \mathrm{~A}$ third alternative would be to consider replacing an existing traditional transfer operation with a parallel transfer line. The cost of such a strategy would likely be somewhat less than the CNC hybrid system. Of course the cost penalty associates with this strategy would be the lack of flexibility for future engine programs.
} 
Table 2 - Engine Plant Conversion

Implementing a Low-Volume Engine into an Existing Engine Line

\begin{tabular}{|c|c|c|}
\hline & $\begin{array}{l}\text { Conversion of Entire } \\
\text { Head Line to Parallel } \\
\text { CNC Line }\end{array}$ & $\begin{array}{l}\text { Addition to Existing } \\
\text { Sequential Flexible } \\
\text { Transfer Line of a Low } \\
\text { Volume Engine Head }\end{array}$ \\
\hline \multicolumn{3}{|l|}{$\begin{array}{l}\text { Expected Cost of Required } \\
\text { Engine Plant Investment }\end{array}$} \\
\hline Block Line & $\$ 10,000,000^{\star *}$ & $\$ 10,000,000$ ** \\
\hline Head Line & $\$ 50,000,000$ & $\$ 20,000,000$ \\
\hline Engine Assembly & $\$ 15,000,000^{\star *}$ & $\$ 15,000,000^{\star \star}$ \\
\hline Total Investment & $\$ 75,000,000$ & $\$ 45,000,000$ \\
\hline Annual Capacity & 300,000 & 30,000 \\
\hline $\begin{array}{l}\text { Average Years of Product } \\
\text { Lifecycle }\end{array}$ & 8 & 8 \\
\hline Total Volume & $2,400,000$ & 240,000 \\
\hline Cost Per Engine & $\$ 31$ per engine & $\$ 188$ per engine \\
\hline $\begin{array}{l}\text { Number of Faculties (or lines) to } \\
\text { Change }\end{array}$ & 15 & 15 \\
\hline Total Cost to Industry & $\$ 1,125,000,000$ & $\$ 675,000,000$ \\
\hline \multicolumn{3}{|c|}{$\begin{array}{l}\text { Note: Cost estimates were gathered from discussions with industry sources. However } \\
\text { CAR did NOT discuss cost with manufacturers or equipment suppliers. } \\
\text { ** Estimates include minimum expected investment to meet flexibility } \\
\text { requirements. Actual investment would likely be higher. }\end{array}$} \\
\hline
\end{tabular}

Another significant cost hurdle may stem from the changes required to engine assembly tooling. Sources suggest a reasonable estimate for an engine assembly line is approximately $\$ 70$ million. The introduction of an alternative valvetrain or other significant change in the bill of materials would likely require significant new investment-both at the engine assembly and component supplier facilities. Based on discussion with industry sources, CAR estimates that it would take a further investment of approximately 25 percent of the original cost assembly to incorporate the needed changes into an existing line. It is likely that if the change were incorporated into a new line, there would be a 15 to 20 percent premium for the added flexibility of another variant on the line.

Importantly, there are indications that manufacturers are preparing for more severe swings in market demand. An example of this is presented by investigating engine assembly technology at Honda Motor Company's engine plant in Sayama, Japan. Historically, spark-ignited engines and diesel engines have been built on separate casting, machining and assembly tooling. Such inflexibility has presented one of the more daunting challenges as manufacturers attempt to plan to meet future requirements. The ability to shift between the two very different products or even mix the engines on a single engine line represents a considerable advantage. Honda has taken substantial steps toward increasing engine manufacturing flexibility-and thus market responsiveness-by developing an engine assembly line that can flex between gasoline 
and diesel engines-an industry first. ${ }^{6}$ The ability to quickly adapt to changing market conditions presents a strong competitive advantage. However, the Honda example is one of extreme-most engine manufacturing facilities, even internal to Honda, are far less flexible. The resources required to convert all manufacturing facilities to the level of flexibility seen in the Sayama facility would require substantial investment, and likely take over a decade to complete.

It is also important to put this discussion into further context. The industry has shown that it can and will produce low volume variants of engines. The industry currently produces numerous high performance low volume variants. However, these high performance derivatives are usually sold at a premium, and thus the manufacturers can expect to recover their investment costs. The majority of the U.S. market does not currently place a premium on fuel economy, and thus it is unlikely that manufacturers could recoup the investment costs for such engines via higher selling prices.

The cost of product development must also be considered when investigating the costs of change. While the cost of developing an engine program varies drastically, it is possible to make some assumptions based on published estimates. For this report, we assume the development cost to update an existing engine family to be approximately $\$ 500,000,000$. Further assuming an annualized production rate of 900,000 units with an eight year life cycle, we assume a development cost of approximately $\$ 69$ per engine. ${ }^{7}$ We further assume that a company could rely heavily on existing engineering to develop a low-volume (i.e. 30,000 units per year) derivative of current product and invest approximately $\$ 80,000,000$ or $\$ 333$ per-unit.

The combined cost of engine product development, facility changeover, and supplier infrastructure change present a significant cost hurdle for industry to meet small volume technology forced regulations. However, it is also valuable to note that in many ways, the ability to adapt to an ever changing market has always been a key characteristic of successful automotive companies. It is likely that those companies that are willing to incorporate flexible and agile strategies will be rewarded with increased market share in coming years. Those that choose inflexible systems and processes will likely suffer.

\section{Regionalization of Powertrains}

We offer another point of consideration for powertrain manufacturing costs. As has been described in this report, scale economies of powertrains (specifically engines and transmissions) present an important topic of consideration when attempting to define and understand costs. The U.S. automobile market has long been considered the world's largest single market for new passenger vehicles. Mass production, and the scale economies associated with it, has been synonymous with the U.S. automotive industry for decades. However, the U.S. market has undergone significant change over the past thirty years. Whether measured by market segmentation, nameplate offerings, or number of participants, the amount of variation and attendant lower per model

\footnotetext{
${ }^{6}$ Doi, Ayako, With changes coming, Honda is converting to flexible gasoline or diesel mix, The Japan Digest, January 31, 2005, page 9

${ }^{7}$ We believe the rough calculation might represent a low estimate of the actual cost. However, we also believe that development cost will decline in the coming years due to increased use of computer tools, and other factors. Thus we believe our estimates represent a realistic 'world class' product development program.
} 
volumes have become an important characteristic of the market. Manufacturers have adjusted to this new paradigm with highly flexible assembly operations.

Importantly, the powertrain has continued to be produced at relatively high volumes, with single engine type-or engine family - applied across many vehicle models. Historically, engine manufacturing modules-or manufacturing lines-have been designed to produce 300,000 or more engines per year. These modules were then located to serve national markets. Importantly, manufacturers were able to allocate engineering costs to several modules, thus recovering their investments. Recent years have seen manufacturers rely increasingly on a 'global' powertrain strategy-developing engine and transmission families that can be used in several national markets. This shift has allowed manufacturers to sell fewer of any one engine type in a single market, yet maintain scale economies by selling the engine in several regional markets.

Currently, the automotive industry is struggling to understand the developing advanced powertrain paradigm. The gasoline-hybrid-electric vehicle presents opportunity for significant decreases in carbon dioxide emissions when driven in congested areas, but may not deliver similar gains when used in less congested areas, and may suffer from poor battery performance in cold weather climates. Conversely, the diesel engine may present potential efficiency gains over the current spark-ignited gasoline engine (and maybe even the HEV in some driving cycles) but suffers from cost and emissions challenges. The gasoline spark-ignited gasoline engine may also offer increased efficiency, at a cost. CAR believes it is wholly possible that each of these powertrains may gain acceptance based on environmental concerns and other factors.

The California legislation presents a further fracture of the U.S. market; it puts increased pressure on all manufacturers to offer a wide range of very different powertrains at relatively low volumes locally. In the long run, the regionalization-or fracture-of the U.S. powertrain market could lead to increased focus on flexible manufacturing, increased opportunities for partnerships and could, in turn, create even more opportunity to develop technology solutions that can be applied locally, but manufactured globally. However, it is likely that such rapid forced fragmentation would create significant nearterm strain and investment challenges for the entire industry. CAR believes this area is deserving of substantial research effort beyond the parameters of this report.

\section{E. Internal Combustion Engine Component Cost Modeling}

CAR used an internally developed engine cost model to estimate component costs for this project. CAR has used the model for previous internal and external projects. It is intended to represent a stylized cost model for the complete vehicle, divided into basic systems. For this project, CAR used input from several sources to further tune the model. The model includes engine mechanical, fuel delivery, engine electrical and exhaust. The model assumes a single overhead cam engine configuration and is closely matched to the NAICS codes. These are stylized costs assuming a scale volume manufacturing scenario (of 300,000 engines per year). This model does not attempt to capture the component development costs, nor other various overhead costs. Table 3 shows the cost estimates for each of the four engine modules as derived from the model. 
Table 3 - Cost of Engine:

Stylized Cost of ICE Engines; Inline 4, V6, Inline 6 Diesel (CIDI), and V8 Configurations

\begin{tabular}{|l|c|c|c|c|}
\hline $\begin{array}{l}\text { Engine Module } \\
\text { as a Percent of } \\
\text { Total }\end{array}$ & $\begin{array}{c}\text { 4-Cylinder SI } \\
\text { Inline } \\
\text { Configuration } \\
\text { (dollars) }\end{array}$ & $\begin{array}{c}\text { 6-Cylinder SI } \\
\text { V } \\
\text { Configuration } \\
\text { (dollars) }\end{array}$ & $\begin{array}{c}\text { 6-Cylinder CIDI } \\
\text { Inline } \\
\text { Configuration } \\
\text { (dollars) }\end{array}$ & $\begin{array}{c}\text { 8-Cylinder SI } \\
\text { V } \\
\text { Configuration } \\
\text { (dollars) }\end{array}$ \\
\hline $\begin{array}{l}\text { Engine } \\
\text { Mechanicals }\end{array}$ & $\$ 816$ & $\$ 1,225$ & $\$ 1,932$ & $\$ 1,523$ \\
\hline Fuel Delivery & $\$ 374$ & $\$ 509$ & $\$ 1,176$ & $\$ 609$ \\
\hline $\begin{array}{l}\text { Engine } \\
\text { Electrical }\end{array}$ & $\$ 321$ & $\$ 452$ & $\$ 420$ & $\$ 479$ \\
\hline Exhaust & $\$ 189$ & $\$ 264$ & $\$ 560$ & $\$ 276$ \\
\hline SCR & N/A & N/A & $\$ 1,500$ & N/A \\
\hline $\begin{array}{l}\text { Total Stylized } \\
\text { Cost }\end{array}$ & $\$ 2,700$ & $\$ 50$ & $\$ 5,588$ & $\$ 2,886$ \\
\hline
\end{tabular}

CAR has also developed a stylized model for a compression injection, direct injection (diesel) engine. This model describes a current Inline 6 cylinder engine with common rail fuel injection.

The after-treatment for diesel engines presents a great challenge for the industry. There was some belief by the sources that that lean $\mathrm{NO}_{\mathrm{x}}$ catalysts or $\mathrm{NO}_{\mathrm{x}}$ absorbers and selective catalytic reduction (SCR) are likely to be technologically viable methods of meeting Tier 2 Bin 5 for $\mathrm{NO}_{x}$ reduction. Yet, there was also strong concern expressed that these technologies were not yet proven to met high mileage durability standards, and may be too costly in their final form. Several companies are also focusing on selective catalytic reduction ( $\mathrm{SCR}$ ) technology for $\mathrm{NO}_{\mathrm{x}}$ reduction. A common strategy for SCR is to periodically inject urea into the exhaust, thus neutralizing $\mathrm{NO}_{\mathrm{x}}$. However, this strategy relies on the user-the driver-to be responsible for assuring that there is adequate urea in the canister. Initially there was great doubt in the technology a viable operation for the U.S. market. Many felt that the E.P.A. would only cautiously consider the implications of shifting responsibility from the manufacturer to the driver. However, given recent discussions with industry sources, SCR appears to be considered an increasingly viable option going forward.

CAR will further focus discussion on the engine mechanical subsystem. It has become commonplace for reports to 'hang on' additional technologies to the current gasoline engine to estimate potential future costs as well as efficiency gains. This has been especially true for mechanical technologies. The cost model presents an opportunity to illustrate the added (and deleted) costs of these technologies, later in this report.

Table 4 represents the stylized costs for the major mechanical parts of the gasoline engine. We will examine more closely the costs associated with addressing changes to the head and block manufacturing, later. Further development of the valvetrain module (balance shafts, camshafts and other valvetrain components) present great opportunity to increase fuel economy and reduced emissions. Thus, there are many potential variations to the current valvetrain solution. Although variations present opportunity for 
decreased carbon dioxide emissions, this report will not attempt to quantify those gains beyond the available literature.

Table 4 - Cost of Mechanical:

\section{Stylized Cost of Major Mechanical Components;}

Gasoline Engine Inline-4, V6 and V8 Configurations

\begin{tabular}{|l|c|c|c|}
\hline $\begin{array}{c}\text { Engine Mechanical } \\
\text { as a Percent of } \\
\text { Total }\end{array}$ & $\begin{array}{c}\text { 4-Cylinder } \\
\text { Inline Configuration } \\
\text { (dollars) }\end{array}$ & $\begin{array}{c}6-\text {-Cylinder } \\
\text { V Configuration } \\
\text { (dollars) }\end{array}$ & $\begin{array}{c}\text { 8-Cylinder, } \\
\text { V Configuration } \\
\text { (dollars) }\end{array}$ \\
\hline $\begin{array}{l}\text { Head and Block } \\
\text { (Machined) }\end{array}$ & $\$ 260$ & $\$ 390$ & $\$ 485$ \\
\hline Valvetrain Module & $\$ 185$ & $\$ 278$ & $\$ 346$ \\
\hline $\begin{array}{l}\text { Pistons, Crankshaft, } \\
\text { Connecting Rod }\end{array}$ & $\$ 148$ & $\$ 223$ & $\$ 277$ \\
\hline Accessories & $\$ 223$ & $\$ 334$ & $\$ 418$ \\
\hline Total Stylized Cost & $\$ 816$ & $\$ 1,225$ & $\$ 1,523$ \\
\hline
\end{tabular}

\section{F. Internal Combustion Engine Component Cost and Fuel Economy Forecasts}

An important element of the vehicle sales forecast for 2009 is the technology likely to be used on those vehicles. Given lead time required by the automotive industry to incorporate new technology into their products, the technology choices for 2009 are relatively limited. This report will address (and attempt to quantify) possible near-term technologies, and also briefly investigate those technologies that appear to be possible long-term options.

Through literature searches, CAR collected a list of potential technologies that served as a foundation. CAR then discussed (i.e. via written, telephone or personal interviews) the technology options with more than 25 individuals (stakeholders from various segments of the industry). These individuals had extensive expertise in the internal combustion engine, and were asked to comment on the cost, fuel efficiency and the viability of those technologies for which they were familiar. CAR has summarized these discussions in Table 5 (Technology).

The authors of this report offer a caveat. These estimates are presented as averages of the responses given by the experts. However, CAR wishes to include the 'it depends' variable in the discussion. That is, invariably, the experts would estimate a cost and efficiency gain for the technology and then comment that their response depended greatly on a variety of factors. Some of these variables were universally controllablesuch as base engine, vehicle segment, etc. However, there were others that were far more localized. For example, there is a wide range of current expertise between companies in core engine engineering; it is possible for a top performer to get significantly better efficiency gains from a given technology than a company with lesser engineering expertise. Conversely, it is also possible that a poor performer may be able to extract more from a technology because 'there is room for improvement'. Several panelists were impressed with (and generally accepted) recent reports that performed modeling on various vehicle segments. However, they indicated that much variance for a 'real world' application should still be expected. They also believed that any variance will tend to be downward biased-that is, real world performance would be less than modeled. 
Table 5 - Gasoline Engine Technology

\begin{tabular}{|c|c|c|}
\hline & $\begin{array}{l}\text { Incremental } \\
\text { Cost }\end{array}$ & $\begin{array}{c}\mathrm{CO}_{2} \text { Emissions } \\
\text { Reduction }\end{array}$ \\
\hline \multicolumn{3}{|l|}{ Valvetrain Technologies } \\
\hline Intake Cam Phasing & $\$ 85$ & 4 \\
\hline Exhaust Cam Phasing & $\$ 90$ & 2 \\
\hline Dual Equal Cam Phasing & $\$ 150$ & 4 \\
\hline Mechanical Variable Valve Lift and Duration & $\$ 350$ & 7 \\
\hline${ }^{\star}$ Electromagnetic Actuation & $\$ 600$ & 9 \\
\hline${ }^{\star}$ Electrohydraulic Actuation & $\$ 700$ & 9 \\
\hline Cylinder Deactivation & $\$ 150$ & 7 \\
\hline \multicolumn{3}{|l|}{ Combustion Chamber } \\
\hline Variable Compression Ratio & $\$ 350$ & 5 \\
\hline GDI-Stoichiometric & $\$ 225$ & 7 \\
\hline${ }^{\star}$ GDI - Lean Burn Stratified Charge & $\$ 500$ & 11 \\
\hline *Gasoline $\mathrm{HCCl}$ & $\$ 700$ & 12 \\
\hline \multicolumn{3}{|l|}{ Transmission Technologies } \\
\hline 6-Speed Automatic Transmission & $\$ 100$ & 6 percent \\
\hline Continuously Variable Transmission (CVT) & $\$ 50$ & 8 percent \\
\hline **Automated Manual Transmission (5/6 sp) & $\begin{array}{c}-\$ 140 \text { to }- \\
\$ 80^{\star \star}\end{array}$ & 6-7 percent over $(A / T)$ \\
\hline
\end{tabular}

Table 5 presents various technologies that represent viable alternatives for increased efficiency gains of the gasoline engine. The cost estimates are incremental based on a 6 -cylinder DOHC engine. We have divided the technologies into three categories: valvetrain, combustion chamber, and transmission. As noted previously, the valvetrain is viewed as a fertile area for increased engine efficiency. Combustion chamber development also presents opportunity, but many of the listed technologies were viewed as long-term candidates. The inclusion of transmission technology reinforces the fact that engine performance is essentially a systems challenge.

An important point to consider with regard to valvetrain (and other engine head technologies) is that they have often been used to increase performance. There has been a steady and significant increase in engine compression ratio over the past several years. Much of that is from increased air flow into the engine created by valvetrain technology. However, much of that gain has gone toward improved performance (i.e. horsepower) instead of fuel consumption reduction. The industry now must face the challenge of leveraging those technologies (and others) that have created high compression ratios to deliver engines that produce fewer emissions (better fuel economy) while still maintaining the performance characteristics that customers have come to expect.

There are several valvetrain technologies-or strategies-that would increase efficiency via better air flow. The ability to affect valve lift and timing has been under development for several years. Currently there is widespread application of discrete timing, with several initial applications of discrete lift. Continuous variable valve lift and timing-or 
the ability to affect the valve opening event at any point-remains a much more difficult challenge, and is expected to be accomplished with camless technology. Recently, in large part due to electronic engine control capabilities, cylinder deactivation has become a viable and relatively cost-effective addition. However, some indicated that cylinder deactivation may reduce an engine's ability to meet ultra strict emission regulations without additional combustion chamber strategies.

Camless (either electromagnetic or electrohydraulic) technology offers the gains associated with continuously variable lift and timing, while adding efficiency of operation. Because it is driven electronically, it does not cause drag on the engine as the chain driven approaches do. Many suggested that such a system would be required to achieve the advanced combustion chamber strategies currently being considered. Camless systems were expected to offer opportunity only in the distant future (usually viewed as at least ten years). Although there are initial variants of continuously variable valve actuation technology available, they are found in vehicles located in higher cost segments. Most respondents greatly doubted the ability to incorporate the system into lower cost segments within the next five years

There are numerous combustion chamber technologies-or more accurately described strategies - that must be considered in this investigation. Homogeneous charge compression ignition, variable compression ratio and gasoline direct injection potentially offer increased efficiency; however significant hurdles remain. For example, regarding the future of $\mathrm{HCCl}$, one engine expert offered the following comment: full $\mathrm{HCCl}$ operation was much like balancing a pencil on its tip. Yes, it is theoretically possible, but extremely difficult. Any such strategy will likely be limited to operation in Stoichiometric, for the foreseeable future.

Finally, CAR inquired about future transmission technology. There was great certainty that 5- and 6-speed transmissions were going to gain strong presence in the U.S. market. There was far less certainty regarding the future of continuously variable transmissions (CVT) and automated manual transmissions (AMT). Several manufacturers will soon begin production of 6 -speed automatic transmissions. The industry sources suggested that a 3-5 percent decrease in carbon dioxide emissions will be derived from the switch from 4 to 6-speed transmissions. CAR expects 6-speed automatics to account for a significant portion of total transmission penetration within the next five years. There was general support that the cost of the 6-speed transmission would be accepted by the consumer. There has also been a general move away from CVT technology by several companies in recent months. Many interviewed expect the 6-speed automatic transmissions to make CVTs far less desirable for most applications in the U.S. market.

The AMT has been presented as a critical technology in several recent repots. Among those interviewed for this report, there was general agreement that automated manual transmissions present opportunity for efficiency gains. The single-sided clutch (SSC), the double sided clutch (DSC) and the dual clutch (DC) are the three fundamental variations of the AMT currently under development. ${ }^{8}$ Generally those that responded to questions regarding automated manual transmissions noted that SSC would not likely meet customer requirements in the U.S. market-and would likely take market share

\footnotetext{
${ }^{8}$ Klugar, Michael and Suampodi, Bapiraju. Smooth in the Clutch, Southwest Today, Summer, 2004 , volume 25 no.2, pp.6-9
} 
from manual transmission-thus doing little to improve carbon dioxide emissions levels. They did consider the other options as potentially offering an alternative to automatic transmissions.

Manual automated transmissions have seen initial application in Europe. There are currently two very diverse market segments for which AMTs are offered. The first is compact, high-volume vehicles, where electromechanical modules are commonly used. In these applications, AMTs offer opportunity to replace the manual clutch for simpler driving while still delivering the fuel economy gains, emissions levels of a manual gearbox. The other segment is the high performance sport market. Driven in part by racing technology, manufacturers are incorporating an electrohydraulic driven module that offers quick gear changes. ${ }^{9}$

Generally, respondents thought that 6-speed automatic transmissions would be the most 'consumer acceptable' approach, but they were willing to recognize that the AMT, because of cost and increased efficiency, may present opportunity for some vehicle segments.

One final note regarding transmissions: several sources commented that transmission options should not be viewed as entirely additive. Increasing the number of gears, or adding continuously variable range allows the engine to operate in its most efficient range for a greater period of time. Importantly, most of the valvetrain technologies at least partially address the same challenge via widening the efficiency range of the engine. Conversely, the AMT addresses the efficiency loss due to the torque converter in automatic transmissions-thus, must be considered additive.

\footnotetext{
${ }^{9}$ Wim, Oude Weernink, 'Automated manuals get off to slow start.' Automotive News, Crain's Publications, January 24, 2005 p.112F
} 
CAR attempted to gain insight into the technologies that may be combined to achieve a 9 percent decrease in carbon dioxide emissions, a 17 percent decrease and finally a 23 percent decrease All of the individuals CAR spoke to for this project were confident that there was room for improvement of the internal combustion engine. There was less certainty regarding the emissions levels that could be attained. Most also believed that unless there was a significant change in consumer demand, the efficiency gains would be used for performance increases instead of decreased emissions reduction.

The respondents generally agreed that the addition of the following technologies would possibly achieve a 9 percent reduction in carbon dioxide emissions: single cam phasing for (DOHC), some basic form of variable valve timing and lift, across a majority of the products is a requirement to achieve a 9 percent carbon dioxide reduction. Cylinder deactivation would also be used in many applications for V6 and V8 engines. Several respondents indicated that such an improvement would be readily attainable with minimal investment.

The above technologies are required plus 6-speed transmissions for mid-size and larger vehicles, AMT for compact car and smaller cross-over segments. Several thought that camless valve actuation would be highly likely to achieve the increase. They also expect manufacturers to use a more aggressive torque converter lock-up. Also, most agreed that important to achieving a 17 percent carbon dioxide reduction would be the conversion of most—if not all—drivetrain accessories to electric driven.

Those that responded indicated that, theoretically, the gasoline engine could become up to 30 percent more efficient (i.e. reduce carbon dioxide by $23 \%$ ); however, they felt it would be extremely difficult and certainly very costly. Most indicated that in order to meet the pending California Standards, vehicles would likely have to include some form of hybridization and some weight reduction. Several respondents thought that the standard could be met with some form of engine shut-off, combined with increased reliance upon electric accessories and the technologies mentioned above, while others strongly believed that the standards would require full hybridization. 


\section{Hybrid Electric Vehicles}

\section{A. Hybrid Electric Vehicle Architecture and Technology}

A natural starting point for the discussion regarding hybrid electric vehicles is to clarify terminology regarding their differing layouts. Appendix I shows the basic technology design for each of the hybrid vehicles currently on the market as well as announced future offerings. ${ }^{10}$ CAR considered three formats of hybrid technology, with several variations, for this report. GM (and soon Chrysler) has chosen to use the integrated starter generator (ISG) layout for their initial entries. Honda is marketing their Integrated Motor Assist (IMA) system. Toyota and Ford offer products using parallel-series HEV technology. The popular press and several technical papers have referred to Parallel Series as 'strong' hybrids and IMA as mild hybrids. However, CAR will refer to the technologies as parallel - series and IMA to avoid making inference to the value of either technology. For this report (specifically the 2009 forecast), CAR will only consider vehicles that use electric power for motive purposes. Thus we will briefly address integrated starter systems, which do not provide motive power, but they will not be included in the final forecast results.

Table 6 shows the electrical motor/generator and battery requirements for selected IMA and parallel HEVs. The vehicle specifications make it readily apparent that the parallelseries system requires higher voltage, and uses higher output from the motors. Another comment regarding the two technologies is pertinent: note the relatively similar output of the two Honda systems. ${ }^{11}$ The two models have very similar power ratings, and thus it is likely that much of the power conversion equipment and controls likely have been shared between models. This appears to match well with Honda's desire to gain manufacturing economies via using 'scaleable' technology that will be addressed later in this report.

Table 6 - Comparison of Hybrid Electric Vehicles

\begin{tabular}{|l|l|l|l|}
\hline \multicolumn{1}{|c|}{ Model } & \multicolumn{1}{|c|}{ Type } & \multicolumn{1}{|c|}{$\begin{array}{c}\text { Electric Motor/Generator } \\
\text { (GEN) }\end{array}$} & $\begin{array}{c}\text { Battery } \\
\text { (Volts) }\end{array}$ \\
\hline Civic & IMA & $10 \mathrm{kw}$ & $144(\mathrm{~V})$ \\
\hline Accord & IMA & $12 \mathrm{kw}$ & $144(\mathrm{~V})$ \\
\hline Prius THS I (2000) & Parallel - Series & 33kw/10kw (Gen) & $274(\mathrm{~V})$ \\
\hline Prius THS II (2004) & Parallel - Series & $49 \mathrm{kw} / 10 \mathrm{kw}$ (Gen) & $202(\mathrm{~V})$ \\
\hline Escape & $\begin{array}{l}\text { Parallel - Series } \\
\text { (AWD) }\end{array}$ & $70 \mathrm{kw} / 28 \mathrm{kw}(\mathrm{Gen})$ & $330(\mathrm{~V})$ \\
\hline Lexus 400h & $\begin{array}{l}\text { Parallel - Series } \\
\text { (AWD) }\end{array}$ & $\begin{array}{l}\text { Front: } 123 \mathrm{ks} / 109 \mathrm{kw}(\mathrm{Gen}) \\
\text { Rear: } 50 \mathrm{~kW}\end{array}$ & $288(\mathrm{~V})$ \\
\hline \multicolumn{2}{|l}{ Source: Company Literature } \\
\hline
\end{tabular}

CAR spent time discussing each of the systems with several industry sources. The general theme of their responses confirmed the belief that the IMA offered a more attractive cost hurdle, while the parallel-series systems might offer more efficiency.

\footnotetext{
${ }^{10}$ Note: We have only included vehicles from each company that were substantially different than the others. The DaimlerChrysler Ram was not included because it was not yet available. The GM AHSII was included because it represents a substantially different approach.

${ }^{11}$ Appendix Honda presents a brief description of the changes Honda incorporated into the HEV versions of the Civic and Accord.
} 
There are numerous reports and technical papers (several of which are included in the list of references) describing the differing technologies. Our discussions with industry experts inevitably came back to the conclusion (an all too familiar one at that) 'it depends'. Those familiar with HEV design were strongly convinced of two things. First, they believed there is a wide range of performance and efficiency gains possible from both systems. Thus, the ability to 'tune' similar systems differently made it nearly impossible to rule out any efficiency estimates, nor confirm that there was any one best approach. In essence, what they said was that at this point there are too many variables to choose the one right path to hybridization. Second, many suggested that the modeling done to test these vehicles was not yet as precise as needed. The ability to predict real world performance is, for obvious reasons, not as advanced as that of the internal combustion engine. Several sources indicated that these challenges should not be viewed as reasons to forgo discussion on the subject, but instead to treat all results with great care.

The added weight of hybrid technology-in both systems-presents further insight into the differences between systems. Table 7 shows the weight of four HEVs and their base alternatives. Upon initial inspection, the increased weight of the Escape SUV (13.3 percent), as compared to the others, is quite remarkable. As illustrated in Appendix I, the Escape and Lexus products approach four-wheel drive ${ }^{12}$ differently. Ford chose to use the traditional transfer case to place power at each wheel. Toyota chose to forgo the transfer case using a system similar to that in the Prius to drive the front wheel and placing a motor in the rear to drive the back wheels. It may be that the deletion of the heavy transfer case presented some weight reduction vis-à-vis the Ford solution. However, several sources suggest that the difference in percentage weight gained between the two products may have as much to do with experience as with technology. These respondents noted that this was Ford's first volume hybrid, whereas Toyota has had several iterations of the technology.

Table 7 - Weight Comparison of Hybrid Vehicle with Non-Hybrid Model

\begin{tabular}{|c|c|c|c|c|}
\hline Vehicle & $\begin{array}{l}\text { Weight of Base } \\
\text { Vehicle } \\
\text { (pounds) }\end{array}$ & $\begin{array}{l}\text { Weight of Hybrid } \\
\text { Electric Vehicle } \\
\text { (pounds) }\end{array}$ & $\begin{array}{l}\text { Weight } \\
\text { Gain } \\
\text { (Percent) }\end{array}$ & $\begin{array}{l}\mathrm{CO}_{2} \\
\text { Reduction* } \\
\text { (Percent) }\end{array}$ \\
\hline Honda Civic (IMA) & 2612 & 2684 & $2.7 \%$ & $30.6 \%$ \\
\hline Honda Accord (IMA) & 3349 & 3501 & $4.5 \%$ & $23.7 \%$ \\
\hline $\begin{array}{l}\text { Ford Escape (Parallel } \\
\text { - Series) }\end{array}$ & 3346 AWD & 3792 AWD & $13.3 \%$ & $36.7 \%$ \\
\hline $\begin{array}{l}\text { Lexus 400H (Parallel } \\
\text { - Series) }\end{array}$ & 4065 AWD & 4365 AWD & $7.4 \%$ & $26.5 \%$ \\
\hline \multicolumn{5}{|c|}{$\begin{array}{l}\text { Note: The Prius does not have a direct 'non-hybrid' version, thus is not included in the } \\
\text { Comparison. } \\
\text { * } \mathrm{CO}_{2} \text { reduction based on comparison of base model to HEV EPA ratings }\end{array}$} \\
\hline
\end{tabular}

This table also highlights the difference between the IMA hybrids (the Accord and Civic), and the parallel - series hybrids. It is reasonable to assume, given larger motors and more components, that the parallel-series systems are heavier. The table confirms this assumption, but we add two caveats. The IMA entries are front-wheel passenger car

\footnotetext{
${ }^{12}$ For this hybridization discussion, we do not differentiate four-wheel-drive from all-wheel-drive. Although the authors understand the technical differences between the two systems and that there may be some efficiency differences, we believe it is reasonable for discussion purposes to generalize them. Therefore, we will generally refer to either as four-wheel-drive or 4WD.
} 
drive vehicles while the parallel - series layout vehicles are in the sport-utility segment, Some of the weight difference can be attributed to the need for increased requirements-and the resulting increase in electric motor and battery weight to meet the segment-specific requirements. Also, Honda has taken several steps to decrease the weight of their hybrids via lightweight materials and other means. Certainly, Ford did not make as many similar changes to the Escape.

The differing 4WD approaches also raise questions regarding towing capability. Vehicles in segments that require towing capability must meet very demanding peak load levels. Although the electric motor presents excellent performance characteristics for some portions of a towing cycle, it also presents drawbacks during others. Table 8 shows the towing specifications of the three 'truck-like' HEVs, and their non-HEV model. Although the Silverado does not meet our hybrid definition, we have included it in the table for illustrative purposes. Each of the three entries offers very different approaches to the hybridization of the Silverado, an ISG system with no reduction in ICE horsepower from the base model. As described earlier, the Escape and 400h, although both considered parallel-series HEVs, take very different approaches to deliver 4WD capability.

Table 8 - Published Towing Specifications For Four-Wheel-Drive (4WD) Hybrid Electric Vehicles

\begin{tabular}{|c|c|c|}
\hline & \multicolumn{2}{|c|}{ Towing Capacity } \\
\hline Vehicle & $\begin{array}{c}\text { Base } \\
\text { (pounds) }\end{array}$ & $\begin{array}{c}\text { HEV } \\
\text { (pounds) }\end{array}$ \\
\hline $\begin{array}{l}\text { Escape } \\
\text { (2WD and 4WD) }\end{array}$ & $\begin{array}{c}\text { 1,500 (2.3 I4 2WD and } \\
\text { 4WD) } \\
\text { 2,000 (3.0 V6 2WD and } \\
\text { 4WD) } \\
\text { 3,500 (3.0V6 Class II } \\
\text { Towing Package 2WD } \\
\text { and 4WD) }\end{array}$ & 1,000 pounds \\
\hline $\begin{array}{l}\text { Silverado } \\
\text { (3.42 Axle 8' Bed } 5.3 \text { V8 Extended Cab) }\end{array}$ & 7,800 pounds & 7,400 pounds \\
\hline RX400h & $\begin{array}{c}3,500 \\
\text { (Towing Prep Package) }\end{array}$ & No difference \\
\hline
\end{tabular}

The Silverado presents an interesting starting point. It relies on a standard gasoline engine (similar to that of the ICE comparison model) for its motive power, yet suffers a 400-pound towing penalty when compared to its base vehicle. Much of this penalty is due to the added weight of the ISG technology. An assumption could be made that-at least in the case of the Silverado-there is a penalty of approximately 5 percent for the weight of the ISG technology. Similarly the Escape suffers approximately a 33 percent decrease in towing capacity when compared to the 14 Escape. Importantly, the 14 engine in the HEV Escape has been modified to decrease carbon dioxide emissions, unlike the standard V8 in the Silverado.

Some sources suggested that the relatively flat torque curve of the electric motor make it an ideal match for towing applications. However, they also admit that the extreme demands of towing require both a short bursts of torque and much longer drawn-out 
peak requirements (such as extended hill-climbing cycles). Such extremes would demand a more powerful gasoline engine than would be otherwise needed. Thus, there was considerable sentiment that heavy towing cycles might present challenges to the hybrid electric vehicle, especially given the likelihood that many HEV entries would rely upon downsized engines to decrease carbon dioxide emissions. It is worthwhile to note that many purchasers of SUVs and pickup trucks have no intention of towing. Some experts indicated that it would be viable to offer HEV versions of such vehicles, with considerably lower towing capacities. Another issue addressed was the drivetrain efficiency of the 4WD drivetrains. CAR inquired, but was unable to gather consistent opinion, regarding drivetrain efficiency of the two variants mechanical 4WD (Escape) and electric 4WD (Lexus). Several of those that responded indicated that they believed it would be more 'palatable' to the consumer to have the traditional mechanical system for towing applications. However, the electrical 4WD system (Lexus) presents an easier packaging solution, since there is no need for a driveshaft tunnel. The electric motors also offer enhanced (quicker) vehicle dynamics control and enhanced regenerative braking, because of the reduction in friction loss. The Mechanical system likely offers higher continuous power for deep cycle towing needs due to the limited cooling of the remote electric motors on the electric 4WD system. It is interesting to note that of the two current 4WD HEV offerings contradict the assumption that towing will be less for the electric 4WD HEV. However it must be noted that the Escape HEV relies on an Atkinson cycle engine, and was the company's first HEV attempt. Conversely, the Lexus uses the same basic engine for both the HEV and non HEV models, and also gains from being third generation technology. One highly knowledgeable source indicated that the cost of the two systems is a 'push'. This is due the added cost of the extra electric motors and electronics for the electric 4WD being offset by the deletion of mechanical driveline components

\section{B. Hybrid Electric Vehicle Bill of Materials and Bill of Process}

As it was valuable to describe the bill of materials and bill of process for the internal combustion engine; it is also useful to examine the same for the hybrid electric vehicle. Figure 3 shows a diagram of a bill of materials for a generic hybrid electric vehicle. Although the internal combustion engine has been left off the diagram, the transmission (or transaxle) has been included. Because the transmission is such an integral part of the HEV system-specifically for the parallel-series hybrids currently in production and expected-we highlight it as a part of the change. The HEV system can be generalized into five main components: power control, electric motor(s), electric drivetrain controls, transmission and battery. Upon initial review, it is apparent that the hybridization of a vehicle presents a significant number of new-and in several instances, expensivecomponents. Although intrinsically it is known that these components are costly, there is little real cost data available. CAR has spent great deal of effort attempting to gather reasonable cost estimates for these components and systems from informed industry stakeholders. These 'estimates' often differed by a factor of five or six. Unquestionably, some of this differentiation can be explained by differing assumptions on development and manufacturing investment. Even allowing for some variance in how such investment is accounted for, there was often significant difference in expected piece cost. From our discussions, it is apparent that there is great uncertainty by many regarding the final cost of hybrid technology. Although this report presents hybrid technology cost estimates, we offer these for discussion purposes only. The assumptions made were based on a review of literature and discussions with several industry sources. We believe that while a select few companies may have a 
comprehensive understanding of HEV piece cost, there is generally very little reliable information regarding total cost. 
Figure 3 - Bill of Materials: Electric Drivetrain Assembly

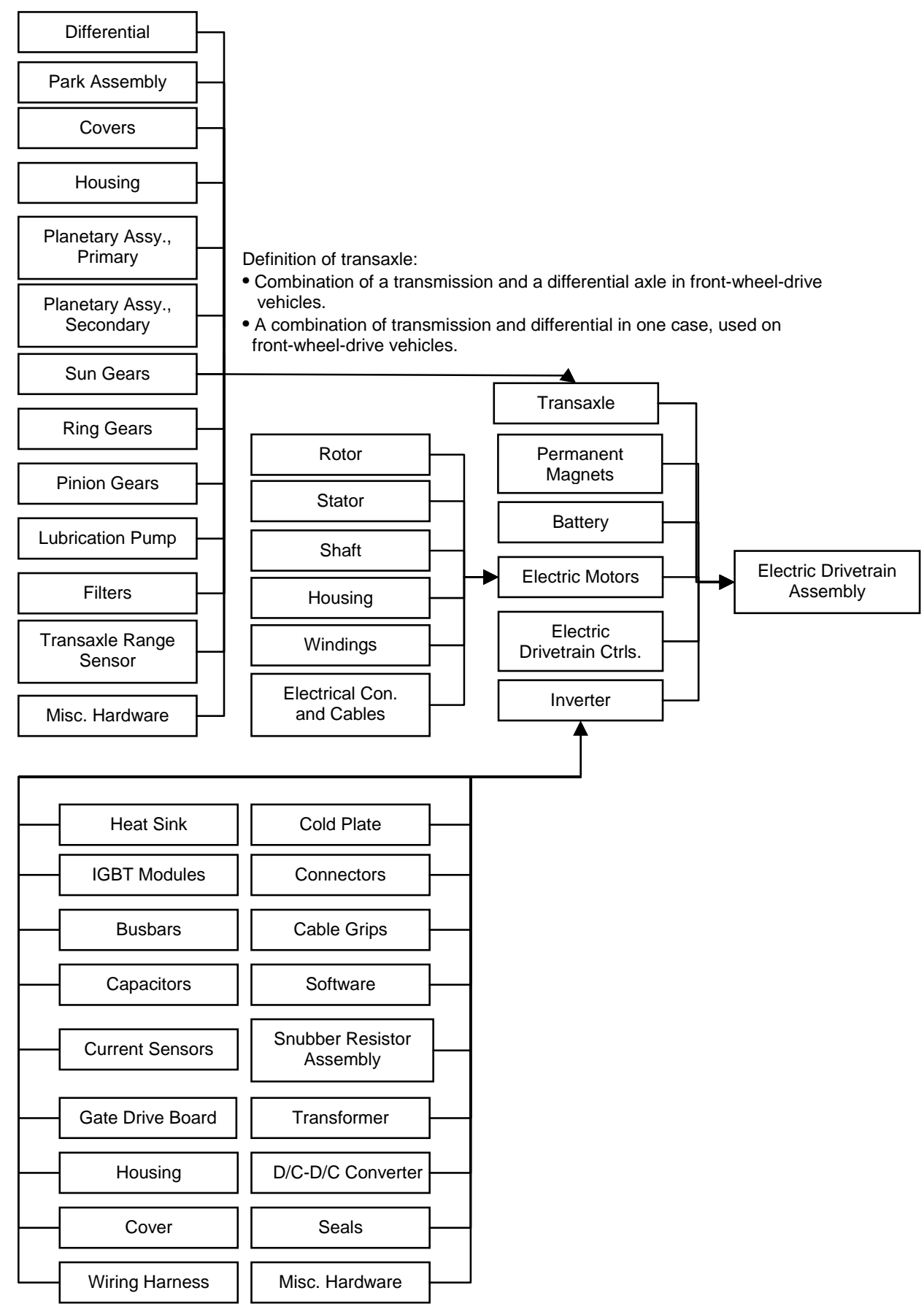


CAR attempted to gain insight into the cost of hybrid electric vehicle component technology. Most respondents were not able to present specific cost estimates, relying instead on likely cost ranges. Many of the sources indicated that, as with many developing technologies, there are numerous approaches to hybridization, thus creating vast differences in component performance requirements. Several also suggested that since only three companies have had significant experience making hybrid electric vehicles-and the components-and even then only at relatively low volume, there was great uncertainty regarding realistic cost estimates

Table 9 shows the range of component cost estimates for a 4-cylinder DOHC compact passenger car. It was assumed that the vehicle would achieve equivalent performance, with a decrease in carbon dioxide emissions of 23 to 31 percent for the integrated starter generator systems, and 27 to 37 percent for the parallel. We present these cost estimates with several caveats. First, the estimates were for an assumed volume of 100,000 components per year-levels that have yet to be achieved by any single manufacturer. Realistically, scale economies for such technologies will be achieved at much higher volumes-as one respondent noted; "The Auto supplier industry doesn't do anything in volumes of 100,000 - and make money at it." Second, as indicated, all of the individuals interviewed were hesitant to discuss costs. All agreed there is great uncertainty regarding the cost structure. Finally, there are some who believe the initial current costs are significantly higher, and specifically with regard to batteries, may be difficult to reduce even with added volumes.

Table 9 - Cost Comparison

Parallel and Integrated Starter Layouts

\begin{tabular}{|c|c|c|}
\hline Parallel-series & Component & $\begin{array}{c}\text { Integrated Starter } \\
\text { Generator }\end{array}$ \\
\hline$\$ 1,800-\$ 2,200$ & Battery (NiMH) & $\$ 1,500-\$ 1,800$ \\
\hline$\$ 600-\$ 680$ & $\begin{array}{c}\text { Inverter (power } \\
\text { conditioning) }\end{array}$ & $\$ 500-\$ 550$ \\
\hline$\$ 850-\$ 900$ & Power Control Unit & $\$ 600-\$ 800$ \\
\hline$\$ 500-\$ 600$ & Electric Motor & $\$ 700-\$ 800$ \\
\hline$\$ 350-\$ 500$ & Generator & Not applicable \\
\hline$\$ 50-\$ 100$ & $\begin{array}{c}\text { Transaxle/power } \\
\text { conversion* }\end{array}$ & Not applicable \\
\hline$\$ 4,150-\$ 4,890$ & Total Target Cost & $\$ 3,300-\$ 3,950$ \\
\hline *Increase over replaced transaxle
\end{tabular}

\section{Hybrid Vehicle Product Offerings}

The penetration of hybrid electric vehicles into the U.S light vehicle market will depend upon numerous factors-not the least of which is availability of product. While some manufacturers have chosen to let the market develop or rely on customer pull, other manufacturers have worked for many years to create market awareness for hybrids believing in the viability of the technology. Given the long lead times for product development, it is important to investigate current and near-term (i.e., two to four year) product plans. As of December 2004, there were five hybrid offerings in the U.S. market (Honda Insight, Civic, Accord, Toyota Prius, and the Ford Escape). CAR estimates that 
by 2009 there will be at least 17 models (those that have been announced ${ }^{13}$ ) and possibly another six to eight models that are currently considered 'likely', for a total of as many as 25 models. Table 10 presents the expected hybrid electric vehicle entries for the U.S. market by 2009. It is important to clarify what we have included as a hybrid vehicle verses what various manufacturers may claim. CAR has only considered those vehicles that use the electric drive for motive power in its forecast, i.e. parallel-series type hybrids such as the Prius and the IMA type hybrids such as the Accord Hybrid. We do not consider ISG systems as hybrids in our forecast; however, these vehicles are included in Table 10 because they will surely be marketed as hybrids.

Certainly the number of models that actually reach the market will be in direct relation to the perceived success of the early offerings, and the uncertainty of wider consumer acceptance. While the expectation of 25 model offerings for introduction does not prove hybrids will be a viable technology option, it greatly increases the likelihood that manufacturers may be capable of gaining initial scale economies by the end of the decade.

\section{Manufacturer Hybrid Vehicle Product Plans}

\section{DaimlerChrysler}

Currently DaimlerChrysler has one ISG vehicle in limited production, the Dodge Ram "Contractor Special" which is scheduled for release in 2005. This vehicle is only being made available for fleet purchase, as it can double as a portable generator for power tools and other equipment. The integrated starter generator system can be meshed with both gasoline and diesel variations of the Ram and is expected to result in a 13\% carbon dioxide reduction. The Dodge Ram and the General Motors ISG pickups were supported in part by work for the U.S. military. In December of 2004, DaimlerChrysler and General Motors announced that they would jointly pursue hybrid powertrain development. The companies have publicly backed a parallel-series dual mode hybrid system which utilizes two electric motors; driving conditions determine their usage. The partnership will combine work currently underway at both companies with the intent of developing technology for initial production in 2007. According to publicly available information, the Mercedes division of DaimlerChrysler will develop rear-wheel- based hybrid application of the shared technology while the Chrysler group will be responsible for the first front-wheel drive application. It is possible that DaimlerChrysler may add a sport utility or pickup hybrid (leveraging the technology developed by General Motors) for their large truck program.

\section{Ford Motor Company}

Ford launched the Escape hybrid in 2004 as a parallel-series hybrid variant on its popular small SUV. This system has led to significant reductions in carbon dioxide emissions and comparable performance to the base V6 Escape. In January of 2005, Ford announced that it was 'pulling forward' the introduction dates for hybrid versions of the Escape's Mercury and Mazda counterparts, the Mariner and Tribute respectively. The Mariner is now scheduled to be introduced in late 2005, with the Tribute to follow a short time later. During development of their current hybrid powertrain, Ford licensed several patents from Toyota. The Mariner and Tribute will use the Escape system.

\footnotetext{
${ }^{13}$ CAR assumes that several current vehicles will be 'replaced' by new technology in the same model. For example, the system in the current GM pickup offering will be replaced by the dual mode system. Thus, the number of introductions represented in the table does not necessarily align with production models in 2009.
} 
However, Ford is currently developing their second generation hybrid system which will debut on the Ford Futura and Mercury Milan sedans in 2008.

\section{General Motors}

General Motors' first hybrid was their GM Hybrid Bus, believing that the hybridization of large vehicles would have a greater impact on the environment. In conjunction with Allison, a parallel-series hybrid system was developed to greatly improve fuel economy and lower emissions. The bus is currently on sale and in use in several major U.S. cities. The company has used this technology as a basis for coming HEV light duty vehicles.

The GMC Sierra 1500 and Chevrolet Silverado ISGs continue with GM's theme of applying hybrid technologies to large vehicles. This pickup utilizes an integrated starter generator for engine shut-off and regenerative braking to replenish its lead-acid batteries. Because there is no assist from the ISG system, the base 5.3 liter V8 comes standard. In 2006, GM has reported that it will launch ISG versions of the Saturn VUE and Chevrolet Malibu that utilize belt alternator technology which allows the engine to be shut off when stopped then started immediately when the driver hits the gas. It is important to note that none of these initial offerings uses the electric motors for motive effort.

In 2007, hybrid versions of the Yukon and Tahoe full size SUVs will be launched with what is being touted as a scaled down version of the system found in the GM Hybrid Bus. This technology will also likely be applied to pickup trucks in 2008, replacing the current ISG pickup offering. It is also likely that GM will leverage the technology developed by the DaimlerChrysler divisions, by introducing a front-wheel-drive and rearwheel-drive application for the dual mode system sometime around 2010.

\section{Honda}

Honda launched its first hybrid, the Insight, in the U.S. in 1999. The car has remained relatively unchanged and is at the top of the fuel economy ratings year after year; achieving almost $70 \mathrm{mpg}$ on the highway, but it remains an extremely low volume vehicle. Honda has announced it will continue to market the Insight, but has no plans for future modification. The car utilizes an integrated starter generator that assists the vehicle during acceleration-known as Integrated Motor Assist (IMA). In 2002, the Civic hybrid was launched, combining an updated IMA system with a 4-cylinder engine. The Civic hybrid was the first hybrid application into an existing car, and was in some respects an experiment to better understand how current platforms might be transformed into an HEV capable platform. In 2004, Honda launched the Accord hybrid, combining IMA with a 6-cylinder engine. The Accord HEV marks an important shift in how manufacturers market hybrid vehicles. It was the first hybrid application that actually increased the horsepower from the base vehicle and demonstrates the performance benefits of hybridization and the immediate torque provided by an electric motor. As such, it will be marketed as a car with the performance of a sport sedan and the fuel economy of a 4-cylinder engine

Future hybrid plans are somewhat unclear for Honda. There has been indication that, even given the Acura 2002 DN-X rear-wheel-drive high-performance hybrid concept vehicle, Honda's luxury arm will not have a hybrid in the near future. It also appears that Honda may be hesitant to apply hybrid technology to SUVs. According to Honda president Takeo Fukui, if people want a more fuel efficient vehicle, "they could shift to a 
car." ${ }^{14}$ Such comments leave open to speculation the cost penalty associated with hybrid technology.

\section{Nissan}

Nissan will introduce a parallel hybrid version of the Altima in 2006. Through a licensing agreement with Toyota, Nissan will essentially purchase all necessary technology and apply it to their existing 4-cylinder engine. Nissan Chief Executive Officer, Carlos Ghosn, has indicated that Nissan is not necessarily convinced that hybrid vehicles present a strong business case, and maintains that his company will not "build or sell cars that don't make a profit." Ghosn credited the threat of more stringent emissions standards in California and states following in California's example as part of the reason for pursuing their first hybrid.

\section{Toyota}

Toyota launched the Prius in 2000 and is currently selling the second generation of the most popular hybrid vehicle. The Prius utilizes a parallel-series hybrid system marketed as Synergy Drive. Toyota introduced the Lexus 400h and Toyota Highlander SUVs which are Toyota's first 6-cylinder Synergy Drive application. Like the Honda Accord, the Toyota sport utilities will be positioned as strong performance vehicles with outstanding fuel economy. Toyota has also announced that they will produce a hybrid version of the Lexus GS450, Toyota's first rear-wheel-drive application in the United States. It has been reported that Toyota will develop hybrid versions of each nameplate they manufacture in the coming years. ${ }^{15}$ Among the more likely near-term introductions are the Camry (possibly before Nissan releases the Altima hybrid), the Sienna (which is built off of the same platform as the Camry), and perhaps the Corolla. A hybrid Tundra pickup is also reportedly being considered.

7. Other Manufacturers

Volkswagen remains committed to clean diesel technology for the near future. However, Volkswagen Chairman Bernd Pischetsrieder confirmed that his company is currently developing a diesel electric hybrid. There is some expectation that Porsche may market a hybrid version of the Cayenne SUV. BMW is not currently pursuing a gasoline hybrid electric vehicle, as they remain committed to hydrogen.

\footnotetext{
${ }^{14}$ Yamaguchi, Yuza, 'Hybrid SUV Not in Honda's 3-Year Plan.' Automotive News, p.1, January, 2005

${ }^{15}$ Treece, James, 'Toyota Plans to develop hybrid versions of every nameplate in lineup.' Autoweek.com, Posted November, 22, 2004.
} 
Table 10 - Light Vehicle Hybrid Electric Vehicles in the U.S. Market 2005-2010 Current, Announced and Possible

\begin{tabular}{|c|c|c|}
\hline Manufacturer/Model (CARB Classification $\left.{ }^{16}\right)$ & Type & $\begin{array}{c}\text { Date } \\
\text { Available }\end{array}$ \\
\hline \multicolumn{3}{|l|}{ Daimler Chrysler } \\
\hline Dodge Ram 'Contractor Special' (LDT2) & ISG & 2005 \\
\hline $\begin{array}{l}\text { Dual Mode Hybrid Vehicles } \\
\text { - Resulting From Partnership With GM (PC/LDT1, } \\
\text { LDT2) }\end{array}$ & Parallel - Series ${ }^{17}$ & $\begin{array}{c}2009-2010 \\
\text { est. }\end{array}$ \\
\hline \multicolumn{3}{|l|}{ Ford } \\
\hline Ford Escape Hybrid (LDT2) & Parallel - Series & 2004 \\
\hline Mercury Mariner Hybrid (LDT2) & Parallel - Series & 2005 \\
\hline Mazda Tribute Hybrid (LDT2) & Parallel - Series & 2006 \\
\hline $\begin{array}{l}\text { Ford Fusion Hybrid/Mercury Milan Hybrid } \\
\text { (PC/LDT1) }\end{array}$ & Parallel-Series & 2008 \\
\hline \multicolumn{3}{|l|}{ General Motors } \\
\hline GMC Sierra/Chevrolet Silverado Hybrid (LDT2) & ISG & 2004 \\
\hline Chevrolet Malibu (PC/LDT1) & BAS & 2006 \\
\hline Saturn Vue (PC/LDT1) & BAS & 2006 \\
\hline $\begin{array}{l}\text { GMC Yukon/Chevrolet Tahoe Hybrid (AHSII) } \\
\text { (LDT2 / MDPV) }\end{array}$ & Parallel - Series & 2007 \\
\hline AHSII Hybrid Pickup (LDT2) & Parallel - Series & 2008 (est.) \\
\hline $\begin{array}{l}\text { Dual Mode Hybrid Vehicles - Resulting from } \\
\text { partnership with DCX (PC/LDT1) }\end{array}$ & Parallel - Series & 2009 (est.) \\
\hline \multicolumn{3}{|l|}{ Honda } \\
\hline Insight (PC/LDT1) & IMA & 1999 \\
\hline Civic (PC/LDT1) & IMA & 2002 \\
\hline Accord (PC/LDT1) & IMA & 2004 \\
\hline \multicolumn{3}{|l|}{ Nissan } \\
\hline Altima (PC/LDT1) & Parallel - Series & 2006 \\
\hline \multicolumn{3}{|l|}{ Toyota } \\
\hline Prius (PC/LDT1) & Parallel-Series & 2000 \\
\hline Highlander (LDT2) & Parallel - Series & 2005 \\
\hline Camry(expected) (PC/LDT1) & Parallel - Series & 2006(est.) \\
\hline Corolla(expected) (PC/LDT1) & Parallel - Series & 2006 (est.) \\
\hline Sienna (expected) (LDT2) & Parallel - Series & 2007 (est.) \\
\hline Lexus 400h (LDT2) & Parallel - Series & 2005 \\
\hline Lexus GS 450 (PC/LDT1) & Parallel - Series & 2006 \\
\hline
\end{tabular}

\footnotetext{
${ }^{16}$ PC/LDT1: Passenger cars and light trucks $0-3750$ LVW. LDT2: 3751 LVW - 8500GVW. MDPV: Passenger vehicles > 8500GVW. The pickup trucks may qualify as MDV's (and thus avoid regulation) if used for commercial purposes; however CARB documents state that differentiating those pickups used for commercial and non-commercial purposes is impossible and believes that using 8500 as the cutoff will produce minimal error. Since the ISG pickups and future AHS II pickups have GVWs $<8500$ they will be classified as LDT2s.
} 


\section{E. Pathways to Scale Economy for Hybrid Electric Vehicles}

All industry sources interviewed indicated that it was vital for the automotive companies to achieve high volumes to gain some measure of scale economy (although, there was little agreement as to what that 'magical' number might be.) Strategically, there are two methods of increasing volume-either by creating technology that is readily scalable (i.e., minimal change to the different components) and incorporating it into a wide range of vehicles within a company, or by designing the system to be applicable across a smaller range of segments, but hoping to gain potential outside customers.

Even given recent comments by Honda indicating that they may not offer hybrid sport utility vehicles, many sources indicated that the Honda strategy appeared to be focused on gaining scale economies via developing highly scaleable technologies. Such a strategy becomes understandable, given that Honda's engine portfolio is primarily (even exclusively) comprised of transversely mounted engines (no larger than 6-cylinders). Conversely, there were some that thought the Toyota system may require more development among segments. However, Toyota has outwardly sought to offer the technology to companies outside the Toyota family. It is certainly possible that Toyota's strategy to gain scale economies includes both a level of scaleable and highly saleable technology.

The General Motors-DaimlerChrysler partnership is focused on making several applications of a base technology, with the intent of gaining volume between the two manufacturers, and selling the systems to other manufacturers. Some sources indicated that the partnership between General Motors and DaimlerChrysler is similar to the Toyota strategy. As announced, it appears that the partnership will have at least three core variants: a rear-wheel-drive 'truck' based variant, a rear-wheel-drive car variant, and a front-wheel-drive car/SUV variant. Each of these variants will be based on core technology but developed for specific applications. Further, companies made it clear that they would continue to look for partners as the program proceeded.

Ford developed their Escape SUV using, in part, licensing agreements with Toyota. However, Ford is currently developing their second generation system. It is understood that their intent is to develop key components of the technology internally (with the support of suppliers). This would suggest they may have a strategy similar to Honda-to create scale volume via spreading the technology throughout the product line. However, it is important to note that Ford has a much more diverse powertrain and product portfolio than Honda, and thus may require more engineering costs to 'fit' the technology into enough products to achieve the desired volumes. Ford could also rely on their supply chain to gain scale economies. 


\section{Historical Vehicle Registration Data Analysis}

\section{A. Segmentation of Polk Data}

The Center for Automotive Research has produced a forecast of future vehicle sales mix (including drivetrain layout, powertrain type, number of cylinders and fuel type) for California and the rest of the United States for 2009. The forecast is made possible through a partnership with the Analytical Solutions Group, R.L. Polk, \& Co. CAR wishes to thank R.L. Polk for its assistance in this effort. The data provided presents great depth and richness, which in turn has allowed CAR and Argonne researchers to achieve a high level of detail in the analysis - a far more complex data set than had originally been discussed in the proposal. We believe it to be a very thorough review-and forecast—of vehicle technology segmentation.

\section{B. Segmentation of Polk Data}

All passenger cars and the portion of LTD1s equal to or less than $3750 \mathrm{lbs}$. (loaded vehicle weight) were grouped together (hereafter referred to as PCLDT1. All LDT2s and the portion of LDT1s $3751 \mathrm{lbs}$. and greater were also grouped together (LDT2). ${ }^{18}$ The LDT2 also includes vehicles with a GVRW of over 8,500 lbs., but a less that 10,000 loaded vehicle weight. Once vehicles were segmented into PCLDT1 and LDT2, CAR then separated the data by transverse (FWD) and longitudinal (RWD), and then twowheel-drive (2WD), all-wheel-drive (AWD), and four-wheel-drive (4WD). The data was further divided by cylinders ( 3 and 4,5 and 6, 8, and 10 and 12 cylinders), and fuel type (gasoline, diesel, HEV, etc.).

The orientation of the engine is essential to the differentiation of FWD/RWD vehicles. The transverse mounted engine is the predominant orientation of FWD, while RWD vehicles have longitudinally mounted engines. This engine orientation is important because it is a possible differentiator for hybrid drivetrain component technology. Those vehicles offered only in AWD were placed into FWD or RWD depending on engine orientation.

Finally, it is important to note that the California data was included in the total U.S. data to represent the current light vehicle market-that is, a representation of current national market segmentation. This was done to compare the status quo, with the California market as a unique entity.

\footnotetext{
${ }^{18}$ The vehicle weights were taken from Wards 2003 Annual Report. There are a number of vehicles counted that were discontinued before 2003. For these vehicles, the appropriate yearbook was used. There were several models (such as the Chevrolet Colorado) which had trim levels both above and below the 3750 mark. Since trim level is not found in the Polk data we differentiated by drivetrain (i.e. the heavier $4 \times 4$ models were separated from the lighter $2 \times 4$ models). CAR also made some alterations to Conversion vehicles (i.e. those vehicles that were designed to be converted to run off CNG). These were divided as "gasoline" or "natural gas" powered vehicles per CAR's estimates of vehicles actually converted.
} 


\section{Overall Market Considerations}

The Center for Automotive Research acquired (through a partnership with R.L. Polk) U.S. (including California) and California vehicle registration data for the years 19992003. The data indicates the U.S. market has seen an increase in LDT2s as a percent of the total market during the years 1999 through 2003. The California market has seen a similar-if not as pronounced-shift during the same period. Table 11 shows PCLDT1 and LDT2 registrations for the United States and California for 1999-2003. It is important to note that this change represents a significant continued shift in consumer vehicle preference that has taken place for over a decade, and has greatly affected vehicle fuel economy and concomitant emissions.

Table 11 - PCLDT1 and LDT2 Registrations:

U.S. and California 1999-2003

\begin{tabular}{|c|c|c|c|c|c|}
\hline & 1999 & 2000 & 2001 & 2002 & 2003 \\
\hline \multicolumn{6}{|l|}{ U.S. } \\
\hline PCLDT1 & $60.9 \%$ & $60.1 \%$ & $59.5 \%$ & $57.5 \%$ & $55.9 \%$ \\
\hline LDT2 & $39.1 \%$ & $39.9 \%$ & $40.5 \%$ & $42.5 \%$ & $44.1 \%$ \\
\hline Total U.S. Market & $100 \%$ & $100 \%$ & $100 \%$ & $100 \%$ & $100 \%$ \\
\hline \multicolumn{6}{|l|}{ California } \\
\hline PCLDT1 & $62.6 \%$ & $61.7 \%$ & $61.3 \%$ & $59.8 \%$ & $59.2 \%$ \\
\hline LDT2 & $37.4 \%$ & $38.3 \%$ & $38.7 \%$ & $40.2 \%$ & $40.8 \%$ \\
\hline Total California Market & $100 \%$ & $100 \%$ & $100 \%$ & $100 \%$ & $100 \%$ \\
\hline
\end{tabular}

A review of the data indicates that the California market is a large and significant portion of the overall U.S. market. The State of California represented approximately 11.1 percent of the U.S. light duty vehicle market in 1999 (Table 12.) However, that percentage grew to 12.1 percent by 2003 . Importantly, the California market represents a somewhat different vehicle mix than the overall U.S. market. The California market includes a higher percentage of PCLDT1, and thus, fewer LDT2s weighing 3751 pounds (loaded weight) or greater.

Table 12 - California Light Duty Vehicle Segmentation as a Percent of U.S. Total

\begin{tabular}{|l|c|c|c|c|c|}
\hline Segmentation & 1999 & 2000 & 2001 & 2002 & 2003 \\
\hline $\begin{array}{l}\text { As a Percent of Passenger } \\
\text { Cars and Light Duty }\end{array}$ & $11.7 \%$ & $12.3 \%$ & $12.6 \%$ & $13.1 \%$ & $13.2 \%$ \\
$\begin{array}{l}\text { Trucks (PCLDT1) } \\
\begin{array}{l}\text { As a Percent of Light Duty } \\
\text { Trucks (LDT2) }\end{array}\end{array}$ & $10.1 \%$ & $10.7 \%$ & $10.9 \%$ & $11.0 \%$ & $10.7 \%$ \\
\hline $\begin{array}{l}\text { As a Percent of Total U.S. } \\
\text { Market }\end{array}$ & $11.1 \%$ & $11.7 \%$ & $11.9 \%$ & $12.2 \%$ & $12.1 \%$ \\
\hline Source: R.L. Polk & & & & \\
\hline
\end{tabular}


D. PCLDT1 Passenger Cars and Light Duty Trucks 1 (equal to or less than 3750 pounds)

The California PCLDT1 market differs in several segments from the total U.S. market. The state has a higher percentage of longitudinal PCLDT1 (Total Longitudinal in Table 13). The U.S. market trends higher for four-wheel-drive vehicles (AWD and 4WD) than does California. All-wheel- and 4-wheel-drive have traditionally been considered a higher priority for drivers in the snow-belt states, and where towing or off-road driving is common. However all-wheel-drive has been increasingly promoted as a performance attribute. With several manufacturers offering new products with all-wheel-drive, it is likely that penetration rates will increase for this powertrain type-in both the U.S. and California markets. The data shows that there has been a reduction in longitudinal drivetrains as a percent of total for the U.S., and increase for California. CAR believes the increase in transverse AWD/4WD during the period presents an important trend.

In the five-year period studied, longitudinal 4WD penetration fell by 19.2 percent in the U.S., and 12.5 percent in California. Much of this loss was due to a reduction in the number of compact pick-up trucks -in part due to those offerings increasing in weight and thus being categorized as LDT2, and in part due to consumers shifting away from that segment. However, penetration rates for transverse 4WD/AWD vehicles rose during the period (170.6 percent for the U.S. and 100.0 percent for California). This change can be seen in the market via the introduction of cross-over utility vehicles.

Table 13 - Drivetrain as a Percent of PCLDT1

\begin{tabular}{|l|c|c|c|c|c|}
\hline & 1999 & 2000 & 2001 & 2002 & 2003 \\
\hline Transverse FWD & 75.6 & 73.5 & 75.6 & 75.9 & 74.6 \\
\hline U.S. & 73.6 & 71.7 & 72.3 & 72.6 & 71.4 \\
\hline California & 7.7 & 1.9 & 3.0 & 3.9 & 4.6 \\
\hline Transverse AWD/4WD & 1.7 & 2.3 & 3.0 & 3.2 \\
\hline U.S. & 1.6 & 1.9 & 2.3 \\
\hline California & 77.3 & 77.8 & 78.6 & 79.8 & 79.2 \\
\hline Total Transverse \\
\hline U.S. & 77.6 & 76.4 & 75.6 & 74.5 \\
\hline California & 75.2 & 75.4 & & \\
\hline Longitudinal RWD & 17.5 & 17.1 & 16.6 & 16.1 & 16.6 \\
\hline U.S. \\
\hline California & 22.1 & 21.7 & 22.5 & 21.8 & 22.3 \\
\hline Longitudinal AWD/4WD \\
\hline U.S. & 5.2 & 5.1 & 4.8 & 4.1 & 4.2 \\
\hline California & 2.7 & 2.9 & 2.9 & 2.6 & 2.4 \\
\hline Total Longitudinal \\
\hline U.S.
\end{tabular}

Tables 14 and 15 present those PCLDT1segments which represent at least one percent of the 2003 total PCLDT1 market. From these tables, it is apparent that the California PCLDT1 market is comprised of a higher percentage of 4-cylinder transverse engines, and 5/6-cylinder longitudinal engines. Conversely, the U.S. market is comprised of a higher percentage of 6-cylinder transverse engines 
The U.S. PCLDT1 market continues to be dominated by $3 / 4-$ and $5 / 6$-cylinder frontwheel-drive vehicles (71.5 percent of the market). .

Table 14 - U.S. PCLDT1:

Drivetrain Segments One Percent or Greater of Total U.S. PCLDT1 2003

Registrations

\begin{tabular}{|l|r|r|r|r|c|}
\hline & 1999 & 2000 & 2001 & 2002 & 2003 \\
\hline Transverse & $40.8 \%$ & $41.0 \%$ & $42.1 \%$ & $43.3 \%$ & $43.3 \%$ \\
\hline FWD/3-4cyl/Gas & $32.6 \%$ & $31.6 \%$ & $30.7 \%$ & $29.8 \%$ & $28.2 \%$ \\
\hline FWD/5-6cyl/Gas & $0.6 \%$ & $0.6 \%$ & $0.9 \%$ & $1.2 \%$ & $1.3 \%$ \\
\hline AWD/5-6cyl/Gas (FWD) & $0.9 \%$ & $0.9 \%$ & $0.9 \%$ & $1.3 \%$ & $1.3 \%$ \\
\hline 4WD+FWD/4cyl/Gas & $2.0 \%$ & $1.8 \%$ & $1.7 \%$ & $1.4 \%$ & $1.2 \%$ \\
\hline FWD/8cyl/Gas & $0.1 \%$ & $1.2 \%$ & $0.6 \%$ & $0.7 \%$ & $1.2 \%$ \\
\hline FWD/6cyl/Flexible & $0.0 \%$ & $0.2 \%$ & $0.9 \%$ & $0.8 \%$ & $1.0 \%$ \\
\hline 4WD+FWD/6cyl/Gas & $4.5 \%$ & $3.1 \%$ & $2.0 \%$ & $2.0 \%$ & $2.5 \%$ \\
\hline Longitudinal & $5.7 \%$ & $6.0 \%$ & $7.3 \%$ & $7.3 \%$ & $7.9 \%$ \\
\hline RWD/4cyl/Gas & $5.9 \%$ & $5.7 \%$ & $6.0 \%$ & $5.7 \%$ & $5.5 \%$ \\
\hline RWD/5-6cyl/Gas & $1.9 \%$ & $1.9 \%$ & $2.2 \%$ & $2.2 \%$ & $2.2 \%$ \\
\hline RWD/8cyl/Gas
\end{tabular}

Front-wheel-drive 3/4- and 5/6-cylinder vehicles also dominate the California market with a combined 68.1 share, but less so than the overall U.S. market in which they have a 71.5 percent share. The rear-wheel-drive 6-cylinder segment has seen significant growth in the California market in recent years. A final note regarding the California PCLDT1 is that 2003 marked an interesting point for the market-the front-wheel-drive 3/4-cylinder HEV sector crossed the one percent market share threshold for the first time.

Table 15 - California PCLDT1:

Drivetrain Segments: One Percent or Greater of Total California PCLDT1 2003 Registrations

\begin{tabular}{|l|c|c|c|c|c|}
\hline & 1999 & 2000 & 2001 & 2002 & 2003 \\
\hline Transverse & & & & & \\
\hline FWD/3-4cyl/Gas & $45.4 \%$ & $45.4 \%$ & $45.8 \%$ & $46.2 \%$ & $46.0 \%$ \\
\hline FWD/5-6cyl/Gas & $26.7 \%$ & $25.1 \%$ & $24.4 \%$ & $23.5 \%$ & $22.1 \%$ \\
\hline 4WD+FWD/4cyl/Gas & $0.9 \%$ & $0.9 \%$ & $0.7 \%$ & $1.1 \%$ & $1.1 \%$ \\
\hline $\begin{array}{l}\text { FWD/3-4cyl/Gas-Elec } \\
\text { HEV }\end{array}$ & $0.0 \%$ & $0.1 \%$ & $0.5 \%$ & $0.8 \%$ & $1.0 \%$ \\
\hline AWD/5-6cyl/Gas (FWD) & $0.6 \%$ & $0.6 \%$ & $0.8 \%$ & $1.2 \%$ & $1.0 \%$ \\
\hline Longitudinal & & & & & \\
\hline RWD/5-6cyl/Gas & $9.3 \%$ & $9.4 \%$ & $11.9 \%$ & $11.8 \%$ & $13.0 \%$ \\
\hline RWD/8cyl/Gas & $5.8 \%$ & $5.7 \%$ & $6.2 \%$ & $6.0 \%$ & $5.6 \%$ \\
\hline RWD/3-4cyl/Gas & $5.2 \%$ & $4.3 \%$ & $3.3 \%$ & $3.3 \%$ & $3.6 \%$ \\
\hline AWD/3-4cyl/Gas (RWD) & $1.3 \%$ & $1.3 \%$ & $1.5 \%$ & $1.5 \%$ & $1.3 \%$ \\
\hline
\end{tabular}

E. Light Duty Trucks 2 (LDT2) 
The LDT2 segment has undergone a significant shift in the past several years. Driven largely by the creation of the cross-over SUV segment, the transverse drivetrain has achieved a higher percent of the light duty segment. The growth of the cross-over SUV segment has contributed to an increased transverse drivetrain penetration rate in the past five years (Table 16). This increase is even more impressive when combined with the decline in minivan-the other transverse based LDT2-registrations during this period. This segment presents an opportunity for carbon dioxide reductions if substituted for the frame-based SUV. However, one must also consider that these vehicles have been used as substitutions for FWD minivans. And, given the higher level of $4 \mathrm{WD} / \mathrm{AWD}$ for the crossover SUVs vis-à-vis minivans, it is possible to overestimate the emissions reductions from this segment shift.

Table 16 - LDT2 Drivetrain (As a Percent of LDT2 Registrations)

\begin{tabular}{|c|c|c|c|c|c|}
\hline & 1999 & 2000 & 2001 & 2002 & 2003 \\
\hline \multicolumn{6}{|c|}{ Transverse FWD } \\
\hline U.S. & $18.0 \%$ & $18.5 \%$ & $17.2 \%$ & $17.2 \%$ & $16.5 \%$ \\
\hline California & $17.7 \%$ & $18.2 \%$ & $16.2 \%$ & $17.7 \%$ & $17.0 \%$ \\
\hline \multicolumn{6}{|c|}{ Transverse AWD/4WD } \\
\hline U.S. & $1.0 \%$ & $1.2 \%$ & $3.1 \%$ & $4.3 \%$ & $6.5 \%$ \\
\hline California & $1.5 \%$ & $1.4 \%$ & $3.1 \%$ & $4.0 \%$ & $6.1 \%$ \\
\hline \multicolumn{6}{|c|}{ Total Transverse } \\
\hline U.S. & $18.9 \%$ & $19.7 \%$ & $20.3 \%$ & $21.5 \%$ & $23.0 \%$ \\
\hline California & $19.2 \%$ & $19.6 \%$ & $19.4 \%$ & $21.7 \%$ & $23.1 \%$ \\
\hline \multicolumn{6}{|c|}{ Longitudinal RWD } \\
\hline U.S. & $35.3 \%$ & $35.9 \%$ & $35.2 \%$ & $33.8 \%$ & $31.7 \%$ \\
\hline California & $49.8 \%$ & $51.0 \%$ & $51.5 \%$ & $49.9 \%$ & $48.4 \%$ \\
\hline \multicolumn{6}{|c|}{ Longitudinal AWD/4WD } \\
\hline U.S. & $45.8 \%$ & $44.4 \%$ & $44.5 \%$ & $44.7 \%$ & $45.2 \%$ \\
\hline California & $31.0 \%$ & $29.4 \%$ & $29.1 \%$ & $28.3 \%$ & $28.4 \%$ \\
\hline \multicolumn{6}{|c|}{ Total Longitudinal } \\
\hline U.S. & $81.1 \%$ & $80.3 \%$ & $79.7 \%$ & $78.5 \%$ & $77.0 \%$ \\
\hline California & $80.8 \%$ & $80.4 \%$ & $80.6 \%$ & $78.3 \%$ & $76.9 \%$ \\
\hline & & & & & \\
\hline
\end{tabular}

In Tables 17 and 18 we summarize light duty truck segments which represent at least one percent of the 2003 total LDT2 market. The most striking comparison is the difference between rear-wheel-drive 8-cylinder penetration rates in the two markets. In California the segment represents nearly 30 percent of the LDT market, while it accounts for slightly over 16 percent of the U.S. market. However, the U.S. market includes a higher percentage of longitudinal four-wheel-drive and all-wheel-drive vehicles.

A closer examination of the U.S. LDT2 (Table 17) market shows several longitudinal segments have lost share in the five years studied. The four-wheel-drive 8-cylinder segment decreased by 4.0 percentage points, the four-wheel-drive 5/6-cylinder segment decreased by 3.1 percentage points and the rear-wheel-drive 6-cylinder decreased its share by 3.7 percent-from 14.4 percent to 10.7 percent (Table 17). Conversely, transverse all-wheel-drive 5/6-cylinder and four-wheel-drive 5/6-cylinder increased 2.4 
percent and 2.5 percent respectively. Over the 1999-2003 period, the share of flex fuel registrations in transverse LDT2 drivetrains decreased, while the share in longitudinal drivetrains increased, particularly in 8 cylinder 4WD models.

Table 17 - U.S. LDT2:

Drivetrain Segments Greater Than One Percent of the Total U.S. LTD2 Registrations

\begin{tabular}{|c|c|c|c|c|c|}
\hline & 1999 & 2000 & 2001 & 2002 & 2003 \\
\hline \multicolumn{6}{|l|}{ Transverse } \\
\hline FWD/6cyl/Gas & $13.9 \%$ & $14.8 \%$ & $13.2 \%$ & $12.8 \%$ & $13.5 \%$ \\
\hline AWD/5-6cyl/Gas & $1.0 \%$ & $1.0 \%$ & $1.7 \%$ & $2.7 \%$ & $3.4 \%$ \\
\hline 4WD+FWD/6cyl/Gas & $0.0 \%$ & $0.2 \%$ & $1.4 \%$ & $1.6 \%$ & $2.5 \%$ \\
\hline FWD/6cyl/Flex & $3.2 \%$ & $3.0 \%$ & $3.2 \%$ & $3.6 \%$ & $2.3 \%$ \\
\hline \multicolumn{6}{|l|}{ Longitudinal } \\
\hline RWD/6cyl/Gas & $14.4 \%$ & $14.5 \%$ & $13.7 \%$ & $13.0 \%$ & $10.7 \%$ \\
\hline RWD/8cyl/Gas & $17.8 \%$ & $18.3 \%$ & $18.5 \%$ & $16.6 \%$ & $16.3 \%$ \\
\hline 4WD+RWD/5-6cyl/Gas & $15.0 \%$ & $14.7 \%$ & $15.2 \%$ & $15.0 \%$ & $11.9 \%$ \\
\hline 4WD+RWD/8cyl/Gas & $22.1 \%$ & $20.7 \%$ & $19.9 \%$ & $17.1 \%$ & $17.1 \%$ \\
\hline AWD/6cyl/Gas & $1.6 \%$ & $1.8 \%$ & $2.1 \%$ & $2.2 \%$ & $2.5 \%$ \\
\hline AWD/8cyl/Gas & $2.0 \%$ & $2.1 \%$ & $2.2 \%$ & $2.5 \%$ & $4.0 \%$ \\
\hline RWD/6cyl/Flex & $0.0 \%$ & $0.1 \%$ & $0.1 \%$ & $0.5 \%$ & $1.3 \%$ \\
\hline RWD/8cyl/Flex & $0.0 \%$ & $0.0 \%$ & $0.3 \%$ & $1.8 \%$ & $1.8 \%$ \\
\hline 4WD+RWD/6cyl/Flex & $1.0 \%$ & $0.8 \%$ & $0.0 \%$ & $0.7 \%$ & $1.9 \%$ \\
\hline 4WD+RWD/8cyl/Flex & $0.0 \%$ & $0.0 \%$ & $0.5 \%$ & $2.8 \%$ & $2.8 \%$ \\
\hline 4WD+RWD/8cyl/Diesel & $2.0 \%$ & $2.2 \%$ & $2.9 \%$ & $3.0 \%$ & $3.1 \%$ \\
\hline
\end{tabular}

Interestingly, California experienced a marked growth in rear-wheel-drive 8-cylinder vehicles during the last five years (Table 18). That segment actually lost a small amount of share in the overall U.S. market. The state also saw a reduction in rear-wheel-drive 6cylinder vehicles, four-wheel-drive 8-cylinder and four-wheel-drive 5/6-cylinder longitudinal drivetrains. Conversely, longitudinal applications for all-wheel-drive (both 5/6-cylinder and 8-cylinder) experienced increased penetration. Front-wheel-drive 5/6cylinder vehicles (of which minivans comprise a significant portion) decreased as a percent of total, while four-wheel-drive and all-wheel-drive 6-cylinder vehicles increased as a percent of total. Finally, it is important to note that four-wheel-drive 8-cylinder diesel engines increased approximately one percent in both markets. 
Table 18 - California LDT2:

Drivetrain Segments Greater Than One Percent of the Total California LTD2 Registrations

\begin{tabular}{|c|c|c|c|c|c|}
\hline & 1999 & 2000 & 2001 & 2002 & 2003 \\
\hline \multicolumn{6}{|l|}{ Transverse } \\
\hline FWD/3-4cyl/Gas & $1.3 \%$ & $0.8 \%$ & $1.1 \%$ & $1.2 \%$ & $1.1 \%$ \\
\hline FWD/5-6cyl/Gas & $16.3 \%$ & $17.0 \%$ & $13.2 \%$ & $13.9 \%$ & $14.1 \%$ \\
\hline 4WD+FWD/6cyl/Gas & $0.0 \%$ & $0.2 \%$ & $1.6 \%$ & $2.0 \%$ & $3.1 \%$ \\
\hline AWD/5-6cyl/Gas & $1.5 \%$ & $1.3 \%$ & $1.5 \%$ & $2.0 \%$ & $2.3 \%$ \\
\hline FWD/5-6cyl/Flex & $0.1 \%$ & $0.3 \%$ & $1.9 \%$ & $2.6 \%$ & $1.8 \%$ \\
\hline \multicolumn{6}{|l|}{ Longitudinal } \\
\hline RWD/5-6cyl/Gas & $20.8 \%$ & $20.4 \%$ & $18.9 \%$ & $17.0 \%$ & $13.6 \%$ \\
\hline RWD/8cyl/Gas & $24.1 \%$ & $25.9 \%$ & $28.9 \%$ & $29.1 \%$ & $29.6 \%$ \\
\hline 4WD+RWD/6cyl/Gas & $9.2 \%$ & $8.0 \%$ & $7.4 \%$ & $6.8 \%$ & $4.4 \%$ \\
\hline 4WD+RWD/8cyl/Gas & $14.4 \%$ & $13.5 \%$ & $13.1 \%$ & $11.6 \%$ & $10.6 \%$ \\
\hline AWD/6cyl/Gas & $1.8 \%$ & $2.1 \%$ & $2.4 \%$ & $2.7 \%$ & $3.3 \%$ \\
\hline AWD/8cyl/Gas & $2.5 \%$ & $2.7 \%$ & $2.9 \%$ & $3.5 \%$ & $5.2 \%$ \\
\hline RWD/6cyl/Flex & $0.0 \%$ & $0.0 \%$ & $0.0 \%$ & $0.8 \%$ & $2.2 \%$ \\
\hline RWD/8cyl/Diesel & $1.0 \%$ & $1.0 \%$ & $1.1 \%$ & $1.1 \%$ & $1.2 \%$ \\
\hline 4WD+RWD/8cyl/Diesel & $1.2 \%$ & $1.3 \%$ & $2.0 \%$ & $2.4 \%$ & $2.8 \%$ \\
\hline
\end{tabular}




\section{Statistical Model}

\section{A. Introduction}

A statistical analysis of the number of vehicles sold in the United States and California from 1999 to 2003 according to weight, drivetrain layout, drive type, cylinders, and fuel was conducted. This section describes the process used to create the statistical models. First, a simplified introduction into the simple logit and multiple choice (multinomial) logit models, which form the foundation of the analysis, is provided. A more in-depth discussion of the models can be found in Pindyck and Rubinfeld (1981). Then, the application of the simple and multiple choice logit models to the data are presented, followed by a description of the manner in which future predictions were generated.

\section{B. The Simple Logit Model}

The simple logit model dictates a binary choice. The dependent variable is the probability or proportion of times one of two choices is made, $P$. The simple logit model is given by:

$$
\log \frac{P}{1-P}=Z=\beta_{0}+\beta_{1} X
$$

Where

$$
\begin{array}{ll}
X & \text { predictor variable } \\
\beta_{0}, \beta_{1} & \text { regression coefficients }
\end{array}
$$

Once the regression coefficients have been estimated, it is possible to transform equation (1) to obtain the probability $P$ :

$$
P=\frac{1}{1+e^{-Z}}=\frac{1}{1+e^{-\left(\beta_{0}+\beta_{1} X\right)}}
$$

With regard to the logit model, please note the following. First, the simple logit model only applies when there are two mutually exclusive choices that can be made and the probability of these two choices sums to one. Hence, if the probability of making the first choice is $P$, then the probability of making the second choice is $1-P$. Second, $Z$ is the log of the ratio of two probabilities. In the case of the simple logit model, it is log $(P / 1-P)$. Both of these concepts carry forward to the multiple choice logit model.

\section{The Multiple Choice Logit Model}

The Multiple Choice Logit model, also known as the multinomial logit model, is a generalization of the simple logit model. As with the simple logit model, the multinomial logit model assumes all choices are mutually exclusive (which is the case in purchasing a vehicle). Therefore, the percentages associated with each choice must sum to 1 : 


$$
\sum_{i=1}^{k} P_{i}=1
$$

Where

$$
k=\quad \text { number of choices. }
$$

For example, there are $k=13$ choices within the PCLDT1 Transverse category (see Table 19). Of course, the percentages must add to $100 \%$, since the 13 choices represent all available choices within the category.

Table 19 - Percent of PCLDT1 Transverse Drivetrains Sold in the U.S. and in CA

\begin{tabular}{|c|c|c|c|c|c|c|c|c|c|c|c|c|c|c|c|}
\hline 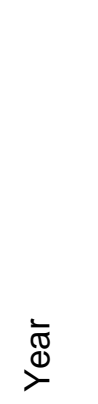 & $\begin{array}{l}\frac{\mathbb{U}}{0} \\
\text { ஸे }\end{array}$ & 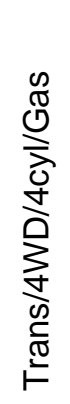 & 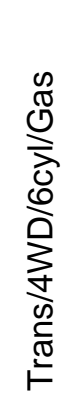 & 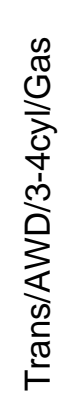 & 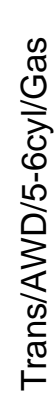 & 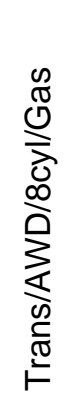 & 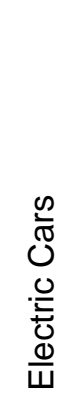 & 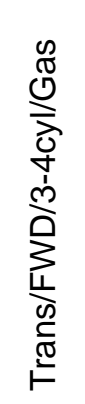 & 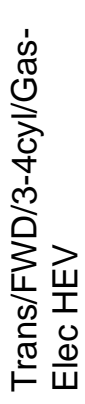 & 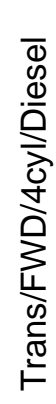 & 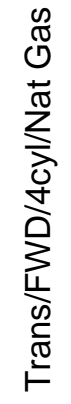 & 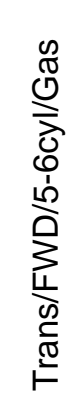 & 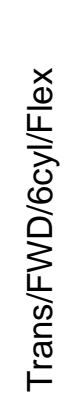 & 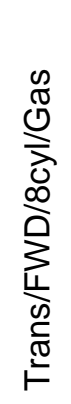 & $\begin{array}{l}\bar{\pi} \\
\stackrel{0}{0} \\
\end{array}$ \\
\hline 1999 & 0 & 1.2 & 0.0 & 0.2 & 0.7 & 0.0 & 0.0 & 60.4 & 0.0 & 0.1 & 0.1 & 35.5 & 0.0 & 1.7 & 100.0 \\
\hline 1999 & 1 & 1.2 & 0.0 & 0.2 & 0.8 & 0.0 & 0.0 & 52.8 & 0.0 & 0.2 & 0.0 & 42.1 & 0.1 & 2.5 & 100.0 \\
\hline 2000 & 0 & 1.2 & 0.1 & 0.4 & 0.8 & 0.0 & 0.0 & 60.2 & 0.2 & 0.0 & 0.1 & 33.3 & 2.1 & 1.5 & 100.0 \\
\hline 2000 & 1 & 1.2 & 0.2 & 0.3 & 0.8 & 0.0 & 0.0 & 52.7 & 0.1 & 0.3 & 0.0 & 40.6 & 1.5 & 2.3 & 100.0 \\
\hline 2001 & 0 & 1.0 & 0.6 & 0.4 & 1.1 & 0.0 & 0.0 & 61.4 & 0.7 & 0.1 & 0.1 & 32.8 & 0.5 & 1.3 & 100.0 \\
\hline 2001 & 1 & 1.2 & 1.2 & 0.3 & 1.1 & 0.0 & 0.0 & 53.6 & 0.2 & 0.3 & 0.0 & 39.1 & 0.8 & 2.1 & 100.0 \\
\hline 2002 & 0 & 1.5 & 0.5 & 0.6 & 1.5 & 0.0 & 0.0 & 61.5 & 1.0 & 0.3 & 0.1 & 31.2 & 0.8 & 0.9 & 100.0 \\
\hline 2002 & 1 & 1.6 & 1.0 & 0.6 & 1.5 & 0.0 & 0.0 & 54.2 & 0.5 & 0.4 & 0.0 & 37.4 & 0.9 & 1.8 & 100.0 \\
\hline 2003 & 0 & 1.5 & 0.5 & 0.9 & 1.4 & 0.0 & 0.0 & 62.3 & 1.3 & 0.3 & 0.1 & 29.9 & 1.1 & 0.8 & 100.0 \\
\hline 2003 & 1 & 1.7 & 1.3 & 1.1 & 1.7 & 0.0 & 0.0 & 54.6 & 0.6 & 0.4 & 0.0 & 35.5 & 1.5 & 1.5 & 100.0 \\
\hline
\end{tabular}
from 1999 to 2003

Since by equation (3) the probabilities must sum to 1.0, the choices are not all independent of one another. Since the choices, (and hence their probabilities), are not independent, one need not create $\mathrm{k}$ different models, but only $\mathrm{k}-1$ models. The multinomial logit models are extensions of equation (1) where the log of the ratio of two probabilities can be captured by a linear regression model: 


$$
\begin{gathered}
\log \frac{P_{2}}{P_{1}}=\beta_{0}^{21}+\beta_{1}^{21} X_{1} \\
\log \frac{P_{3}}{P_{1}}=\beta_{0}^{31}+\beta_{1}^{31} X_{1} \\
\Lambda \\
\log \frac{P_{k}}{P_{1}}=\beta_{0}^{k 1}+\beta_{1}^{k 1} X_{1}
\end{gathered}
$$

Where

$\begin{array}{ll}P_{1} & \text { probability associated with the first choice } \\ P_{2} & \text { probability associated with the second choice } \\ P_{3} & \text { probability associated with the third choice } \\ P_{k} & \text { probability associated with the } \mathrm{k}^{\text {th }} \text { choice } \\ \beta_{0}{ }^{21}, \beta_{1}{ }^{21} & \text { coefficients for the model involving } P_{1} \text { and } P_{2} \\ \beta_{0}{ }^{31}, \beta_{1}{ }^{31} & \text { coefficients for the model involving } P_{1} \text { and } P_{3} \\ \beta_{0}{ }^{k 1}, \beta_{1}{ }^{k 1} & \text { coefficients for the model involving } P_{1} \text { and } P_{k}\end{array}$

Moving from the $k-1$ models to the probabilities of the $k$ choices is a little more complicated. Solving equation (4) for $P_{k}$ yields:

$$
P_{k}=P_{1} e^{\beta_{0}^{k 1}+\beta_{1}^{k 1} X_{1}}
$$

Thus, each model provides the probability of a particular choice as a function of $P_{1} . P_{1}$ must then be selected such that the sum of all the probabilities equals 1 , thereby satisfying equation (3).

\section{Application of the Logit Model to the Drivetrain Data}

The goal was to model the probability or proportion of the U.S. and California market that would be captured by each drivetrain type based on five years of historical data from 1999 to 2003 . The data was provided by R.L. Polk.

\section{E. The Data for Modeling}

CAR separated the data to better match the segmentation required by CARB for $A B$ 1493 and to permit further analysis. Starting with the R.L. Polk data (EPA classifications), all passenger cars (PC) and the portion of light duty truck one (LDT1) equal to or less than $3750 \mathrm{lbs}$. (loaded vehicle weight) were grouped together into the category PCLDT1. All light duty truck 2 (LDT2) and the portion of LDT1s equal to or more than $3751 \mathrm{lbs}$. were grouped together into the category LDT2. ${ }^{19}$ The PCLDT1 and

\footnotetext{
${ }^{19}$ The vehicle weights were taken from Wards 2003 Annual Report. There are a number of vehicles counted that were discontinued before 2003. For these vehicles, the appropriate yearbook was used. There were several models such as the Chevrolet Colorado which had trim levels both above and
} 
LDT2 data was then further separated by engine orientation into transverse (front-wheeldrive) and longitudinal (rear-wheel-drive). Finally, the vehicles were broken down into their specific drivetrains by drive type (2WD, 4WD, AWD), number of cylinders, and fuel.

Table 20 shows the segmentation of the different drivetrains. Level one is the weight category split (PCLDT1, LDT2). Level two is the engine orientation split (transverse, longitudinal). Level three is the individual drivetrain. Since there are only two choices for level one and level two, the simple logit model was applied. For level three, there were multiple choices, thus the multinomial logit was applied.

Table 20 - Vehicle Segmentation of Vehicle Registration

\begin{tabular}{|c|c|c|c|}
\hline \multicolumn{4}{|c|}{ Level One } \\
\hline \multicolumn{2}{|c|}{$\begin{array}{c}\text { Passenger Cars and Light Duty Trucks } \\
\text { Equal to or Less Than } 3750 \text { Loaded Weight) }\end{array}$} & \multicolumn{2}{|c|}{$\begin{array}{c}\text { Light Duty Trucks Equal to or Greater Than } \\
3751 \text { Loaded Weight }\end{array}$} \\
\hline \multicolumn{4}{|c|}{ Level Two } \\
\hline $\begin{array}{l}\text { PCLDT1 Transverse } \\
\text { (Front- Wheel-Drive } \\
\text { Bias) }\end{array}$ & $\begin{array}{l}\text { PCLDT1 } \\
\text { Longitudinal (Rear- } \\
\text { Wheel-Drive Bias) }\end{array}$ & $\begin{array}{l}\text { LDT2 Transverse } \\
\text { (Front- Wheel-Drive } \\
\text { Bias) }\end{array}$ & $\begin{array}{l}\text { LDT2 Longitudinal (Rear- } \\
\text { Wheel- Drive Bias) }\end{array}$ \\
\hline \multicolumn{4}{|c|}{ Level Three } \\
\hline FWD/3-4cyl/Gas & RWD/Rotary/Gas & FWD/3-4cyl/Gas & RWD/4cyl/Gas \\
\hline FWD/5-6cyl/Gas & RWD/3-4cyl/Gas & FWD/5-6cyl/Gas & RWD/5-6cyl/Gas \\
\hline FWD/8cyl/Gas & RWD/5-6cyl/Gas & FWD/5-6cyl/Flex & RWD/8cyl/Gas \\
\hline FWD/4cyl/Diesel & RWD/8cyl/Gas & FWD Electric & RWD/10cyl/Gas \\
\hline FWD/6cyl/Flex & RWD/10-12cyl/Gas & AWD/4cyl/Gas & RWD/4cyl/Diesel \\
\hline FWD/4cyl/Nat Gas & RWD/4cyl/Flex & AWD/5-6cyl/Gas & RWD/5-6cyl/Diesel \\
\hline $\begin{array}{l}\text { FWD/3-4cyl/Gas- } \\
\text { Elec HEV }\end{array}$ & RWD/6cyl/Flex & 4WD+FWD/4cyl/Gas & RWD/8cyl/Diesel \\
\hline $\begin{array}{l}\text { FWD/Electric( Cars } \\
\text { Only) }\end{array}$ & RWD/6cyl/Diesel & 4WD+FWD/6cyl/Gas & RWD/6cyl/Flex \\
\hline AWD/3-4cyl/Gas & RWD/8cyl/Nat Gas & & RWD/8cyl/Flex \\
\hline AWD/5-6cyl/Gas & RWD/Electric & & RWD/8cyl/Nat Gas \\
\hline AWD/8cyl/Gas & AWD/3-4cyl/Gas & & RWD/10cyl/Propane \\
\hline 4WD+FWD/4cyl/Gas & AWD/5-6cyl/Gas & & AWD/4cyl/Gas \\
\hline \multirow[t]{12}{*}{ 4WD+FWD/6cyl/Gas } & AWD/8cyl/Gas & & AWD/6cyl/Gas \\
\hline & AWD/10-12cyl/Gas & & AWD/8cyl/Gas \\
\hline & 4WD+RWD/4cyl/Gas & & AWD/6cyl/Flex \\
\hline & 4WD+RWD/6cyl/Gas & & 4WD+RWD/4cyl/Gas \\
\hline & & & 4WD+RWD/6cyl/Gas \\
\hline & & & 4WD+RWD/8cyl/Gas \\
\hline & & & 4WD+RWD/10cyl/Gas \\
\hline & & & 4WD+RWD/6cyl/Diesel \\
\hline & & & 4WD+RWD/8cyl/Diesel \\
\hline & & & 4WD+RWD/6cyl/Flex \\
\hline & & & 4WD+RWD/8cyl/Flex \\
\hline & & & 4WD+RWD/10cyl/Propane \\
\hline
\end{tabular}

below the $3750 \mathrm{lb}$. mark. Since trim level is not found in the Polk data we used drivetrain (i.e. the heavier $4 \times 4$ models were separated from the lighter $2 \times 4$ models). CAR also made some alterations to conversion vehicles (i.e. those vehicles that were designed to be converted to run off CNG). These were divided "gasoline" or "natural gas"-powered vehicles per CAR's estimates of vehicles actually converted. 
The statistics package used was Statgraphics V5.1 for Windows. Of the three software packages considered (SPSS, Minitab, Statgraphics) Statgraphics was the only package that would accept proportions as the raw data (as opposed to the actual choices consisting of a series of zeros and ones). Statgraphics, therefore, needed the sample size used to compute the proportions. The sample was the number of total vehicles sold within the particular category being modeled.

The modeling process and results for each level are presented below.

F. Level $1-P C L D T 1$ vs. LDT2

As there were only two weight categories, the simple logit model was applied to the data:

$$
\log \frac{P}{1-P}=\beta_{0}+\beta_{1} X_{1}+\beta_{2} X_{2}
$$

Where

$\begin{array}{ll}P & \text { probability of PCLDT1 } \\ X_{1} & \text { year } \\ X_{2} & \text { indicator variable for U.S. or CA } \\ \beta_{0,}, \beta_{1}, \beta_{2} & \text { regression coefficients }\end{array}$

The results of the LSE regression are provided in Table 21. All variables are significant, and, as can be seen from the high adjusted $R^{2}$ value, the model fits the data extremely well.

Table 21 - LSE Regression Results for the PCLDT1 Model

\begin{tabular}{|l|c|c|c|c|}
\hline \multicolumn{1}{|c|}{ Parameter } & Estimate & Standard Error & T Statistic & P-Value \\
\hline CONSTANT & 101.9120 & 10.1652 & 10.0257 & 0.0000 \\
\hline Year & -0.0508 & 0.0051 & -9.9980 & 0.0000 \\
\hline US $=1 / C A=0$ & 0.1619 & 0.0236 & 6.8731 & 0.0002 \\
\hline
\end{tabular}

R-Squared (adjusted for d.f.) $=94.1$ percent 
Applying equation (2) we obtained the following predictive models:

PCLDT1: $\quad P_{P C L D T 1}=\frac{1}{1+e^{-Z}}=\frac{1}{1+e^{-\left(101.912-0.05079 X_{1}-0.161912 X_{2}\right)}}$

LDT2:

$$
P_{L D T 2}=1-P_{P C L D T 1}
$$

Where

$$
\begin{array}{ll}
X_{1} & \text { Year } \\
X_{2} & 1 \text { if U.S.; } 0 \text { if California }
\end{array}
$$

Equations (7) and (8) are the base models used to make the predictions discussed in section III (I. Model Predictions).

\section{G. Level 2 - Transverse vs. Longitudinal}

Within each Level One category, the drivetrains were further divided into their drivetrain layout: transverse (front-wheel-drive) versus longitudinal (rear-wheel-drive). Since within each weight category there are only two choices, the simple logit model of equation (6) was applied twice: once for the PCLDT1 category and once for the LDT2 category. This process resulted in four models. Since the process to create the models is the same, only the process for creating the PCLDT1 transverse and longitudinal models will be described.

The probability of selecting a transverse drivetrain within the PCLDT1 weight category is given by.

$$
\log \frac{P}{1-P}=\beta_{0}+\beta_{1} X_{1}+\beta_{2} X_{2}
$$

Where
$P \quad$ probability of a transverse drivetrain within PCLDT1
$X_{1} \quad$ year
$X_{2} \quad$ indicator variable for U.S. or CA
$\beta_{0}, \beta_{1}, \beta_{2} \quad$ regression coefficients

The results of the LSE regression are provided in Table 22. All variables are significant, and as can be seen from the high adjusted $R^{2}$ value, the model fits the data extremely well. 
Table 22a - LSE Regression Results for the PCLDT1 Trans vs. Long Model

\begin{tabular}{|l|c|c|c|c|}
\hline \multicolumn{1}{|c|}{ Parameter } & Estimate & Standard Error & T Statistic & P-Value \\
\hline CONSTANT & -58.27 & 16.11 & -3.618 & 0.0085 \\
\hline Year & 0.02977 & 0.008050 & 3.698 & 0.0077 \\
\hline US/CA=0 & -0.1970 & 0.03449 & -5.713 & 0.0007 \\
\hline \multicolumn{4}{r}{ R-Squared (adjusted for d.f.) $=82.8$ percent } \\
\end{tabular}

Applying equation ((2) we obtain the following predictive models for the PCLDT1 weight category:

PCLDT1 Transverse: $\quad P_{\text {Transverse }}=\frac{1}{1+e^{-Z}}=\frac{1}{1+e^{-\left(-57.2737+0.0297699 X_{1}-0.197034 X_{2}\right)}}$

PCLDT1 Longitudinal: $\quad P_{\text {Longitudinal }}=1-P_{\text {Transverse }}$

Where

$\begin{array}{ll}X_{1} & \text { Year } \\ X_{2} & 1 \text { if U.S.; } 0 \text { if California }\end{array}$

Equations (9) (10) and (11) represent the percent of PCLDT1 vehicles that are sold with the transverse and longitudinal engine orientation respectively.

Table 23b - LSE Regression Results for the LDT2 Trans vs. Long Model

\begin{tabular}{|l|c|c|c|c|}
\hline Parameter & Estimate & Standard Error & T Statistic & P-Value \\
\hline CONSTANT & -123.8960 & 9.8289 & -12.6053 & 0.0000 \\
\hline Year & 0.0612 & 0.0049 & 12.4691 & 0.0000 \\
\hline US/CA=0 & -0.0039 & 0.0235 & -0.1648 & 0.8737 \\
\hline \multicolumn{4}{r|}{ R-Squared (adjusted for d.f.) $=94.5$ percent }
\end{tabular}

The corresponding models for LDT2 were obtained in the same way (Table 22b) and are given by:

LDT2 Transverse: $\quad P_{\text {Transverse }}=\frac{1}{1+e^{-Z}}=\frac{1}{1+e^{-\left(-123.9+0.0612442 X_{1}-0.00387406 X_{2}\right)}}$

LDT2 Longitudinal: $\quad P_{\text {Longitudinal }}=1-P_{\text {Transverse }}$

Where

$X_{1} \quad$ Year

$X_{2} \quad 1$ if U.S.; 0 if California 
These equations are the base models used to make the predications discussed in section III (I. Model Predictions).

\section{H. Level 3 - Drivetrains}

It was determined that the multinomial logit model was not a reasonable option for Level Three (drivetrain) analyses. Instead linear regression was used to forecast Level three volumes.

\section{Model Predictions}

This section explains how the models developed in the previous section are used to make predictions. It is beyond the scope of this report to present every model. Instead, the report shall present one example of applying the simple logit model and one example of applying the multinomial logit model. Appendix III presents the complete results for the multinomial logit model.

The reader is cautioned about using the models for making future predictions. As with any model that is based on historical data, extrapolating beyond the range of the data must be done with caution. Caution must be used when extrapolating by the entire range of the data, as is done here (5-years). Such extrapolations must be carefully examined and adjusted based on other factors-such as the availability of drivetrains that were not available during the study period, the cost of fuel, and other factors not currently captured by the model. This section does not discuss the adjustments. The purpose of this section is to explain how the model predictions were derived, and does not interpret the results of the prediction in any way. The adjustment and interpretation of the adjusted predictions are presented and discussed in later sections.

\section{J. Level 1-PCLDT1 vs. LDT2}

The PCLDT1 model was computed using the simple logit model. Table 23 presents the data as well as the results of applying equation (7). The percent of actual and predicted LDT2 vehicles sold can be computed from equation (8). It is interesting to note how well the model fits the actual data. This fit can also be seen in Figure 4, which shows the predicted and actual percentage of PCLDT1 vehicles sold in the United States (U.S.) and California (CA). The graph of the predicted values and the graph of the actual values are very close to one another justifying a high degree of confidence in the model. 
Table 24 - Model Table for PCLDT1

\begin{tabular}{|r|r|r|r|r|r|r|r|}
\hline Year & $\begin{array}{r}\text { U.S/ } \\
\text { CA }\end{array}$ & \multicolumn{1}{|c|}{ Total Sold } & Model & $\begin{array}{c}\text { PCLDT1 } \\
\text { (actual) }\end{array}$ & $\begin{array}{c}\text { PCLDT1 } \\
\text { (pred.) }\end{array}$ & $\begin{array}{c}\text { PCLDT1 } \\
\text { (\% act.) }\end{array}$ & $\begin{array}{r}\text { PCLDT1 } \\
\text { (\% pred.) }\end{array}$ \\
\hline 1999 & CA & $1,831,953$ & 0.54479 & $1,147,373$ & $1,159,491$ & $62.6 \%$ & $63.3 \%$ \\
\hline 1999 & US & $16,583,488$ & 0.38288 & $9,790,626$ & $9,859,996$ & $59.0 \%$ & $59.5 \%$ \\
\hline 2000 & CA & $2,047,490$ & 0.49400 & $1,264,171$ & $1,271,590$ & $61.7 \%$ & $62.1 \%$ \\
\hline 2000 & US & $17,532,348$ & 0.33209 & $10,239,429$ & $10,208,514$ & $58.4 \%$ & $58.2 \%$ \\
\hline 2001 & CA & $2,018,113$ & 0.44321 & $1,237,658$ & $1,229,079$ & $61.3 \%$ & $60.9 \%$ \\
\hline 2001 & US & $16,967,214$ & 0.28130 & $9,806,506$ & $9,669,012$ & $57.8 \%$ & $57.0 \%$ \\
\hline 2002 & CA & $2,013,651$ & 0.39242 & $1,201,564$ & $1,201,878$ & $59.7 \%$ & $59.7 \%$ \\
\hline 2002 & US & $16,620,485$ & 0.23051 & $9,242,741$ & $9,263,813$ & $55.6 \%$ & $55.7 \%$ \\
\hline 2003 & CA & $1,998,898$ & 0.34163 & $1,180,615$ & $1,168,529$ & $59.1 \%$ & $58.5 \%$ \\
\hline 2003 & US & $16,613,357$ & 0.17972 & $8,979,911$ & $9,051,106$ & $54.1 \%$ & $54.5 \%$ \\
\hline 2004 & CA & $2,050,950$ & 0.29084 & & $1,173,557$ & & $57.2 \%$ \\
\hline 2004 & US & $16,925,000$ & 0.12893 & & $9,007,272$ & & $53.2 \%$ \\
\hline 2005 & CA & $2,075,150$ & 0.24005 & & $1,161,515$ & & $56.0 \%$ \\
\hline 2005 & US & $17,150,000$ & 0.07814 & & $8,909,846$ & & $52.0 \%$ \\
\hline 2006 & CA & $2,105,400$ & 0.18926 & & $1,152,021$ & & $54.7 \%$ \\
\hline 2006 & US & $17,400,000$ & 0.02735 & & $8,818,956$ & & $50.7 \%$ \\
\hline 2007 & CA & $2,159,400$ & 0.13847 & & $1,154,334$ & & $53.5 \%$ \\
\hline 2007 & US & $17,700,000$ & -0.02344 & & $8,746,274$ & & $49.4 \%$ \\
\hline 2008 & CA & $2,171,600$ & 0.08768 & & $1,133,371$ & & $52.2 \%$ \\
\hline 2008 & US & $17,800,000$ & -0.07423 & & $8,569,819$ & & $48.1 \%$ \\
\hline 2009 & CA & $2,201,700$ & 0.03689 & & $1,121,153$ & & $50.9 \%$ \\
\hline 2009 & US & $17,850,000$ & -0.12502 & & $8,367,815$ & & $46.9 \%$ \\
\hline
\end{tabular}

Figure 4 - Predicted and Actual Percentages of PCLDT1 Vehicles Sold in the U.S. and CA

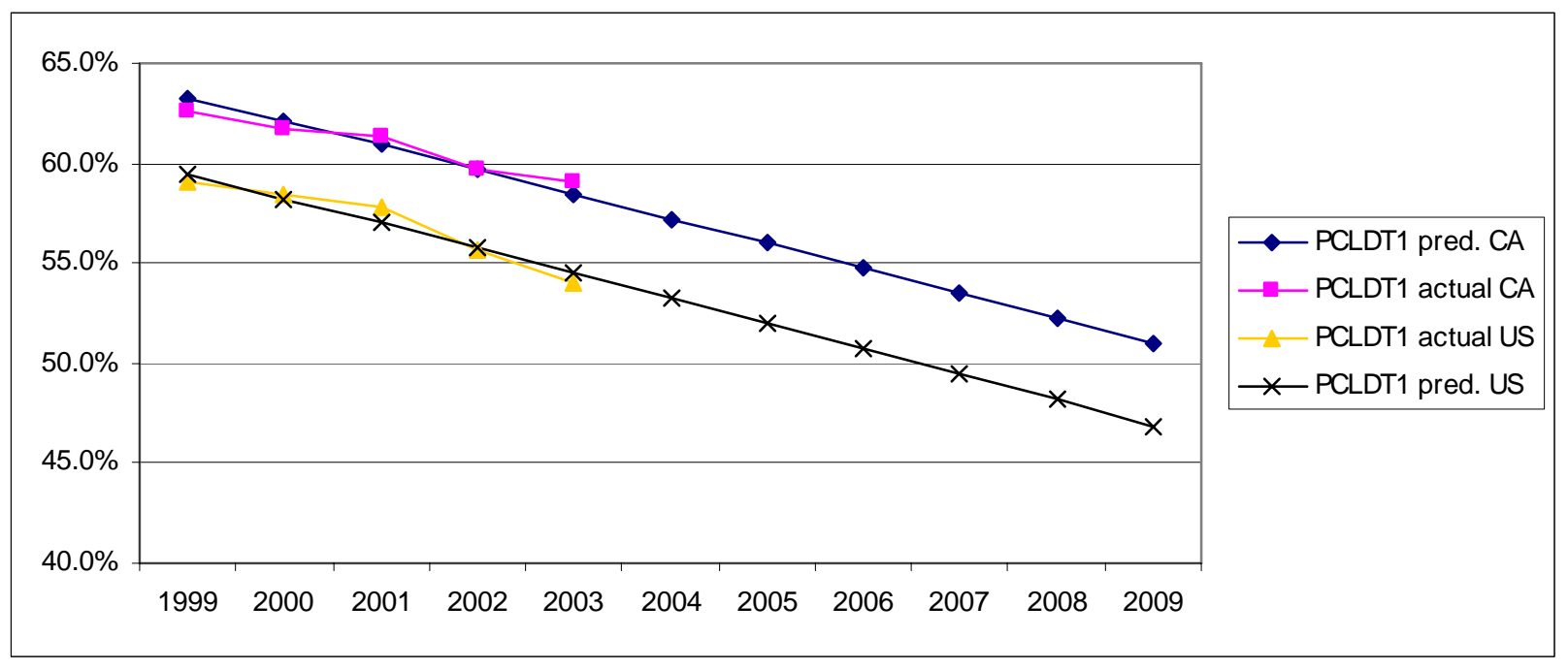




\section{The U.S. and California Vehicle Forecast for 2009}

\section{A. Introduction}

The vehicle segmentation forecast for the U.S. and California markets is defined by two elements. The first is an estimate of overall sales for the year 2009; the other element represents the segmentation percentages for the numerous powertrain options. CAR relied on two prominent industry forecasts (J.D. Power and CSM Worldwide) to estimate overall light vehicle sales for the year 2009. CAR then applied the percentages derived from the Logit model (in the manner described in section III) to forecast PCLDT1 and LDT2, and transverse and longitudinal drivetrain layout shares for 2009. CAR then used linear regression modeling to forecast powertrain segmentation.

\section{B. Overall Vehicle Forecast:}

As noted, CAR relied on two prominent industry forecasts to estimate total sales for 2009. These two estimates were averaged to present a consensus forecast of vehicle sales. It is important to note that the data used to estimate market segmentation was derived from registration; the consensus vehicle forecast for 2009 is presented as vehicle sale. However, it is generally agreed that registrations represent a strong proxy for sales. Thus, CAR believes that basing the sales forecast on registration data presents a reasonable solution.

\section{Results for Levels One and Two (Logit Model)}

Tables 24 - 26 show the forecast for the 2004-2009 model years for total sales, and longitudinal and transverse drivetrains for the U.S. and California markets. The model forecasts further growth of the California market as a percent of the total U.S. market (12.1 percent in 2004 to 12.3 percent in 2009). Although this rate of change is less than in the period during which the historical data was examined, it is important to note that California as a percent of U.S. registrations actually decreased from 2002 (12.3) to 2003 (12.1). The model also forecasts a shift from PCLDT1 to LDT2s during the period. By 2009, the model estimates that 50.9 percent of California and 46.9 percent U.S. vehicles sales will be LDT2s as defined here.

Table 25 - Total PCLDT1 and LDT2 Sales (Level One)

Forecast 2004-2009 Results (in units) of Logit Model

\begin{tabular}{|c|c|c|c|c|r|c|}
\hline & \multicolumn{2}{|c|}{ Total Market } & \multicolumn{2}{c|}{ PCLDT1 } & \multicolumn{2}{c|}{ LDT2 } \\
\hline Year & California & U.S. & California & U.S. & \multicolumn{1}{c|}{ California } & U.S. \\
\hline 2004 & $2,050,950$ & $16,925,000$ & $1,173,557$ & $9,007,272$ & 877,393 & $7,917,728$ \\
\hline 2005 & $2,075,150$ & $17,150,000$ & $1,161,515$ & $8,909,846$ & 913,635 & $8,240,154$ \\
\hline 2006 & $2,105,400$ & $17,400,000$ & 1,152020 & $8,818,956$ & 953,379 & $8,581,044$ \\
\hline 2007 & $2,159,400$ & $17,700,000$ & $1,154,333$ & $8,746,274$ & $1,005,066$ & $8,953,726$ \\
\hline 2008 & $2,171,600$ & $17,800,000$ & $1,133,371$ & $8,569,819$ & $1,038,229$ & $9,230,181$ \\
\hline 2009 & $2,201,700$ & $17,850,000$ & $1,121,152$ & $8,367,815$ & $1,080,547$ & $9,482,185$ \\
\hline
\end{tabular}

The PCLDT1 segment is forecast to have a slight decrease in longitudinal-or rearwheel-drive share. Although some manufactures are returning a portion of their portfolio to rear-wheel-drive layout, we also expect to see an increase in front-wheel-drive crossover vehicles. However, it various parties within the industry believe that technology 
development (i.e. traction and stability control) will be capable of offsetting the traditionally poor bad-weather handling characteristics of rear-wheel-drive vehicles, which could change this forecast.

Table 26 - Level Two PCLDT1

Sales Forecast 2004-2009 Results (in units) of Logit Model

\begin{tabular}{|r|r|r|r|r|}
\hline & \multicolumn{2}{|c|}{ California } & \multicolumn{2}{c|}{ U.S. } \\
\hline Year & Transverse & \multicolumn{1}{|c|}{ Longitudinal } & \multicolumn{1}{c|}{ Transverse } & \multicolumn{1}{c|}{ Longitudinal } \\
\hline $\mathbf{2 0 0 4}$ & 899,425 & 274,132 & $7,204,211$ & $1,803,062$ \\
\hline $\mathbf{2 0 0 5}$ & 896,337 & 265,178 & $7,168,376$ & $1,741,470$ \\
\hline $\mathbf{2 0 0 6}$ & 895,004 & 257,017 & $7,136,162$ & $1,682,794$ \\
\hline $\mathbf{2 0 0 7}$ & 902,708 & 251,626 & $7,117,182$ & $1,629,092$ \\
\hline $\mathbf{2 0 0 8}$ & 892,018 & 241,353 & $7,011,902$ & $1,557,917$ \\
\hline $\mathbf{2 0 0 9}$ & 887,948 & 233,205 & $6,883,323$ & $1,484,492$ \\
\hline
\end{tabular}

The LDT2 forecast, unlike that of the PCLDT1 forecast shows an increase in transverse drivetrains. This increase is driven by the rapid introduction in recent years of car-based utility vehicles, or CUVs. These vehicles have taken share from the traditional rearwheel drive sport utility segment. It is reasonable to expect this trend to continue for several years.

Table 27 - Level Two LDT2

Sales Forecast 2004-2009 Results (in units) of Logit Model

\begin{tabular}{|r|r|r|r|r|}
\hline & \multicolumn{2}{|c|}{ California } & \multicolumn{2}{c|}{ U.S. } \\
\hline Year & Transverse & \multicolumn{1}{c|}{ Longitudinal } & Transverse & \multicolumn{1}{c|}{ Longitudinal } \\
\hline $\mathbf{2 0 0 4}$ & 208,351 & 669,042 & $1,880,190$ & $6,037,537$ \\
\hline $\mathbf{2 0 0 5}$ & 227,251 & 686,383 & $2,049,601$ & $6,190,552$ \\
\hline $\mathbf{2 0 0 6}$ & 248,215 & 705,164 & $2,234,100$ & $6,346,943$ \\
\hline $\mathbf{2 0 0 7}$ & 273,698 & 731,368 & $2,438,266$ & $6,515,460$ \\
\hline $\mathbf{2 0 0 8}$ & 295,503 & 742,726 & $2,627,118$ & $6,603,063$ \\
\hline $\mathbf{2 0 0 9}$ & 321,198 & 759,349 & $2,818,630$ & $6,663,555$ \\
\hline
\end{tabular}

D. Results for Level Three (Regression Model)

CAR used the results of the Logit model as the basis for the final forecast. However, because the model used only five years of historical data, it failed to realistically predict future sales when applied to each individual powertrain option. Therefore, CAR applied the logit model to the split between PCLDT1 and light trucks, and to transverse and longitudinal drivetrains within the PCLDT1and light truck segments as described in Section III. Using those results, CAR then applied linear regression to each of the powertrain segments to create a detailed forecast for 2009. These results are presented in appendix IV.

However, there were segments that were not realistically modeled by the linear regressions. For these segments, CAR relied upon its knowledge of industry trends and future product plans to 'tune the results' and better indicate likely future sales trends. The changes (and the explanation for those changes) to the linear regression models can be found in Appendix V. The final forecast is presented in Tables 27 through 34. 


\section{E. Technological Uncertainty}

As noted, CAR believes this forecast represents a reasonable estimate of the 2009 U.S. and California markets. However, it is important to note that, as with any prediction, there are many variables that can affect the actual numbers. With regard to powertrain technology, this is one of the most uncertain times since the early years of the industry.

Currently, the automotive industry is struggling to understand the developing advanced powertrain paradigm. There are several competing technologies that may offer increased fuel efficiency and reduced emissions-albeit at an increased cost. The hybrid electric vehicle presents opportunity for significant decreases in carbon dioxide emissions when driven in congested areas; but may not deliver similar gains when used in less congested areas; and may suffer from poor battery performance in cold weather climates. Conversely, the diesel engine offers potential efficiency gains over the current spark-ignited gasoline engine (and maybe the HEV in some driving cycles) but suffers from cost and emissions challenges. The spark-ignited gasoline engine may also offer increased efficiency but at a cost. It is wholly possible that each of these powertrains could gain acceptance. It is also possible-although unlikely-that each of these technologies could fail to meet consumer requirements, and vanish from the marketplace in the coming years.

\section{F. Technology Assumptions:}

In addition to technological uncertainty, we must consider the ongoing public policy discussions regarding fuel economy and vehicle emissions. To complete this model, CAR has made several assumptions regarding technology and policy issues. We believe these assumptions to be reasonable-albeit, highly debatable. The following is a review of market factors we believe add increased variability to the powertrain segmentation.

1. Hybrid Technology: The CAR forecast calls for what we would describe as a strong growth in hybrid penetration. However, there will most certainly be critics that the market will be either significantly lower-or higher-than the CAR estimates. Although there are indications that hybrid technology is becoming a viable option for a portion of the light vehicle market, the extent and duration of that market is still uncertain. Cost will remain an issue; appropriateness for the driving cycle of several segments is also uncertain. CAR relied on announced plans and discussions with various industry sources to develop an estimate for HEV penetration for 2009.

2. Diesel Technology: The forecast calls for a modest increase in diesel application in PCLDT1 and a slightly more aggressive increase in LDT2 (although some of the growth in trucks is due to the inclusion of GVW over 8,500 lbs.). Most experts interviewed by CAR believed there will be positive resolution regarding the environmental acceptability (i.e. at a minimum, the ability to meet Tier 2 Bin 5) of the diesel engine within the next five years. The diesel engine, especially diesel aftertreatment technology, represents a variable which could be considered highly volatile. As such, developments in diesel technology could change the forecast markedly.

3. All-Wheel-Drive in the Passenger Car Market: While this technology does not present the high visibility of the other technology choices, it does present unique difficulty in 
forecasting. Several manufacturers have recently, or will soon, introduce all-wheel-drive as an option on high-volume models. Many of these vehicles are being positioned as an alternative to the perceived safety advantages offered by all-wheel-drive SUV and CUV offerings. However, some of these all-wheel-drive vehicles are being positioned as performance vehicles. This has important implications for the California market, where the poor weather performance attributes of all-wheel-drive are not a strong market driver, but where a higher mix of performance type rear-wheel-drive passenger cars are sold.

4. Flex Fuel Vehicles: The inclusion of flex fuel vehicles in the forecast presents opportunity for a significant amount of variability. The offering of a flex fuel option is highly variable and is often driven by many factors including, but not limited to, government encouragement, corporate policy and emissions, and even corporate public relations. The conversion of an existing gasoline engine to a flex fuel capable engine is a relatively low cost ${ }^{20}$ method of gaining credits toward emission standards, or even gaining public relations benefits. Therefore it is difficult to forecast the total number of products available to the market-and even more difficult to estimate by powertrain segment. CAR has been very cautious with the forecast for flex fuel or other alternative fueled vehicles (note that CNG and propane were significant enough to be included only in LDT2 longitudinal segment). This caution should not be read as doubt for the given technologies. Their benefits and costs are rather well understood. Instead, it can be attributed to the fact that these technologies are driven by policy, and do not necessarily reflect a 'normal' business strategy. The Alternative Motor Fuel Act of 1988 (and its recent extension) will assure that the manufacturers continue to consider flex-fuel and dedicated alternative fuel vehicles. At least one Midwest state continues to contemplate legislation that would require increased availability of ethanol capable vehicles. Conversely, other states have indicated some concern as to the actual number of flex fueled vehicles that ever use alternative fuels.

\footnotetext{
${ }^{20}$ Manufacturers will understandably have difficulties with the term 'relatively' low cost. However, their actions suggest that the use of flex fuel vehicles to gain emission credits is at least to some extent, a cost effective measure.
} 
Table 28 - United States PCLDT1Registrations, Transverse Layout 1999-2003 Actual and 2009 Forecasted (Percent of Segment)

\begin{tabular}{|l|r|r|r|r|r|r|}
\hline \multicolumn{1}{|c|}{ Vehicle Summary } & \multicolumn{1}{c|}{1999} & \multicolumn{1}{c|}{2000} & \multicolumn{1}{c|}{2001} & \multicolumn{1}{c|}{2002} & \multicolumn{1}{c|}{2003} & \multicolumn{1}{c|}{2009} \\
\hline FWD/3-4cyl/Gas & $52.8 \%$ & $52.7 \%$ & $53.6 \%$ & $54.2 \%$ & $54.6 \%$ & $53.8 \%$ \\
\hline FWD/5-6cyl/Gas & $42.1 \%$ & $40.6 \%$ & $39.1 \%$ & $37.4 \%$ & $35.5 \%$ & $27.6 \%$ \\
\hline FWD/8cyl/Gas & $2.5 \%$ & $2.3 \%$ & $2.1 \%$ & $1.8 \%$ & $1.5 \%$ & $0.1 \%$ \\
\hline FWD/4cyl/Diesel & $0.2 \%$ & $0.3 \%$ & $0.3 \%$ & $0.4 \%$ & $0.4 \%$ & $0.8 \%$ \\
\hline FWD/6cyl/Flexible & $0.1 \%$ & $1.5 \%$ & $0.8 \%$ & $0.9 \%$ & $1.5 \%$ & $0.9 \%$ \\
\hline FWD/4cyl/Nat Gas & $0.0 \%$ & $0.0 \%$ & $0.0 \%$ & $0.0 \%$ & $0.0 \%$ & $0.0 \%$ \\
\hline $\begin{array}{l}\text { FWD/3-4cyl/Gas-Elec } \\
\text { HEV }\end{array}$ & $0.0 \%$ & $0.1 \%$ & $0.2 \%$ & $0.5 \%$ & $0.6 \%$ & $6.0 \%$ \\
\hline FWD5/6Gas-Elec HEV & $\mathrm{N} / \mathrm{A}$ & $\mathrm{N} / \mathrm{A}$ & $\mathrm{N} / \mathrm{A}$ & $\mathrm{N} / \mathrm{A}$ & $\mathrm{N} / \mathrm{A}$ & $1.6 \%$ \\
\hline AWD/4cyl/Gas & $0.2 \%$ & $0.3 \%$ & $0.3 \%$ & $0.6 \%$ & $1.1 \%$ & $2.0 \%$ \\
\hline AWD/5-6cyl/Gas & $0.8 \%$ & $0.8 \%$ & $1.1 \%$ & $1.5 \%$ & $1.7 \%$ & $3.0 \%$ \\
\hline AWD/8cyl/Gas & $0.0 \%$ & $0.0 \%$ & $0.0 \%$ & $0.0 \%$ & $0.0 \%$ & $0.0 \%$ \\
\hline 4WD+FWD/4cyl/Gas & $1.2 \%$ & $1.2 \%$ & $1.2 \%$ & $1.6 \%$ & $1.7 \%$ & $2.2 \%$ \\
\hline 4WD+FWD/6cyl/Gas & $0.0 \%$ & $0.2 \%$ & $1.2 \%$ & $1.0 \%$ & $1.3 \%$ & $2.0 \%$ \\
\hline Total US PCLDT1 Tran & $100.0 \%$ & $100.0 \%$ & $100.0 \%$ & $100.0 \%$ & $100.0 \%$ & $100.0 \%$ \\
\hline (Passenger cars and light duty trucks equal to or less than 3750 loaded weight.) & & \\
\hline
\end{tabular}

Table 29 - California PCLDT1Registrations, Transverse Layout 1999-2003 Actual and 2009 Forecasted (Percent of Segment)

\begin{tabular}{|c|c|c|c|c|c|c|}
\hline Vehicle Summary & 1999 & 2000 & 2001 & 2002 & 2003 & 2009 \\
\hline FWD/3-4cyl/Gas & $60.4 \%$ & $60.2 \%$ & $61.4 \%$ & $61.2 \%$ & $61.7 \%$ & $55.8 \%$ \\
\hline FWD/5-6cyl/Gas & $35.5 \%$ & $33.3 \%$ & $32.8 \%$ & $31.0 \%$ & $29.6 \%$ & $19.9 \%$ \\
\hline FWD/8cyl/Gas & $1.7 \%$ & $1.5 \%$ & $1.3 \%$ & $0.9 \%$ & $0.8 \%$ & $0.1 \%$ \\
\hline FWD/4cyl/Diesel & $0.1 \%$ & $0.0 \%$ & $0.1 \%$ & $0.3 \%$ & $0.3 \%$ & $0.6 \%$ \\
\hline FWD/6cyl/Flex & $0.0 \%$ & $2.1 \%$ & $0.5 \%$ & $0.8 \%$ & $1.1 \%$ & $0.9 \%$ \\
\hline FWD/4cyl/Nat Gas & $0.1 \%$ & $0.1 \%$ & $0.1 \%$ & $0.1 \%$ & $0.1 \%$ & $0.1 \%$ \\
\hline $\begin{array}{l}\text { FWD/3-4cyl/Gas-Elec } \\
\text { HEV }\end{array}$ & $0.0 \%$ & $0.2 \%$ & $0.7 \%$ & $1.0 \%$ & $1.3 \%$ & $12.0 \%$ \\
\hline FWD/5-6cyl/Gas/HEV & $\mathrm{N} / \mathrm{A}$ & $\mathrm{N} / \mathrm{A}$ & $\mathrm{N} / \mathrm{A}$ & $\mathrm{N} / \mathrm{A}$ & $\mathrm{N} / \mathrm{A}$ & 2. $0 \%$ \\
\hline AWD/3-4cyl/Gas & $0.2 \%$ & $0.4 \%$ & $0.4 \%$ & $0.6 \%$ & $0.8 \%$ & $2.0 \%$ \\
\hline AWD/5-6cyl/Gas & $0.7 \%$ & $0.8 \%$ & $1.1 \%$ & $1.5 \%$ & $1.4 \%$ & $3.0 \%$ \\
\hline AWD/8cyl/Gas & $0.0 \%$ & $0.0 \%$ & $0.0 \%$ & $0.0 \%$ & $0.0 \%$ & $0.0 \%$ \\
\hline 4WD+FWD/4cyl/Gas & $1.2 \%$ & $1.2 \%$ & $1.0 \%$ & $1.4 \%$ & $1.5 \%$ & $2.2 \%$ \\
\hline 4WD+FWD/6cyl/Gas & $0.0 \%$ & $0.1 \%$ & $0.6 \%$ & $0.5 \%$ & $0.5 \%$ & $1.3 \%$ \\
\hline Total CA PCLDT1 Tran & $100.0 \%$ & $100.0 \%$ & $100.0 \%$ & $100.0 \%$ & $100.0 \%$ & \\
\hline
\end{tabular}


Table 30 - U.S. LDT2 Registrations,

Transverse Layout 1999-2003 Actual and 2009 Forecasted (Percent of Segment)

\begin{tabular}{|l|r|r|r|r|r|r|}
\hline \multicolumn{1}{|c|}{ Vehicle Summary } & \multicolumn{1}{|c|}{1999} & \multicolumn{1}{c|}{2000} & \multicolumn{1}{c|}{2001} & \multicolumn{1}{c|}{2002} & \multicolumn{1}{c|}{2003} & \multicolumn{1}{c|}{2009} \\
\hline FWD/4cyl/Gas & $4.9 \%$ & $3.7 \%$ & $3.9 \%$ & $3.7 \%$ & $3.2 \%$ & $2.8 \%$ \\
\hline FWD/6cyl/Gas & $73.4 \%$ & $75.2 \%$ & $64.8 \%$ & $59.5 \%$ & $58.6 \%$ & $44.7 \%$ \\
\hline FWD/6cyl/Flex & $16.7 \%$ & $15.1 \%$ & $15.9 \%$ & $16.6 \%$ & $10.0 \%$ & $5.0 \%$ \\
\hline Trans/FWD/3-4cyl/HEV & $\mathrm{N} / \mathrm{A}$ & $\mathrm{N} / \mathrm{A}$ & $\mathrm{N} / \mathrm{A}$ & $\mathrm{N} / \mathrm{A}$ & $\mathrm{N} / \mathrm{A}$ & $4.0 \%$ \\
\hline $\begin{array}{l}\text { Trans/FWD/5/6- } \\
\text { cyl/HEV }\end{array}$ & $\mathrm{N} / \mathrm{A}$ & $\mathrm{N} / \mathrm{A}$ & $\mathrm{N} / \mathrm{A}$ & $\mathrm{N} / \mathrm{A}$ & $\mathrm{N} / \mathrm{A}$ & $4.0 \%$ \\
\hline $\begin{array}{l}\text { Trans/4WD/3-4cyl/HEV } \\
\text { (includes AWD) }\end{array}$ & $\mathrm{N} / \mathrm{A}$ & $\mathrm{N} / \mathrm{A}$ & $\mathrm{N} / \mathrm{A}$ & $\mathrm{N} / \mathrm{A}$ & $\mathrm{N} / \mathrm{A}$ & $2.0 \%$ \\
\hline $\begin{array}{l}\text { Trans/4WD } \\
\text { /5/6cyl/HEV (includes } \\
\text { AWD) }\end{array}$ & $\mathrm{N} / \mathrm{A}$ & $\mathrm{N} / \mathrm{A}$ & $\mathrm{N} / \mathrm{A}$ & $\mathrm{N} / \mathrm{A}$ & $\mathrm{N} / \mathrm{A}$ & \\
\hline AWD/4cyl/Gas & $0.0 \%$ & $0.0 \%$ & $0.2 \%$ & $0.2 \%$ & $0.2 \%$ & $1.0 \%$ \\
\hline AWD/5-6cyl/Gas & $5.1 \%$ & $4.9 \%$ & $8.4 \%$ & $12.6 \%$ & $14.8 \%$ & $15.0 \%$ \\
\hline 4WD+FWD/4cyl/Gas & $0.0 \%$ & $0.0 \%$ & $0.0 \%$ & $0.0 \%$ & $2.5 \%$ & $3.9 \%$ \\
\hline 4WD+FWD/6cyl/Gas & $0.0 \%$ & $1.2 \%$ & $6.8 \%$ & $7.3 \%$ & $10.7 \%$ & $15.6 \%$ \\
\hline Total US LDT2 Tran & $100.0 \%$ & $100.0 \%$ & $100.0 \%$ & $100.0 \%$ & $100.0 \%$ & $100.0 \%$ \\
\hline
\end{tabular}

Table 31 - California LDT2 Registrations,

Transverse Layout 1999-2003 Actual and 2009 Forecasted (Percent of Segment)

\begin{tabular}{|l|r|r|r|r|r|r|}
\hline \multicolumn{1}{|c|}{ Vehicle Summary } & \multicolumn{1}{|c|}{1999} & 2000 & \multicolumn{1}{c|}{2001} & \multicolumn{1}{c|}{2002} & \multicolumn{1}{c|}{2003} & \multicolumn{1}{c|}{2009} \\
\hline FWD/3-4cyl/Gas & $6.9 \%$ & $4.3 \%$ & $5.9 \%$ & $5.3 \%$ & $4.8 \%$ & $2.8 \%$ \\
\hline FWD/5-6cyl/Gas & $84.8 \%$ & $86.7 \%$ & $68.2 \%$ & $64.2 \%$ & $60.8 \%$ & $44.7 \%$ \\
\hline FWD/5-6cyl/Flex & $0.3 \%$ & $1.7 \%$ & $9.7 \%$ & $12.0 \%$ & $7.9 \%$ & $5.0 \%$ \\
\hline Trans/FWD/3-4cyl/HEV & $\mathrm{N} / \mathrm{A}$ & $\mathrm{N} / \mathrm{A}$ & $\mathrm{N} / \mathrm{A}$ & $\mathrm{N} / \mathrm{A}$ & $\mathrm{N} / \mathrm{A}$ & $4.0 \%$ \\
\hline Trans/FWD/5-6cyl/HEV & $\mathrm{N} / \mathrm{A}$ & $\mathrm{N} / \mathrm{A}$ & $\mathrm{N} / \mathrm{A}$ & $\mathrm{N} / \mathrm{A}$ & $\mathrm{N} / \mathrm{A}$ & $4.0 \%$ \\
\hline $\begin{array}{l}\text { Trans/4WD/3-4cyl/HEV } \\
\text { (includes AWD) }\end{array}$ & $\mathrm{N} / \mathrm{A}$ & $\mathrm{N} / \mathrm{A}$ & $\mathrm{N} / \mathrm{A}$ & $\mathrm{N} / \mathrm{A}$ & $\mathrm{N} / \mathrm{A}$ & $2.0 \%$ \\
\hline $\begin{array}{l}\text { Trans/4WD } \\
\text { /5/6cyl/HEV (includes } \\
\text { AWD) }\end{array}$ & $\mathrm{N} / \mathrm{A}$ & $\mathrm{N} / \mathrm{A}$ & $\mathrm{N} / \mathrm{A}$ & $\mathrm{N} / \mathrm{A}$ & $\mathrm{N} / \mathrm{A}$ & $2.0 \%$ \\
\hline AWD/4cyl/Gas & $0.0 \%$ & $0.0 \%$ & $0.0 \%$ & $0.0 \%$ & $0.0 \%$ & $1.0 \%$ \\
\hline AWD/5-6cyl/Gas & $8.0 \%$ & $6.4 \%$ & $7.9 \%$ & $9.2 \%$ & $10.0 \%$ & $15.0 \%$ \\
\hline 4WD+FWD/4cyl/Gas & $0.0 \%$ & $0.0 \%$ & $0.0 \%$ & $0.0 \%$ & $2.9 \%$ & $3.9 \%$ \\
\hline 4WD+FWD/6cyl/Gas & $0.0 \%$ & $0.9 \%$ & $8.3 \%$ & $9.3 \%$ & $13.6 \%$ & $15.6 \%$ \\
\hline Total CA LDT2 Tran & $100.0 \%$ & $100.0 \%$ & $100.0 \%$ & $100.0 \%$ & $100.0 \%$ & $100.0 \%$ \\
\hline
\end{tabular}


Table 32 - United States PCLDT1Registrations, Longitudinal Layout 1999-2003 Actual and 2009 Forecasted (Percent of Segment)

\begin{tabular}{|l|r|r|r|r|r|r|}
\hline \multicolumn{1}{|c|}{ Vehicle Summary } & \multicolumn{1}{c|}{1999} & \multicolumn{1}{c|}{2000} & \multicolumn{1}{c|}{2001} & \multicolumn{1}{c|}{2002} & \multicolumn{1}{c|}{2003} & \multicolumn{1}{c|}{2009} \\
\hline RWD/4cyl/Gas & $19.9 \%$ & $14.2 \%$ & $9.4 \%$ & $10.1 \%$ & $12.1 \%$ & $11.6 \%$ \\
\hline RWD/5-6cyl/Gas & $25.1 \%$ & $26.8 \%$ & $34.0 \%$ & $36.2 \%$ & $37.8 \%$ & $41.0 \%$ \\
\hline RWD/8cyl/Gas & $25.8 \%$ & $25.6 \%$ & $27.8 \%$ & $28.4 \%$ & $26.5 \%$ & $25.8 \%$ \\
\hline RWD/10-12cyl/Gas & $0.1 \%$ & $0.2 \%$ & $0.2 \%$ & $0.2 \%$ & $0.3 \%$ & $0.4 \%$ \\
\hline RWD/4cyl/Flex & $0.0 \%$ & $4.3 \%$ & $4.0 \%$ & $3.0 \%$ & $0.1 \%$ & $1.8 \%$ \\
\hline RWD/6cyl/Flex & $5.9 \%$ & $6.0 \%$ & $1.8 \%$ & $1.6 \%$ & $2.7 \%$ & $0.2 \%$ \\
\hline RWD/6cyl/Diesel & $0.2 \%$ & $0.0 \%$ & $0.0 \%$ & $0.0 \%$ & $0.0 \%$ & $0.3 \%$ \\
\hline RWD/8cyl/Nat Gas & $0.0 \%$ & $0.0 \%$ & $0.0 \%$ & $0.0 \%$ & $0.0 \%$ & $0.0 \%$ \\
\hline $\begin{array}{l}\text { RWD/Rotary } \\
\text { Engine/Gas }\end{array}$ & $0.0 \%$ & $0.0 \%$ & $0.0 \%$ & $0.0 \%$ & $0.5 \%$ & $0.4 \%$ \\
\hline AWD/4cyl/Gas & $8.5 \%$ & $8.6 \%$ & $10.2 \%$ & $11.0 \%$ & $10.7 \%$ & $10.7 \%$ \\
\hline AWD/6cyl/Gas & $1.8 \%$ & $4.5 \%$ & $4.1 \%$ & $2.4 \%$ & $2.8 \%$ & $3.6 \%$ \\
\hline AWD/8cyl/Gas & $0.1 \%$ & $0.4 \%$ & $0.3 \%$ & $0.3 \%$ & $0.7 \%$ & $2.7 \%$ \\
\hline AWD/10-12cyl/Gas & $0.0 \%$ & $0.0 \%$ & $0.0 \%$ & $0.0 \%$ & $0.0 \%$ & $0.1 \%$ \\
\hline 4WD+RWD/4cyl/Gas & $3.8 \%$ & $4.0 \%$ & $3.0 \%$ & $2.5 \%$ & $1.5 \%$ & $0.4 \%$ \\
\hline 4WD+RWD/5-6cyl/Gas & $8.8 \%$ & $5.6 \%$ & $5.0 \%$ & $4.3 \%$ & $4.3 \%$ & $1.0 \%$ \\
\hline $\begin{array}{l}\text { Total U.S. PCLDT1 } \\
\text { Long }\end{array}$ & $100.0 \%$ & $100.0 \%$ & $100.0 \%$ & $100.0 \%$ & $100.0 \%$ & $100.0 \%$ \\
\hline
\end{tabular}

Table 33 - California PCLDT1Registrations, Longitudinal Layout 1999-2003 Actual and 2009 Forecasted (Percent of Segment)

\begin{tabular}{|l|r|r|r|r|r|r|}
\hline \multicolumn{1}{|c|}{ Vehicle Summary } & \multicolumn{1}{c|}{1999} & \multicolumn{1}{c|}{2000} & \multicolumn{1}{c|}{2001} & \multicolumn{1}{c|}{2002} & \multicolumn{1}{c|}{2003} & \multicolumn{1}{c|}{2009} \\
\hline RWD/4cyl/Gas & $21.2 \%$ & $17.3 \%$ & $12.8 \%$ & $13.6 \%$ & $14.2 \%$ & $13.0 \%$ \\
\hline RWD/5-6cyl/Gas & $37.7 \%$ & $38.3 \%$ & $46.9 \%$ & $48.2 \%$ & $51.2 \%$ & $53.1 \%$ \\
\hline RWD/8cyl/Gas & $23.3 \%$ & $23.3 \%$ & $24.5 \%$ & $24.4 \%$ & $21.9 \%$ & $20.0 \%$ \\
\hline RWD/10-12cyl/Gas & $0.2 \%$ & $0.3 \%$ & $0.4 \%$ & $0.2 \%$ & $0.3 \%$ & $2.0 \%$ \\
\hline RWD/4cyl/Flex & $0.0 \%$ & $2.6 \%$ & $2.4 \%$ & $1.6 \%$ & $0.0 \%$ & $0.0 \%$ \\
\hline RWD/6cyl/Flex & $6.5 \%$ & $6.1 \%$ & $1.5 \%$ & $1.2 \%$ & $2.4 \%$ & $0.2 \%$ \\
\hline RWD/6cyl/Diesel & $0.1 \%$ & $0.0 \%$ & $0.0 \%$ & $0.0 \%$ & $0.0 \%$ & $0.2 \%$ \\
\hline RWD/8cyl/Nat Gas & $0.0 \%$ & $0.1 \%$ & $0.0 \%$ & $0.1 \%$ & $0.1 \%$ & $0.1 \%$ \\
\hline RWD/Rotary/Gas & $0.0 \%$ & $0.0 \%$ & $0.0 \%$ & $0.0 \%$ & $0.4 \%$ & $0.8 \%$ \\
\hline AWD/3-4cyl/Gas & $5.2 \%$ & $5.1 \%$ & $6.0 \%$ & $6.1 \%$ & $5.3 \%$ & $5.8 \%$ \\
\hline AWD/5-6cyl/Gas & $0.3 \%$ & $0.9 \%$ & $1.4 \%$ & $1.3 \%$ & $1.1 \%$ & $1.8 \%$ \\
\hline AWD/8cyl/Gas & $0.1 \%$ & $0.3 \%$ & $0.3 \%$ & $0.2 \%$ & $0.3 \%$ & $1.7 \%$ \\
\hline AWD/10-12cyl/Gas & $0.0 \%$ & $0.0 \%$ & $0.0 \%$ & $0.0 \%$ & $0.0 \%$ & $0.1 \%$ \\
\hline 4WD+RWD/4cyl/Gas & $1.5 \%$ & $1.8 \%$ & $1.4 \%$ & $0.8 \%$ & $0.5 \%$ & $0.2 \%$ \\
\hline 4WD+RWD/6cyl/Gas & $3.8 \%$ & $3.8 \%$ & $2.3 \%$ & $2.3 \%$ & $2.2 \%$ & $1.0 \%$ \\
\hline Total CA PCLDT1 Long & $100.0 \%$ & $100.0 \%$ & $100.0 \%$ & $100.0 \%$ & $100.0 \%$ & $100.0 \%$ \\
\hline
\end{tabular}


Table 34 - U.S. LDT2 Registrations, Longitudinal Layout 1999-2003 Actual and 2009 Forecasted (Percent of Segment)

\begin{tabular}{|l|r|r|r|r|r|r|}
\hline \multicolumn{1}{|c|}{ Vehicle Summary } & 1999 & \multicolumn{1}{c|}{2000} & 2001 & \multicolumn{1}{c|}{2002} & \multicolumn{1}{c|}{2003} & \multicolumn{1}{c|}{2009} \\
\hline RWD/4cyl/Gas & $1.5 \%$ & $1.5 \%$ & $1.0 \%$ & $0.7 \%$ & $0.5 \%$ & $0.1 \%$ \\
\hline RWD/6cyl/Gas & $17.8 \%$ & $18.0 \%$ & $17.2 \%$ & $16.6 \%$ & $13.9 \%$ & $11.6 \%$ \\
\hline RWD/8cyl/Gas & $22.0 \%$ & $22.8 \%$ & $23.2 \%$ & $21.1 \%$ & $21.2 \%$ & $19.6 \%$ \\
\hline RWD/10cyl/Gas & $0.6 \%$ & $0.6 \%$ & $0.5 \%$ & $0.3 \%$ & $0.2 \%$ & $0.0 \%$ \\
\hline RWD/4cyl/Diesel & $0.0 \%$ & $0.0 \%$ & $0.0 \%$ & $0.0 \%$ & $0.0 \%$ & $0.5 \%$ \\
\hline RWD/6cyl/Diesel & $0.3 \%$ & $0.3 \%$ & $0.3 \%$ & $0.2 \%$ & $0.4 \%$ & $1.0 \%$ \\
\hline RWD/8cyl/Diesel & $1.4 \%$ & $1.4 \%$ & $1.4 \%$ & $1.1 \%$ & $1.0 \%$ & $1.5 \%$ \\
\hline RWD/6cyl/Flex & $0.0 \%$ & $0.2 \%$ & $0.1 \%$ & $0.6 \%$ & $1.6 \%$ & $2.0 \%$ \\
\hline RWD/8cyl/Flex & $0.0 \%$ & $0.0 \%$ & $0.4 \%$ & $2.3 \%$ & $2.3 \%$ & $2.0 \%$ \\
\hline RWD/8cyl/Nat Gas & $0.0 \%$ & $0.0 \%$ & $0.0 \%$ & $0.0 \%$ & $0.0 \%$ & $0.0 \%$ \\
\hline RWD/10cyl/Propane & $0.0 \%$ & $0.0 \%$ & $0.0 \%$ & $0.0 \%$ & $0.0 \%$ & $0.0 \%$ \\
\hline AWD/4cyl/Gas & $0.0 \%$ & $0.0 \%$ & $0.0 \%$ & $0.0 \%$ & $0.2 \%$ & $0.3 \%$ \\
\hline AWD/6cyl/Gas & $1.9 \%$ & $2.2 \%$ & $2.6 \%$ & $2.8 \%$ & $3.3 \%$ & $5.9 \%$ \\
\hline AWD/8cyl/Gas & $2.5 \%$ & $2.7 \%$ & $2.8 \%$ & $3.2 \%$ & $5.2 \%$ & $9.1 \%$ \\
\hline AWD/6cyl/Flex & $0.0 \%$ & $0.0 \%$ & $0.0 \%$ & $0.1 \%$ & $0.4 \%$ & $0.1 \%$ \\
\hline 4WD+RWD/4cyl/Gas & $0.8 \%$ & $0.6 \%$ & $0.4 \%$ & $0.3 \%$ & $0.3 \%$ & $0.1 \%$ \\
\hline 4WD+RWD/5-6cyl/Gas & $18.5 \%$ & $18.3 \%$ & $19.0 \%$ & $19.1 \%$ & $15.5 \%$ & $13.0 \%$ \\
\hline 4WD+RWD/8cyl/Gas & $27.3 \%$ & $25.8 \%$ & $25.0 \%$ & $21.8 \%$ & $22.2 \%$ & $20.0 \%$ \\
\hline 4WD+RWD/10cyl/Gas & $0.9 \%$ & $1.1 \%$ & $0.9 \%$ & $0.7 \%$ & $0.5 \%$ & $0.3 \%$ \\
\hline 4WD+RWD/6cyl/Diesel & $0.8 \%$ & $0.9 \%$ & $0.8 \%$ & $0.7 \%$ & $1.1 \%$ & $1.7 \%$ \\
\hline 4WD+RWD/8cyl/Diesel & $2.5 \%$ & $2.7 \%$ & $3.6 \%$ & $3.8 \%$ & $4.1 \%$ & $7.4 \%$ \\
\hline 4WD+RWD/6cyl/Flex & $1.2 \%$ & $1.1 \%$ & $0.1 \%$ & $1.0 \%$ & $2.5 \%$ & $0.8 \%$ \\
\hline 4WD+RWD/8cyl/Flex & $0.0 \%$ & $0.0 \%$ & $0.6 \%$ & $3.5 \%$ & $3.7 \%$ & $2.0 \%$ \\
\hline 4WD+RWD/10cyl/Propane & $0.0 \%$ & $0.0 \%$ & $0.0 \%$ & $0.0 \%$ & $0.0 \%$ & $0.0 \%$ \\
\hline Long/4WD/8cyl/HEV/Gas & $\mathrm{N} / \mathrm{A}$ & $\mathrm{N} / \mathrm{A}$ & $\mathrm{N} / \mathrm{A}$ & $\mathrm{N} / \mathrm{A}$ & $\mathrm{N} / \mathrm{A}$ & $1.0 \%$ \\
\hline Total U.S. LDT2 Long & $100.0 \%$ & $100.0 \%$ & $100.0 \%$ & $100.0 \%$ & $100.0 \%$ & $100.0 \%$ \\
\hline
\end{tabular}


Table 35 - California LDT2 Registrations, Longitudinal Layout 1999-2003 Actual and 2009 Forecasted (Percent of Segment)

\begin{tabular}{|l|r|r|r|r|r|r|}
\hline \multicolumn{1}{|c|}{ Vehicle Summary } & 1999 & 2000 & \multicolumn{1}{c|}{2001} & 2002 & 2003 & \multicolumn{1}{c|}{2009} \\
\hline RWD/4cyl/Gas & $3.1 \%$ & $3.1 \%$ & $1.8 \%$ & $1.3 \%$ & $1.0 \%$ & $0.2 \%$ \\
\hline RWD/5-6cyl/Gas & $25.8 \%$ & $25.4 \%$ & $23.5 \%$ & $21.7 \%$ & $17.7 \%$ & $13.5 \%$ \\
\hline RWD/8cyl/Gas & $29.9 \%$ & $32.2 \%$ & $35.8 \%$ & $37.2 \%$ & $38.5 \%$ & $38.7 \%$ \\
\hline RWD/10cyl/Gas & $1.2 \%$ & $1.2 \%$ & $1.2 \%$ & $1.0 \%$ & $0.7 \%$ & $0.2 \%$ \\
\hline RWD/4cyl/Diesel & $0.0 \%$ & $0.0 \%$ & $0.0 \%$ & $0.0 \%$ & $0.0 \%$ & $0.1 \%$ \\
\hline RWD/5-6cyl/Diesel & $0.4 \%$ & $0.3 \%$ & $0.2 \%$ & $0.2 \%$ & $0.3 \%$ & $0.3 \%$ \\
\hline RWD/8cyl/Diesel & $1.2 \%$ & $1.2 \%$ & $1.3 \%$ & $1.3 \%$ & $1.5 \%$ & $1.3 \%$ \\
\hline RWD/6cyl/Flex & $0.0 \%$ & $0.0 \%$ & $0.0 \%$ & $1.0 \%$ & $2.9 \%$ & $1.2 \%$ \\
\hline RWD/8cyl/Flex & $0.0 \%$ & $0.0 \%$ & $0.0 \%$ & $0.0 \%$ & $0.4 \%$ & $0.5 \%$ \\
\hline RWD/8cyl/Nat Gas & $0.1 \%$ & $0.1 \%$ & $0.1 \%$ & $0.1 \%$ & $0.1 \%$ & $0.1 \%$ \\
\hline RWD/10cyl/Propane & $0.0 \%$ & $0.0 \%$ & $0.0 \%$ & $0.0 \%$ & $0.0 \%$ & $0.0 \%$ \\
\hline AWD/4cyl/Gas & $0.0 \%$ & $0.0 \%$ & $0.0 \%$ & $0.0 \%$ & $0.1 \%$ & $0.3 \%$ \\
\hline AWD/6cyl/Gas & $2.2 \%$ & $2.6 \%$ & $3.0 \%$ & $3.5 \%$ & $4.3 \%$ & $6.4 \%$ \\
\hline AWD/8cyl/Gas & $3.1 \%$ & $3.3 \%$ & $3.6 \%$ & $4.5 \%$ & $6.8 \%$ & $10.1 \%$ \\
\hline AWD/6cyl/Flex & $0.0 \%$ & $0.0 \%$ & $0.0 \%$ & $0.0 \%$ & $0.1 \%$ & $0.1 \%$ \\
\hline 4WD+RWD/4cyl/Gas & $0.4 \%$ & $0.3 \%$ & $0.2 \%$ & $0.2 \%$ & $0.2 \%$ & $0.0 \%$ \\
\hline 4WD+RWD/6cyl/Gas & $11.4 \%$ & $10.0 \%$ & $9.2 \%$ & $8.6 \%$ & $5.7 \%$ & $4.7 \%$ \\
\hline 4WD+RWD/8cyl/Gas & $17.9 \%$ & $16.8 \%$ & $16.3 \%$ & $14.9 \%$ & $13.8 \%$ & $12.0 \%$ \\
\hline 4WD+RWD/10cyl/Gas & $0.8 \%$ & $1.1 \%$ & $0.9 \%$ & $0.7 \%$ & $0.6 \%$ & $0.3 \%$ \\
\hline 4WD+RWD/6cyl/Diesel & $0.6 \%$ & $0.6 \%$ & $0.5 \%$ & $0.4 \%$ & $0.5 \%$ & $0.9 \%$ \\
\hline 4WD+RWD/8cyl/Diesel & $1.4 \%$ & $1.6 \%$ & $2.5 \%$ & $3.0 \%$ & $3.6 \%$ & $5.5 \%$ \\
\hline 4WD+RWD/6cyl/Flex & $0.5 \%$ & $0.2 \%$ & $0.0 \%$ & $0.3 \%$ & $1.0 \%$ & $0.5 \%$ \\
\hline 4WD+RWD/8cyl/Flex & $0.0 \%$ & $0.0 \%$ & $0.0 \%$ & $0.0 \%$ & $0.2 \%$ & $1.0 \%$ \\
\hline 4WD+RWD/10cyl/Propane & $0.0 \%$ & $0.0 \%$ & $0.0 \%$ & $0.0 \%$ & $0.0 \%$ & $0.1 \%$ \\
\hline Long/4WD/8cyl/HEV/Gas & $\mathrm{N} / \mathrm{A}$ & $\mathrm{N} / \mathrm{A}$ & $\mathrm{N} / \mathrm{A}$ & $\mathrm{N} / \mathrm{A}$ & $\mathrm{N} / \mathrm{A}$ & $2.0 \%$ \\
\hline Total CA LDT2 Long & $100.0 \%$ & $100.0 \%$ & $100.0 \%$ & $100.0 \%$ & $100.0 \%$ & $100.0 \%$ \\
\hline
\end{tabular}




\section{List of References}

Abe, Tomoya, Kenichi Nagahiro, Takatoshi Aoki, Hideki Minami, Masahiro Kikuchi, Seiichi Hosogai, Development of New 2.2-liter Turbocharged Diesel Engine for the EURO-IV Standards, 2004 SAE World Congress, SAE International, Warrendale, PA, March (2004-01-1316)

Anderson, Leonard, California Air Board Prepares to Vote on Car Emissions, Reuters, September 24, 2004

Bergquist, Gloria, Eloy Garcia, Automakers Report on Fuel Economy Progress to California Regulators, The Alliance of Automobile Manufacturers, July 7, 2004

Botti, Jean J., Carl E. Miller, Powertrains of the Future: Reducing the Impact of Transportation on the Environment, 1999 International Congress and Exposition, SAE International, Warrendale, PA, March

(1999-01-0991)

Christensen, Magnus, Bengt Johansson, Homogeneous Charge Compression Ignition With Water Injection, 1999 International Congress and Exposition, SAE International, Warrendale, PA, March (1999-01-0182)

Duval, M., Comparing the Benefits and Impacts of Hybrid Electric Vehicle Options for Compact Sedan and Sport Utility Vehicles. Electric Power Research Institute, July 2002

Eichlseder, Helmut, Eckard Baumann, Peter Müller, Stephan Rubbert, Gasoline Direct Injection - A Promising Engine Concept for Future Demands, SAE 2000 World Congress, SAE International, Warrendale, PA, March (2000-01-0248)

Flierl, R., M. Klüting, The Third Generation of Valvetrains - New Fully Variable Valvetrains for Throttle-Free Load Control, SAE 2000 World Congress, SAE International, Warrendale, PA, March (2000-01-1227)

Green, D.L., et. al., Future potential of Hybrid and Diesel Powertrains in the U.S. Light Duty Vehicle Market, Oak Ridge National Laboratory, 2004

Herrmuth, Holger, Thomas Cartus, Robert Ducellari, Otfried Derschmidt, Combined NOx and PM Exhaust Gas Aftertreatment Approaches for HSDI Diesel Engines, 2004 SAE World Congress, SAE International, Warrendale, PA, March (2004-01-1425)

Husted, Harry L., A Comparative Study of the Production Applications of Hybrid Electric Powertrains, 2003 Future Transportation Technology Conference, SAE International, Warrendale, PA, June (2003-01-2307)

Hammett, Patrick, et al. Fuel Saving technology and Facilities Conversion: Cost, Benefits and Incentives. Transportation Research Institute, The University of Michigan, Report Number 2005-1, November 2004

Järvi, likka, VAVACT-Variable Valve Actuation Mechanism, 2003 SAE World Congress, SAE International, Warrendale, PA, March (2003-01-0025) 


\section{References (continued)}

Kreuter, Peter, Peter Heuser, Joachim Reinicki-Murmann, Rüdiger Erz, Ulrich Peter, Oliver Böcker, Variable Valve Actuation - Switchable and Continuously Variable Valve Lifts, 2003 SAE World Congress, SAE International, Warrendale, PA, March (2003-010026)

Lancefield, Tim, Ian Methley, Ulf Räse, Thomas Kuhn, The Application of Variable Event Valve Timing to a Modern Diesel Engine, SAE 2000 World Congress, SAE International, Warrendale, PA, March(2000-01-1229)

Lave, Lester B., Heather L. MacLean, An Environmental-Economic Evaluation of Hybrid Electric and Other Advanced Vehicles, SAE International, Warrendale, PA (2001-013738)

Lave, Lester B., H. MacLean, R. Lankey, S. Joshi, F. McMichael, A. Horvath, C. Hendrickson, Life Cycle Inventories of Conventional and Alternative Automobile Fuel/Propulsion Systems: Summary and Conclusions, 2000 Total Life Cycle Conference and Exposition, SAE International, Warrendale, PA, April (2000-01-1504)

Manugistics, Statgraphics V5.1

McDonald, Joseph, Progress in the Development of Tier 2 Light-Duty Diesel Vehicles, 2004 SAE World Congress, SAE International, Warrendale, PA, March (2004-01-1791 Ogawa, Hirohisa, Masato Matsuki, Takahiro Eguchi, Development of a Power Train for the Hybrid Automobile - The Civic Hybrid, 2003 SAE World Congress, SAE International, Warrendale, PA, March(2003-01-0083)

New Auto Fuel Economy Regulation: Nothing In It For Californians, The Alliance of Automobile Manufacturers, September 23, 2004

Parvate-Patil, G. B., H. Hong, B. Gordon, An Assessment of Intake and Exhaust Philosophies for Variable Valve Timing, 2003 SAE/JSAE Small Engine Technology Conference \& Exhibition, SAE International, Warrendale, PA, (SAE2003-32-0078, JSAE 20034378)

Pierik, Ronald J., James F. Burkhard, Design and Development of a Mechanical Variable Valve Actuation System, SAE 2000 World Congress, SAE International, Warrendale, PA, March (2000-01-1221)

Pindyck, Robert S. and Rubinfeld, Daniel L. Economic Models and Economic Forecasts, $2^{\text {nd }}$ ed., McGraw Hill, New York, New York, 1981.

Plungis, Jeff, California Rules Costly, Say Carmakers, Detroit News Washington Bureau, September 23, 2004

Public Hearing to Consider Adoption of Regulations to Control Greenhouse Gas Emissions from Motor Vehicles, California Environmental Protection Agency Air Resources Board, September 23, 2004 


\section{References (Continued)}

Roberts, Martyn, Benefits and Challenges of Variable Compression Ratio (VCR), 2003 SAE World Congress, SAE International, Warrendale, PA, March (2003-01-0398)

Ronning, Jeffrey J., Gregory L. Grant, Global Hybrid Electric Vehicle Markets and Missions, 1999 Future Transportation Technology Conference and Exposition, SAE International, Warrendale, PA, August (1999-01-2946)

Schöffmann, W., F. Beste, R. Marquard, Lightweight Engine Design Strategies, 2000 Future Car Congress, SAE International, Warrendale, PA, April (2000-01-1546)

Schwaderlapp, Markus, Knut Habermann, Kurt I. Yapici, Variable Compression Ratio A Design Solution for Fuel Economy Concepts, SAE 2002 World Congress, SAE International, Warrendale, PA, March (2002-01-1103)

Sellnau, Mark, Eric Rask, Two-Step Variable Valve Actuation for Fuel Economy, Emissions, and Performance, 2003 SAE World Congress, SAE International, Warrendale, PA, March (2003-01-0029)

Spicher, U., J. Reissing, J. M. Kech, J. Gindele, Gasoline Direct Injection (GDI) Engines - Development Potentialities, 1999 Future Transportation Technology Conference and Exposition, SAE International, Warrendale, PA, August (1999-01-2938)

Stodolsky, Frank, Linda Gaines, Christopher L. Marshall, Feng An, James J. Eberhart, Total Fuel Cycle Impacts of Advanced Vehicles, 1999 International Congress and Exposition, SAE International, Warrendale, PA, March (1999-01-0322)

Sun, Ruonan, Rick Thomas, Charles L. Gray, Jr., An HCCI Engine: Power Plant for a Hybrid Vehicle, 2004 SAE World Congress, SAE International, Warrendale, PA, March (2004-01-0933)

Tai, Chun, Tsu-Chin Tsao, Norbert A. Schörn, Michael B. Levin, Increasing Torque Output From a Turbodiesel With Camless Valvetrain, SAE 2002 World Congress, SAE International, Warrendale, PA, March (2002-01-1108)

Trask, Nate R., Mazen Hammoud, Mohammad Haghgooie, Thomas W. Megli, Wen Dai, Optimization Techniques and Results for the Operating Modes of a Camless Engine, 2003 SAE World Congress, SAE International, Warrendale, PA, March (2003-01-0033)

Weiss et al., 2000, On the Road in 2020: A Life-Cycle Analysis of New Automobile Technologies, MIT Energy Laboratory Report No. MIT EL 00-003, Energy Laboratory, Massachusetts Institute of Technology, Cambridge, Mass., Oct.

Yu, R. C., A. S. Cole, B. J. Stroia, S. C. Huang, Ken Howden, Steve Chalk, Development of Diesel Exhaust Aftertreatment System for Tier II Emissions, 2002 Future Car Congress, SAE International, Warrendale, PA, June (2002-01-1867) 
Appendix I

Hybrid Electric Vehicle Layout:

Selected Vehicles Available in the U.S. Vehicle Market

Figure I.1: 2004 Honda Civic

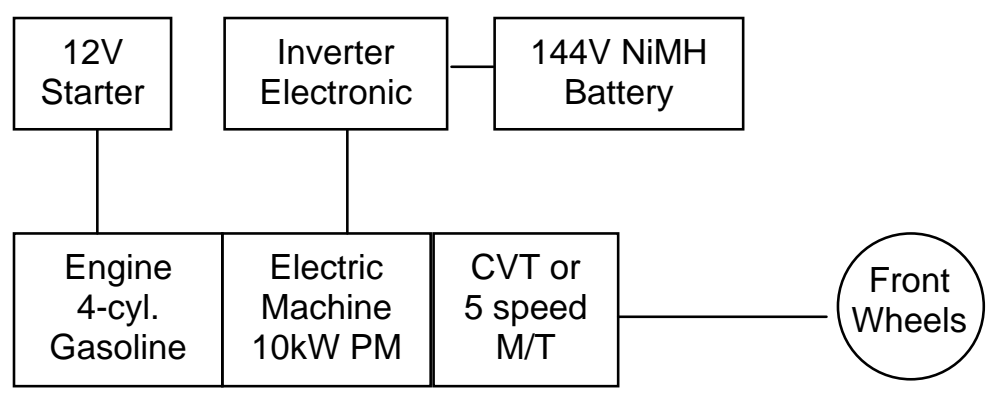

Figure I.2: 2005 Honda Accord

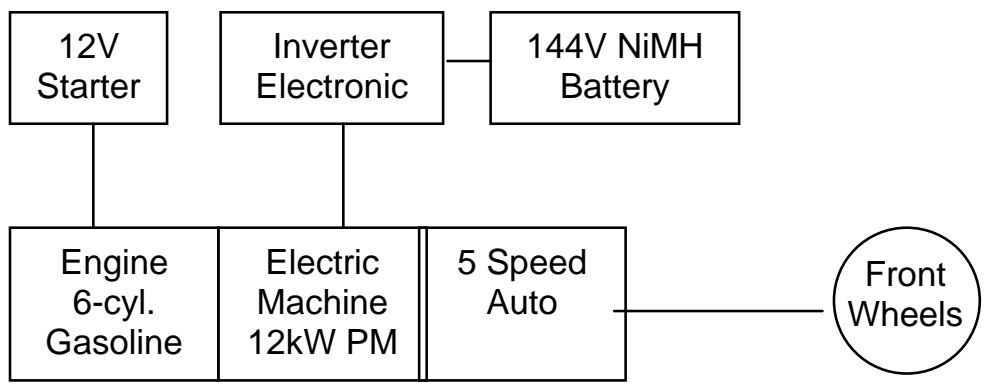

Figure I.3: 2000 Toyota Prius (THS I)

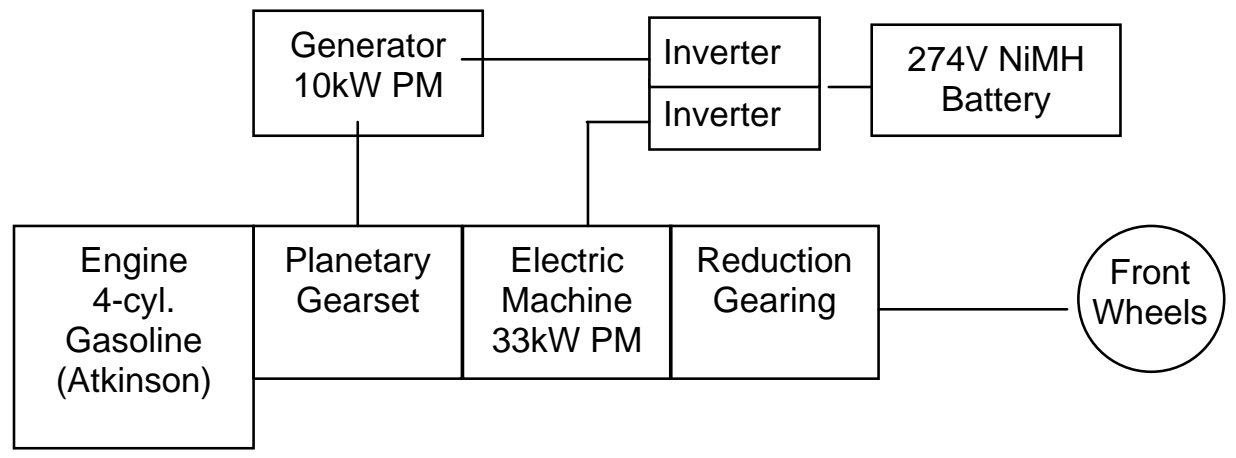


Figure I.4: 2004 Toyota Prius (THS II)

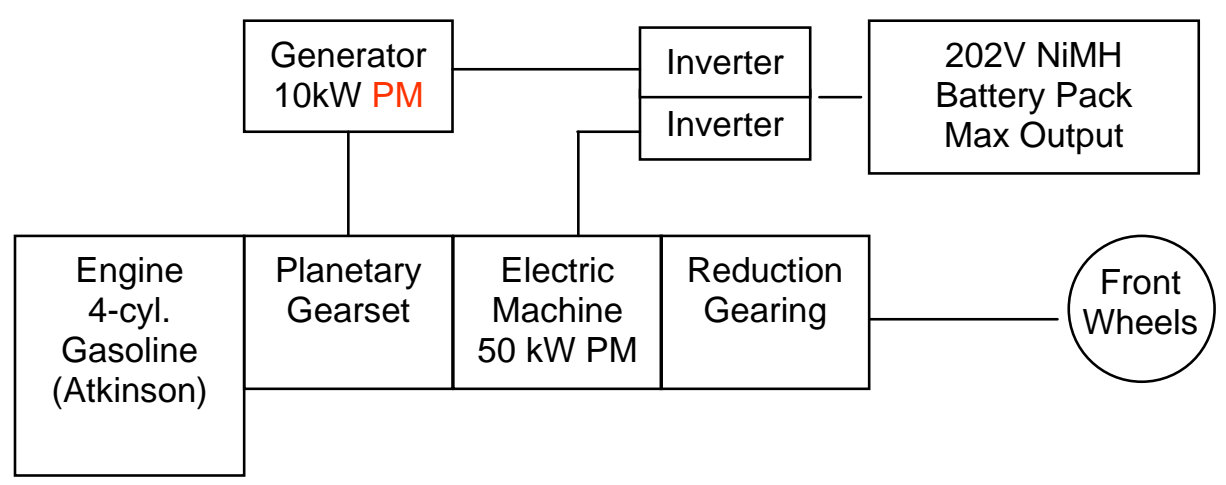

Figure I.5: 2005 Ford Escape

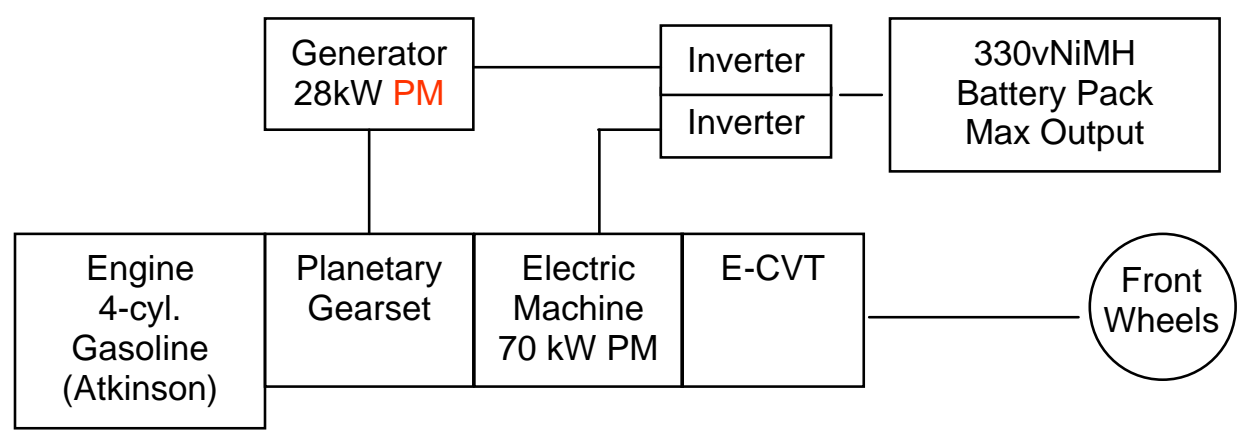

Figure I.6: 2006 Lexus 400h

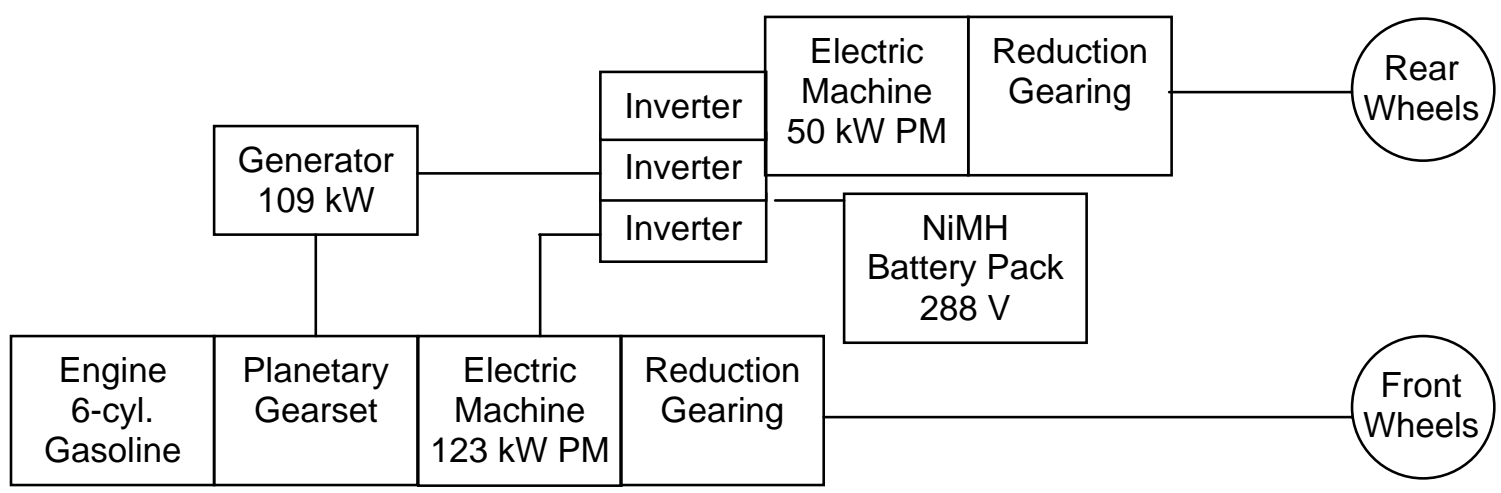


Figure I.7: 2005 General Motors Sierra / Chevrolet Silverado

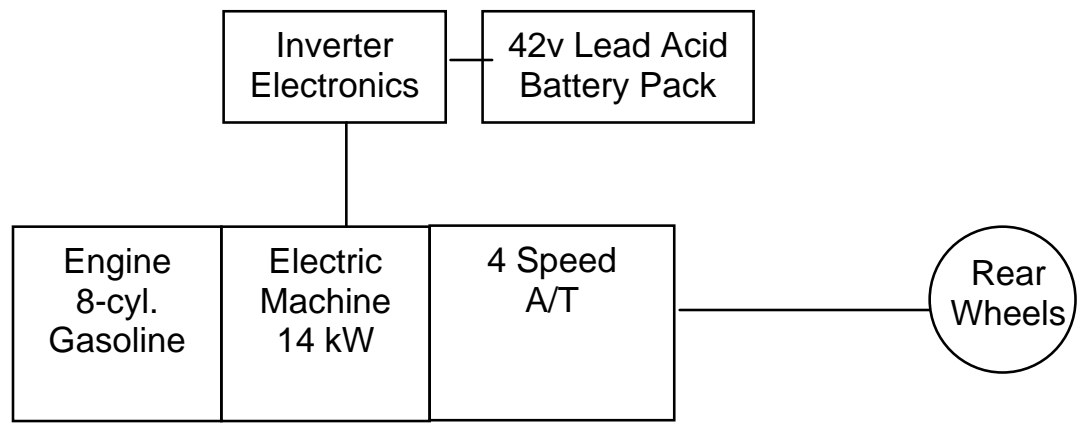

Figure I.8: General Motors Future SUV (AHS II) Expected

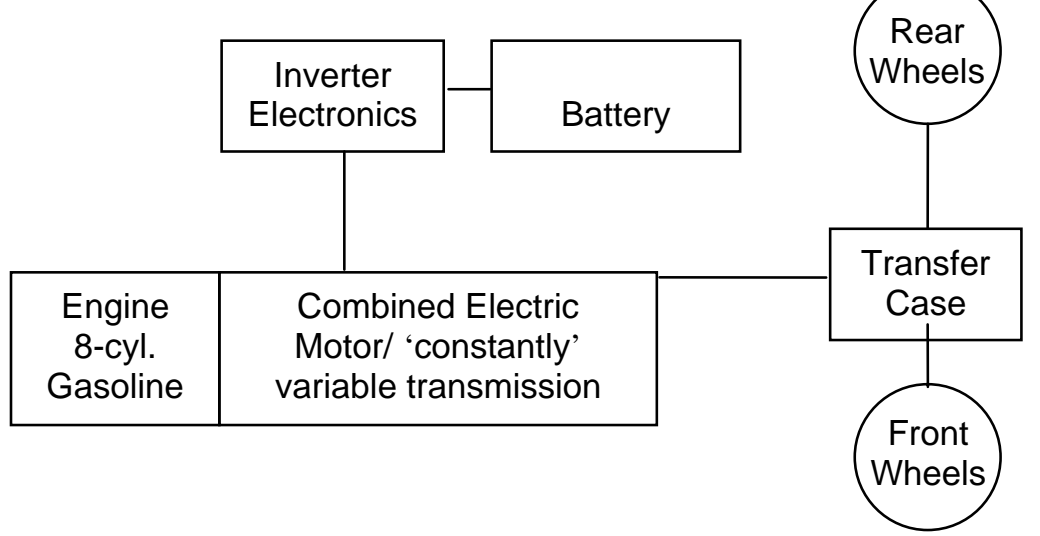




\section{Appendix II \\ The Honda IMA System - Converting ICE to HEV}

In 2002 Honda demonstrated that its hybrid system, initially developed for the Honda Insight, could be scaled to fit a Civic in a cost effective manner. Since then, the mid-sized Accord has been hybridized and a casual observer would be hard pressed to tell either of the two newest Honda hybrids from its traditional ICE base vehicles. Although Honda has made several technical improvements between the Civic Hybrid and Accord Hybrid, it is possible to show a generalized process of what must be done to an existing car to convert it into a hybrid electric vehicle by studying these two products.

Under the Hood (and the trunk)

Perhaps the most important part of Honda's hybrid system is the Integrated Motor Assist (IMA). The IMA is an electric motor positioned between the engine and transmission that adds power during acceleration by working in conjunction with the engine. The IMA also supplies power to restart the engine after an idle stop and acts as a generator during regenerative braking that sends power back to the car's battery. Because the IMA motor must fit between the engine and transmission, some modification is required to keep the total width the same as an engine and transmission combination in the base vehicle. In the case of the Civic, the new engine was sufficiently small $-1.3 \mathrm{~L}$ compared to $1.7 \mathrm{~L}$ in the base vehicle - to fit the IMA motor. The Accord however proved to be more challenging. Honda wanted to use a 3.0L engine and five speed automatic transmission as found in the base Accord. To accommodate the 68mm thick IMA motor the engine and transmission were designed to be thinner than those found in the base Accord.

Both the Civic and Accord Hybrids contain a version of cylinder deactivation, resulting in lower carbon dioxide emissions. The Civic utilizes the Cylinder Idling System (CIS) which reduces the engine's pumping losses by sealing the intake and exhaust valves of three cylinders when fuel flow is cut during deceleration. The Accord has a more advanced cylinder deactivation system known as Variable Cylinder Management (VCM). VCM allows the rear bank of three cylinders to shut off during various parts of the driving cycle, resulting in more fuel efficient three cylinder operation. The intake and exhaust valves are also sealed to keep pumping losses to a minimum.

The air conditioning system in the Accord Hybrid is also much more advanced than its gasoline only counterpart. The Accord Hybrid utilizes a dual scroll hybrid compressor to power its air conditioning system. This system allows for the air conditioning to run on mechanical power from the engine or electrical power from the battery. The major implication is that the air conditioner can now run while the vehicle is at idle stop, something that the system in the Civic Hybrid can not match. The lack of an advanced compressor in the Civic Hybrid may be attributable to the different target markets for the two vehicles. That is, the increase in price for a Civic Hybrid due to an advanced air conditioning system may make it too expensive for the intended market.

Another formerly belt driven system, power steering, has also been changed to run off of electricity in the two hybrids. In the conventional Accord and Civic power from the engine is utilized to keep hydraulic pressure at an acceptable level. This has been replaced with an electric motor which allows for steering operation during an idle stop 
period as well as relieving the load on the internal combustion engine, thus increasing fuel economy and reducing emissions.

The electrical handling system known as the IMA Intelligent Power Unit (IPU) consists of the battery pack, the power control unit, and an integrated cooling unit. The entire system is located behind the rear seat for both hybrid vehicles and consumes some of the base vehicle's trunk space. Both vehicles utilize a $144 \mathrm{v}$ battery which differs from the Toyota Hybrid System, in which each vehicle is designed with different batteries, and highlights Honda's effort to create a scaleable technology that can be applied throughout its lineup if so desired. The IPU electronics are located next to the battery and controls the flow of energy to and from the IMA motor. The cooling system uses air from the cabin in order to keep the electronics in a safe temperature range. As noted, the inclusion of these electronic components behind the rear bench reduces trunk space specifically from $12.9 \mathrm{ft}^{3}$ to $10.1 \mathrm{ft}^{3}$ for the Civic, and from $14 \mathrm{ft}^{3}$ to $11.2 \mathrm{ft}^{3}$ for the Accord. Since the battery put out $144 \mathrm{v}$ and many of the vehicles' systems run on the conventional $12 \mathrm{v}$, an inverter is also necessary in both the Accord Hybrid and Civic Hybrid.

\section{Body and Interior}

There are also several improvements made to the hybrid vehicle bodies to enhance fuel economy. Perhaps the most noticeable is the addition of a small lip spoiler to the trunk of each car. The spoiler, which is absent from both base vehicles, serves to reduce turbulence and thus improve aerodynamics. Wheels and tires also undergo a change. For the Civic Hybrid, low rolling resistance tires are used, however there are no such tires on the high performance Accord Hybrid - as they would detract from the driving experience. The Accord Hybrid does have unique aluminum wheels however which decrease carbon dioxide emissions by reducing weight. The Accord Hybrid also makes use of aluminum on the hood, rear knuckle, and bumper beam to further reduce weight. It is unlikely that these aluminum components will find their way onto the Civic Hybrid as they may increase the cost of the vehicle by an unacceptable amount for the segment. The Accord Hybrid also reduces weight by eliminating the spare tire and replacing it with an Instant Mobility System - a kit consisting of tire sealant and a pump.

Both interiors remain relatively unchanged, the most noticeable difference is a new instrument cluster which has a gauge showing that the driver is either using power from the IMA during acceleration or recharging the battery during braking. The Accord Hybrid also uses a novel solution to deal with the added noise shutting off a bank of cylinders on a V6 produces. The system known as Active Noise Control (ANC) uses two microphones in the cabin to detect the specific "booming" noise from the engine during three cylinder operation and then emits an audio signal through the audio system with the opposite wave which effectively cancels out the noise. The system only responds to booming and will not cancel out conversations or other noise created in the cabin. The Civic Hybrid has no need for this system as there is no mechanical cylinder. 


\section{Appendix III}

Logit Model Results:

Level 1: Total Market-PCLDT1 and Light Trucks (2) and

Level 2: Transverse and Longitudinal Drivetrain for PCLDT1 and Light Trucks (2)

\section{Level 1 U.S. and California Market Forecasts}

Logit Model Statistics

$\begin{array}{lrr}\text { Parameter } & \text { Estimate } & \text { P-Value } \\ \text { CONSTANT } & 101.912 & 0.0000 \\ \text { us_ca } & 0.162 & 0.0002 \\ \text { Year } & -0.0508 & 0.0000\end{array}$

\begin{tabular}{|c|c|c|c|c|c|}
\hline \multicolumn{6}{|c|}{ Table II.1 Model Data: Total Market: PCLDT1 and LDT2 (2) } \\
\hline Year & $\begin{array}{c}\text { California } \\
\text { (CA) and } \\
\text { United } \\
\text { States } \\
\text { (US) }\end{array}$ & $\begin{array}{c}\text { Sold } \\
\text { (PCLDT1 } \\
\text { only) }\end{array}$ & $\begin{array}{c}\text { Sample } \\
\text { Size } \\
\text { (PCLDT1 + } \\
\text { LDT2) }\end{array}$ & $\begin{array}{l}\text { Percent } \\
\text { PCLDT1 }\end{array}$ & $\begin{array}{l}\text { Response } \\
\text { Variables }\end{array}$ \\
\hline 1999 & $\mathrm{CA}$ & $1,147,373$ & $1,831,953$ & 0.626 & 0.545 \\
\hline 1999 & US & $9,790,626$ & $16,583,488$ & 0.590 & 0.383 \\
\hline 2000 & $\mathrm{CA}$ & $1,264,171$ & $2,047,490$ & 0.617 & 0.494 \\
\hline 2000 & US & $10,239,429$ & $17,532,348$ & 0.584 & 0.332 \\
\hline 2001 & $\mathrm{CA}$ & $1,237,658$ & $2,018,113$ & 0.613 & 0.443 \\
\hline 2001 & US & $9,806,506$ & $16,967,214$ & 0.578 & 0.281 \\
\hline 2002 & $\mathrm{CA}$ & $1,201,564$ & $2,013,651$ & 0.597 & 0.392 \\
\hline 2002 & US & $9,242,741$ & $16,620,485$ & 0.556 & 0.231 \\
\hline 2003 & $\mathrm{CA}$ & $1,180,615$ & $1,998,898$ & 0.591 & 0.342 \\
\hline 2003 & US & $8,979,911$ & $16,613,357$ & 0.541 & 0.180 \\
\hline 2004 & $\mathrm{CA}$ & & $2,050,950$ & & 0.291 \\
\hline 2004 & US & & $16,925,000$ & & 0.129 \\
\hline 2005 & $\mathrm{CA}$ & & $2,075,150$ & & 0.240 \\
\hline 2005 & US & & $17,150,000$ & & 0.078 \\
\hline 2006 & CA & & $2,105,400$ & & 0.189 \\
\hline 2006 & US & & $17,400,000$ & & 0.027 \\
\hline 2007 & $\mathrm{CA}$ & & $2,159,400$ & & 0.138 \\
\hline 2007 & US & & $17,700,000$ & & -0.023 \\
\hline 2008 & $\mathrm{CA}$ & & $2,171,600$ & & 0.088 \\
\hline 2008 & US & & $17,800,000$ & & -0.074 \\
\hline 2009 & $\mathrm{CA}$ & & $2,201,700$ & & 0.037 \\
\hline 2009 & US & & $17,850,000$ & & -0.125 \\
\hline
\end{tabular}




\begin{tabular}{|c|c|c|c|c|}
\hline \multicolumn{5}{|c|}{ Table II.2 Model Predictions: PCLDT1 and LDT2 (2) Sales } \\
\hline Year & $\begin{array}{c}\text { California } \\
\text { (CA) and } \\
\text { United } \\
\text { States } \\
\text { (US) }\end{array}$ & Estimate & $\begin{array}{c}\text { PCLDT1 } \\
\text { PREDICTION }\end{array}$ & $\begin{array}{c}\text { LDT2 } \\
\text { PREDICTION }\end{array}$ \\
\hline 1999 & CA & 0.633 & $1,159,491$ & 672,462 \\
\hline 1999 & US & 0.595 & $9,859,996$ & $6,723,492$ \\
\hline 2000 & $\mathrm{CA}$ & 0.621 & $1,271,590$ & 775,900 \\
\hline 2000 & US & 0.582 & $10,208,514$ & $7,323,834$ \\
\hline 2001 & CA & 0.609 & $1,229,079$ & 789,034 \\
\hline 2001 & US & 0.570 & $9,669,012$ & $7,298,202$ \\
\hline 2002 & CA & 0.597 & $1,201,878$ & 811,773 \\
\hline 2002 & US & 0.557 & $9,263,813$ & $7,356,672$ \\
\hline 2003 & CA & 0.585 & $1,168,529$ & 830,369 \\
\hline 2003 & US & 0.545 & $9,051,106$ & $7,562,251$ \\
\hline 2004 & CA & 0.572 & $1,173,557$ & 877,393 \\
\hline 2004 & US & 0.532 & $9,007,272$ & $7,917,728$ \\
\hline 2005 & CA & 0.560 & $1,161,515$ & 913,635 \\
\hline 2005 & US & 0.520 & $8,909,846$ & $8,240,154$ \\
\hline 2006 & CA & 0.547 & $1,152,021$ & 953,379 \\
\hline 2006 & US & 0.507 & $8,818,956$ & $8,581,044$ \\
\hline 2007 & $\mathrm{CA}$ & 0.535 & $1,154,334$ & $1,005,066$ \\
\hline 2007 & US & 0.494 & $8,746,274$ & $8,953,726$ \\
\hline 2008 & CA & 0.522 & $1,133,371$ & $1,038,229$ \\
\hline 2008 & US & 0.481 & $8,569,819$ & $9,230,181$ \\
\hline 2009 & $\mathrm{CA}$ & 0.509 & $1,121,153$ & $1,080,547$ \\
\hline 2009 & US & 0.469 & $8,367,815$ & $9,482,185$ \\
\hline
\end{tabular}

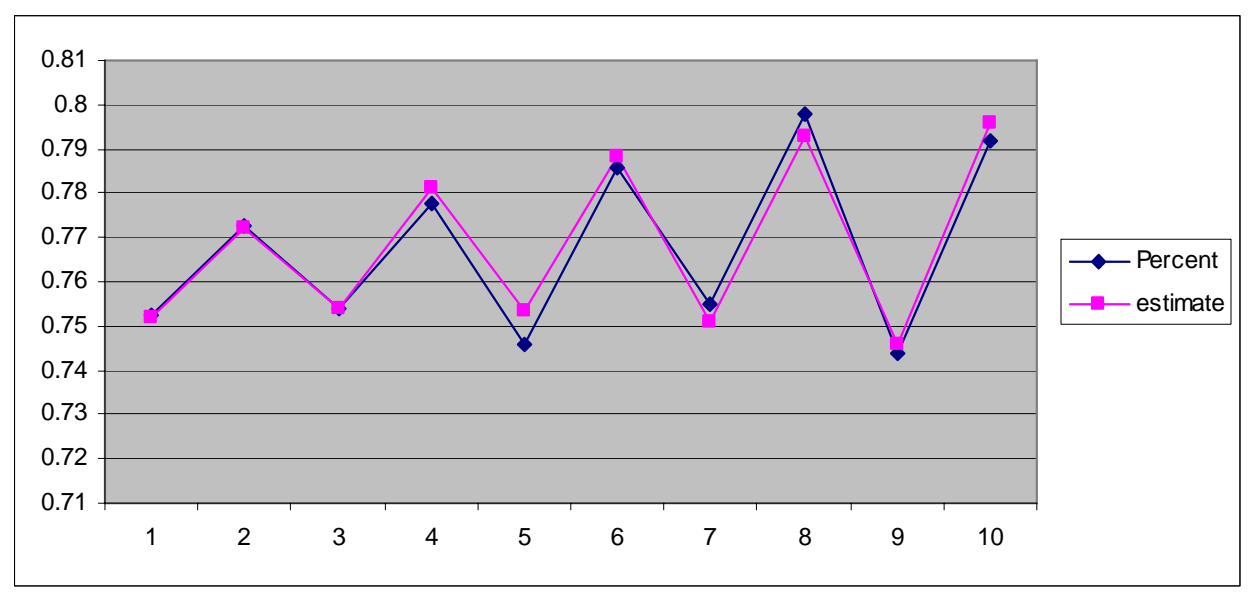




\section{Level 1 U.S. and California Market Forecasts}

\section{A. PCLDT1}

Logit Model Statistics

$\begin{array}{lrr}\text { Parameter } & \text { Estimate } & \text { P-Value } \\ \text { CONSTANT } & -58.274 & 0.0085 \\ \text { us_ca } & -0.197 & 0.0077 \\ \text { Year } & 0.0298 & 0.0007\end{array}$

\begin{tabular}{|c|c|c|c|c|c|}
\hline \multicolumn{6}{|c|}{ Table II.3 Model Data: PCLDT1, Transverse and Longitudinal } \\
\hline Year & $\begin{array}{c}\text { California } \\
\text { (CA) and } \\
\text { United } \\
\text { States } \\
\text { (US) }\end{array}$ & $\begin{array}{c}\text { Sold } \\
\text { (PCLDT1 } \\
\text { Transverse } \\
\text { only) }\end{array}$ & $\begin{array}{c}\text { Sample } \\
\text { Size } \\
\text { (Transverse + } \\
\text { Longitudinal) }\end{array}$ & Percent & $\begin{array}{l}\text { Response } \\
\text { Variables }\end{array}$ \\
\hline 1999 & CA & 863,087 & $1,147,373$ & 0.752 & 1.039 \\
\hline 1999 & US & $7,565,325$ & $9,790,626$ & 0.773 & 1.236 \\
\hline 2000 & $\mathrm{CA}$ & 952,966 & $1,264,171$ & 0.754 & 1.069 \\
\hline 2000 & US & $7,961,429$ & $10,239,429$ & 0.778 & 1.266 \\
\hline 2001 & $\mathrm{CA}$ & 923,237 & $1,237,658$ & 0.746 & 1.099 \\
\hline 2001 & US & $7,704,923$ & $9,806,506$ & 0.786 & 1.296 \\
\hline 2002 & $\mathrm{CA}$ & 906,979 & $1,201,564$ & 0.755 & 1.129 \\
\hline 2002 & US & $7,374,269$ & $9,242,741$ & 0.798 & 1.326 \\
\hline 2003 & $\mathrm{CA}$ & 878,029 & $1,180,615$ & 0.744 & 1.158 \\
\hline 2003 & US & $7,111,723$ & $8,979,911$ & 0.792 & 1.355 \\
\hline 2004 & CA & & $1,173,557$ & & 1.188 \\
\hline 2004 & US & & $9,007,272$ & & 1.385 \\
\hline 2005 & $\mathrm{CA}$ & & $1,161,515$ & & 1.218 \\
\hline 2005 & US & & $8,909,846$ & & 1.415 \\
\hline 2006 & $\mathrm{CA}$ & & $1,152,021$ & & 1.248 \\
\hline 2006 & US & & $8,818,956$ & & 1.445 \\
\hline 2007 & $\mathrm{CA}$ & & $1,154,334$ & & 1.277 \\
\hline 2007 & US & & $8,746,274$ & & 1.474 \\
\hline 2008 & $\mathrm{CA}$ & & $1,133,371$ & & 1.307 \\
\hline 2008 & US & & $8,569,819$ & & 1.504 \\
\hline 2009 & $\mathrm{CA}$ & & $1,121,153$ & & 1.337 \\
\hline 2009 & US & & $8,367,815$ & & 1.534 \\
\hline
\end{tabular}




\begin{tabular}{|r|r|r|r|r|}
\hline \multicolumn{5}{|c|}{$\begin{array}{c}\text { Table II.4 Model Predictions: PCLDT1, Transverse and } \\
\text { Longitudinal }\end{array}$} \\
Year & $\begin{array}{c}\text { California } \\
\text { (CA) and } \\
\text { (US) }\end{array}$ & $\begin{array}{c}\text { Transverse } \\
\text { Share } \\
\text { Estimate }\end{array}$ & \multicolumn{1}{c|}{ Transverse } & Longitudinal \\
\hline 1999 & CA & 0.739 & 847,581 & 299,792 \\
\hline 1999 & US & 0.775 & $7,586,997$ & $2,203,629$ \\
\hline 2000 & CA & 0.744 & 941,073 & 323,098 \\
\hline 2000 & US & 0.780 & $7,987,516$ & $2,251,913$ \\
\hline 2001 & CA & 0.750 & 928,295 & 309,363 \\
\hline 2001 & US & 0.785 & $7,699,471$ & $2,107,035$ \\
\hline 2002 & CA & 0.756 & 907,880 & 293,684 \\
\hline 2002 & US & 0.790 & $7,302,861$ & $1,939,880$ \\
\hline 2003 & CA & 0.761 & 898,492 & 282,123 \\
\hline 2003 & US & 0.795 & $7,139,143$ & $1,840,768$ \\
\hline 2004 & CA & 0.766 & 899,425 & 274,132 \\
\hline 2004 & US & 0.800 & $7,204,211$ & $1,803,062$ \\
\hline 2005 & CA & 0.772 & 896,337 & 265,178 \\
\hline 2005 & US & 0.805 & $7,168,376$ & $1,741,470$ \\
\hline 2006 & CA & 0.777 & 895,004 & 257,017 \\
\hline 2006 & US & 0.809 & $7,136,162$ & $1,682,794$ \\
\hline 2007 & CA & 0.782 & 902,708 & 251,626 \\
\hline 2007 & US & 0.814 & $7,117,182$ & $1,629,092$ \\
\hline 2008 & CA & 0.787 & 892,018 & 241,353 \\
\hline 2008 & US & 0.818 & $7,011,902$ & $1,557,917$ \\
\hline 2009 & CA & 0.792 & 887,948 & 233,205 \\
\hline 2009 & US & 0.823 & $6,883,323$ & $1,484,492$ \\
\hline
\end{tabular}

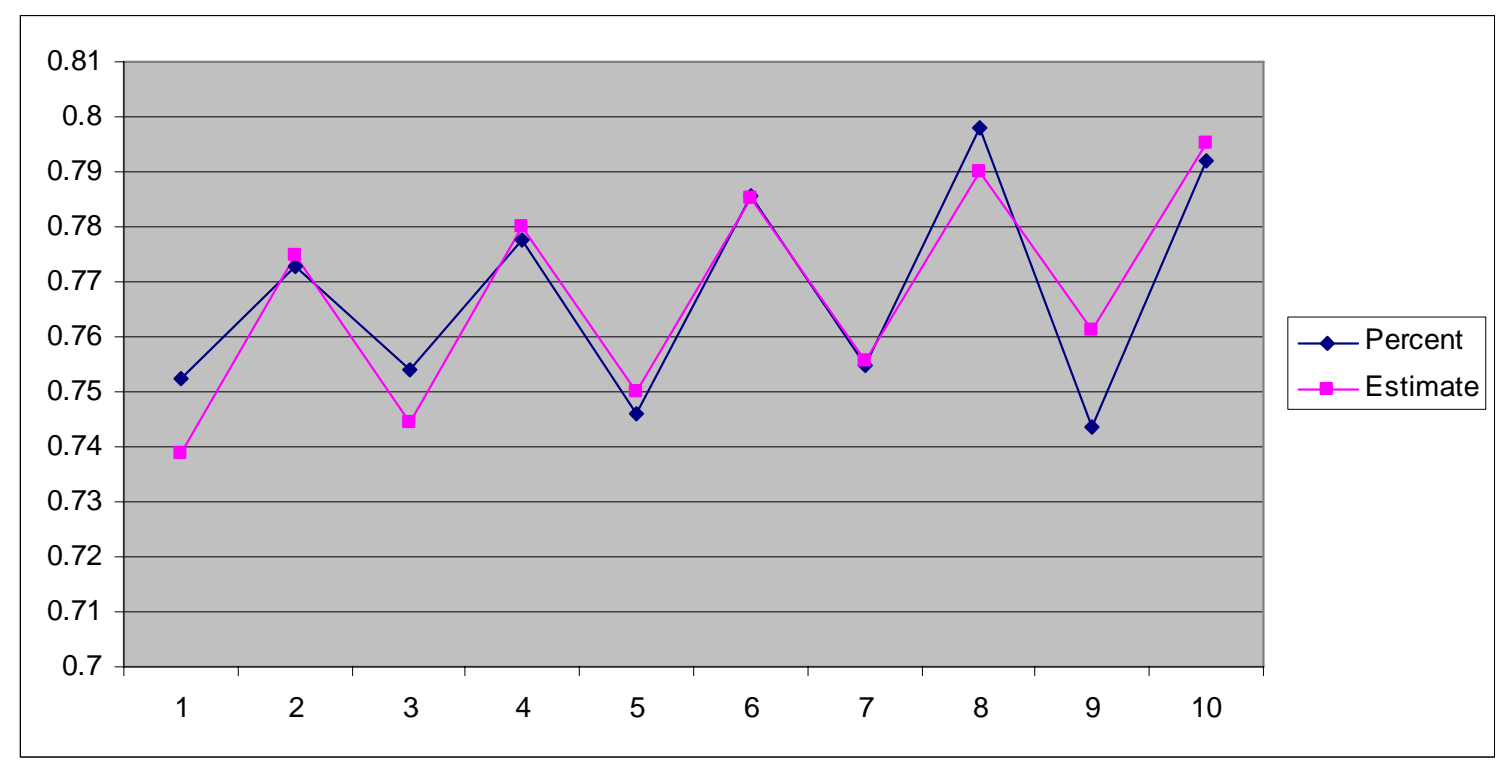


B. LDT2 (2)

Logit Model Statistics

Parameter

CONSTANT

us_ca

Year

$\begin{array}{cr}\text { Estimate } & \text { P-Value } \\ -123.896 & 0.000 \\ -0.00387 & 0.874 \\ 0.0612 & 0.000\end{array}$

\begin{tabular}{|l|c|r|r|r|r|}
\hline \multicolumn{7}{|c|}{ Table II.5 Model Data :LDT2 (2), Transverse and Longitudinal } \\
\hline & $\begin{array}{c}\text { California (CA) } \\
\text { and } \\
\text { United States } \\
\text { Year }\end{array}$ & $\begin{array}{c}\text { Sold } \\
\text { (transverse } \\
\text { of LTD2 } \\
\text { ONLY) }\end{array}$ & $\begin{array}{c}\text { Sample } \\
\text { Size } \\
\text { (all LDT2) }\end{array}$ & $\begin{array}{c}\text { Percent of } \\
\text { LDT2 that is } \\
\text { Transverse }\end{array}$ & $\begin{array}{c}\text { Response } \\
\text { Variables }\end{array}$ \\
\hline 1999 & CA & 131,552 & 684,580 & 0.192 & -1.473 \\
\hline 1999 & US & $1,286,048$ & $6,792,862$ & 0.189 & -1.473 \\
\hline 2000 & CA & 153,910 & 783,319 & 0.196 & -1.412 \\
\hline 2000 & US & $1,435,989$ & $7,292,919$ & 0.197 & -1.412 \\
\hline 2001 & CA & 151,293 & 780,455 & 0.194 & -1.350 \\
\hline 2001 & US & $1,453,201$ & $7,160,708$ & 0.203 & -1.350 \\
\hline 2002 & CA & 176,551 & 812,087 & 0.217 & -1.289 \\
\hline 2002 & US & $1,585,312$ & $7,377,744$ & 0.215 & -1.289 \\
\hline 2003 & CA & 189,250 & 818,283 & 0.231 & -1.228 \\
\hline 2003 & US & $1,757,126$ & $7,633,446$ & 0.230 & -1.228 \\
\hline $\mathbf{2 0 0 4}$ & CA & & $\mathbf{8 7 7 , 3 9 3}$ & & $\mathbf{- 1 . 1 6 7}$ \\
\hline $\mathbf{2 0 0 4}$ & US & & $\mathbf{7 , 9 1 7 , 7 2 8}$ & & $\mathbf{- 1 . 1 6 7}$ \\
\hline $\mathbf{2 0 0 5}$ & CA & & $\mathbf{9 1 3 , 6 3 5}$ & & $\mathbf{- 1 . 1 0 5}$ \\
\hline $\mathbf{2 0 0 5}$ & US & & $\mathbf{8 , 2 4 0 , 1 5 4}$ & & $\mathbf{- 1 . 1 0 5}$ \\
\hline $\mathbf{2 0 0 6}$ & CA & & $\mathbf{9 5 3 , 3 7 9}$ & & $\mathbf{- 1 . 0 4 4}$ \\
\hline $\mathbf{2 0 0 6}$ & US & & $\mathbf{8 , 5 8 1 , 0 4 4}$ & & $\mathbf{- 1 . 0 4 4}$ \\
\hline $\mathbf{2 0 0 7}$ & CA & & $\mathbf{1 , 0 0 5 , 0 6 6}$ & & $\mathbf{- 0 . 9 8 3}$ \\
\hline $\mathbf{2 0 0 7}$ & US & & $\mathbf{8 , 9 5 3 , 7 2 6}$ & & $\mathbf{- 0 . 9 8 3}$ \\
\hline $\mathbf{2 0 0 8}$ & CA & & $\mathbf{1 , 0 3 8 , 2 2 9}$ & & $\mathbf{- 0 . 9 2 2}$ \\
\hline $\mathbf{2 0 0 8}$ & US & & $\mathbf{9 , 2 3 0 , 1 8 1}$ & & $\mathbf{- 0 . 9 2 2}$ \\
\hline $\mathbf{2 0 0 9}$ & CA & & $\mathbf{1 , 0 8 0 , 5 4 7}$ & & $\mathbf{- 0 . 8 6 0}$ \\
\hline $\mathbf{2 0 0 9}$ & US & & $\mathbf{9 , 4 8 2 , 1 8 5}$ & & $\mathbf{- 0 . 8 6 0}$ \\
\hline
\end{tabular}




\begin{tabular}{|r|r|r|r|r|}
\hline \multicolumn{5}{|c|}{ Table II.6 Model Predictions: LDT2 (2), Transverse and Longitudinal } \\
\hline Year & $\begin{array}{c}\text { California (CA) } \\
\text { and } \\
\text { United States } \\
\text { (US) }\end{array}$ & $\begin{array}{c}\text { Transverse } \\
\text { Share } \\
\text { Estimate } \\
\text { (of LDT2) }\end{array}$ & \multicolumn{1}{c|}{ Transverse } & Longitudinal \\
\hline 1999 & CA & 0.187 & 127,681 & 556,899 \\
\hline 1999 & US & 0.187 & $1,266,941$ & $5,525,921$ \\
\hline 2000 & CA & 0.196 & 153,516 & 629,803 \\
\hline 2000 & US & 0.196 & $1,429,280$ & $5,863,639$ \\
\hline 2001 & CA & 0.206 & 160,627 & 619,828 \\
\hline 2001 & US & 0.206 & $1,473,761$ & $5,686,947$ \\
\hline 2002 & CA & 0.216 & 175,413 & 636,674 \\
\hline 2002 & US & 0.216 & $1,593,616$ & $5,784,128$ \\
\hline 2003 & CA & 0.227 & 185,386 & 632,897 \\
\hline 2003 & US & 0.227 & $1,729,395$ & $5,904,051$ \\
\hline 2004 & CA & 0.237 & 208,351 & 669,042 \\
\hline 2004 & US & 0.237 & $1,880,190$ & $6,037,537$ \\
\hline 2005 & CA & 0.249 & 227,251 & 686,383 \\
\hline 2005 & US & 0.249 & $2,049,601$ & $6,190,552$ \\
\hline 2006 & CA & 0.260 & 248,215 & 705,164 \\
\hline 2006 & US & 0.260 & $2,234,100$ & $6,346,943$ \\
\hline 2007 & CA & 0.272 & 273,698 & 731,368 \\
\hline 2007 & US & 0.272 & $2,438,266$ & $6,515,460$ \\
\hline 2008 & CA & 0.285 & 295,503 & 742,726 \\
\hline 2008 & US & 0.285 & $2,627,118$ & $6,603,063$ \\
\hline 2009 & CA & 0.297 & 321,198 & 759,349 \\
\hline 2009 & US & 0.297 & $2,818,630$ & $6,663,555$ \\
\hline
\end{tabular}

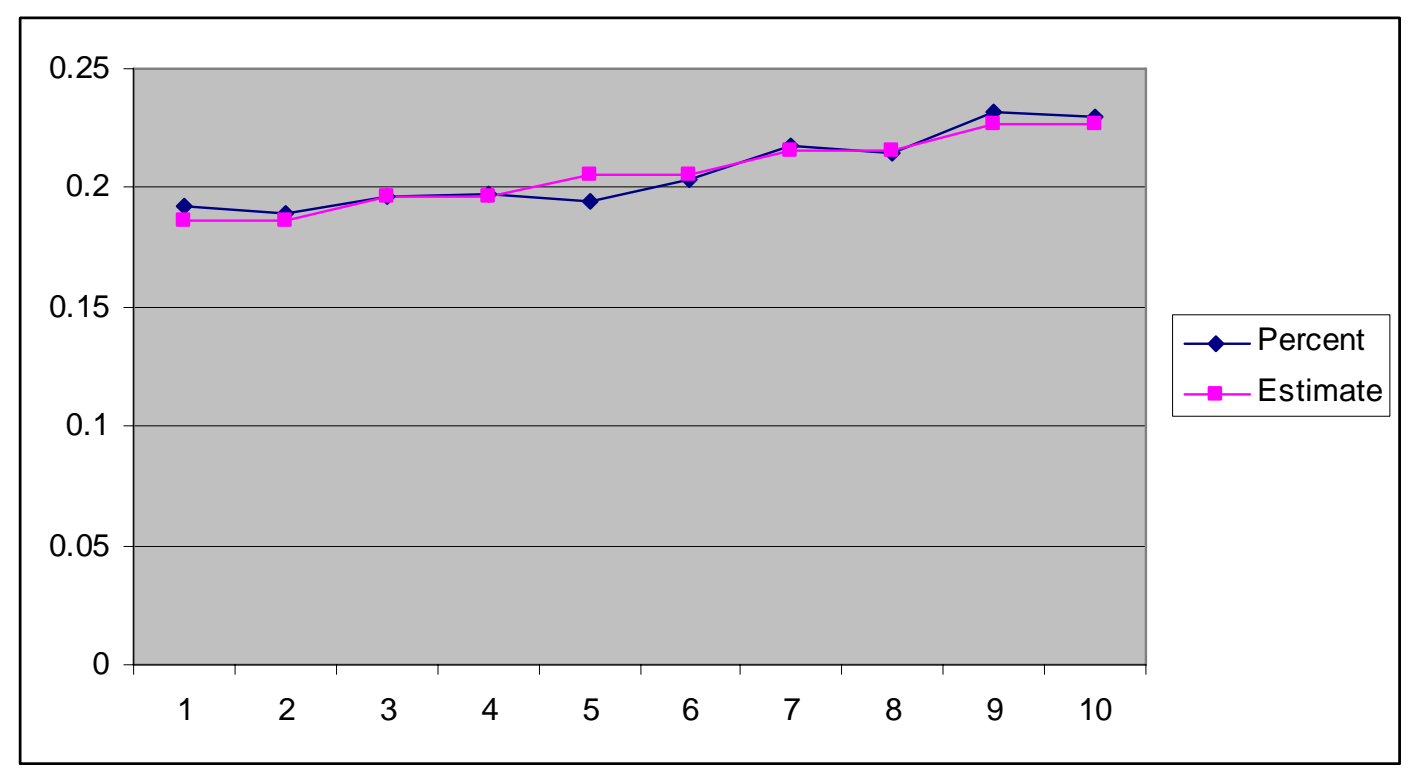




\section{Appendix IV \\ Linear Regression Results}

The Regression Results appendix shows the output of the level three linear regression analysis. Each regression was first run including both "Year" and "CAvsUS" and if both coefficients had P-Values lower than 0.10, they would be used to forecast future vehicle sales. However, if one of the variables had a P-Value greater than 0.10 , it was removed and the regression was rerun. These variables exhibit a coefficient of zero (indicated by a blank cell). The new coefficients were then used in the analysis. If there were no statistically significant coefficients (P-Values lower than .1), the mathematical average of the data points was used. 


\section{LDT1 Transverse}

\begin{tabular}{|l|r|c|c|}
\hline 4WD-4Cyl-Gas & \multicolumn{1}{|c|}{ Adj. $\mathrm{R}^{2}$} & F-stat & p-value \\
\hline Overall Model & 0.418 & 7.472 & 0.0257 \\
\hline & Coefficient & t-stat & p-value \\
\hline Intercept & -2.0910 & -2.716 & 0.0264 \\
\hline year & 0.00105 & 2.733 & 0.0257 \\
\hline US_CA & & & \\
\hline
\end{tabular}

\begin{tabular}{|l|r|r|r|}
\hline 4WD-6cyl-Gas & \multicolumn{1}{|c|}{ Adj. $\mathrm{R}^{2}$} & \multicolumn{1}{l|}{ F-stat } & \multicolumn{1}{c|}{-value } \\
\hline Overall Model & 0.641 & 9.026 & 0.0115 \\
\hline & Coefficient & \multicolumn{1}{c|}{ t-stat } & \multicolumn{1}{c|}{-value } \\
\hline Intercept & -4.847 & -3.655 & 0.00813 \\
\hline year & 0.00242 & 3.657 & 0.0081 \\
\hline US_CA & 0.00405 & 2.163 & 0.0674 \\
\hline
\end{tabular}

\begin{tabular}{|l|r|r|l|}
\hline AWD-3-4cyl-Gas & \multicolumn{1}{|l|}{ Adj. $\mathrm{R}^{2}$} & F-stat & $\mathrm{p}$-value \\
\hline Overall Model & 0.822 & 42.479 & 0.000185 \\
\hline & Coefficient & t-stat & p-value \\
\hline Intercept & -3.625 & -6.509 & 0.000186 \\
\hline year & 0.00181 & 6.518 & 0.000185 \\
\hline US_CA & & & \\
\hline
\end{tabular}

\begin{tabular}{|l|r|l|l|}
\hline AWD-5-6cyl-Gas & \multicolumn{1}{|c|}{ Adj. $\mathrm{R}^{2}$} & F-stat & p-value \\
\hline Overall Model & 0.877 & 65.296 & $4.06 \mathrm{E}-05$ \\
\hline & Coefficient & t-stat & p-value \\
\hline Intercept & -4.598 & -8.0605 & $4.14 \mathrm{E}-05$ \\
\hline year & 0.00230 & 8.0806 & $4.06 \mathrm{E}-05$ \\
\hline US_CA & & & \\
\hline
\end{tabular}

\begin{tabular}{|l|r|l|l|}
\hline AWD-8cyl-Gas & \multicolumn{1}{|c|}{ Adj. $\mathrm{R}^{2}$} & \multicolumn{1}{l|}{ F-stat } & $\mathrm{p}$-value \\
\hline Overall Model & 0.761 & 29.686 & 0.00061 \\
\hline & Coefficient & t-stat & p-value \\
\hline Intercept & -0.155 & -5.445 & 0.000612 \\
\hline year & $7.77 \mathrm{E}-05$ & 5.449 & 0.00061 \\
\hline US_CA & & & \\
\hline
\end{tabular}

\begin{tabular}{|l|r|r|l|}
\hline FWD-3-4cyl-Gas & \multicolumn{1}{|c|}{ Adj. $\mathrm{R}^{2}$} & \multicolumn{1}{l|}{ F-stat } & $\mathrm{p}$-value \\
\hline Overall Model & 0.995 & 863.735 & \multicolumn{1}{|c|}{ 4.18E-09 } \\
\hline & Coefficient & \multicolumn{1}{c|}{-stat } & p-value \\
\hline Intercept & -9.624 & -7.323 & 0.00016 \\
\hline year & 0.00512 & 7.788 & 0.000108 \\
\hline US_CA & -0.0758 & -40.827 & $1.38 \mathrm{E}-09$ \\
\hline
\end{tabular}




\begin{tabular}{|l|r|r|l|}
\hline $\begin{array}{l}\text { FWD-3-4cyl-Gas-Elec } \\
\text { HEV }\end{array}$ & \multicolumn{1}{|c|}{ Adj. $\mathrm{R}^{2}$} & \multicolumn{1}{|c|}{ F-stat } & p-value \\
\hline Overall Model & 0.859 & 28.336 & 0.000441 \\
\hline & Coefficient & t-stat & p-value \\
\hline Intercept & -5.0945 & -6.729 & 0.000270 \\
\hline year & 0.00255 & 6.737 & 0.000268 \\
\hline US_CA & -0.00359 & -3.359 & 0.0121 \\
\hline
\end{tabular}

\begin{tabular}{|l|r|c|c|}
\hline FWD-4cyl-Diesel & \multicolumn{1}{|c|}{ Adj. $\mathrm{R}^{2}$} & \multicolumn{1}{l|}{ F-stat } & p-value \\
\hline Overall Model & 0.786 & 17.529 & 0.00188 \\
\hline & Coefficient & t-stat & p-value \\
\hline Intercept & -1.190 & -4.253 & 0.00378 \\
\hline year & 0.000595 & 4.259 & 0.00375 \\
\hline US_CA & 0.00163 & 4.114 & 0.00450 \\
\hline
\end{tabular}

\begin{tabular}{|l|r|l|l|}
\hline FWD-4cyl-Nat Gas & \multicolumn{1}{|c|}{ Adj. $\mathrm{R}^{2}$} & F-stat & $\mathrm{p}$-value \\
\hline Overall Model & 0.60273 & 14.655 & 0.00503 \\
\hline & Coefficient & t-stat & p-value \\
\hline Intercept & 0.000769 & 8.481822 & $2.86 \mathrm{E}-05$ \\
\hline year & & & \\
\hline US_CA & -0.000490 & -3.828 & 0.00503 \\
\hline
\end{tabular}

\begin{tabular}{|l|r|c|l|}
\hline FWD-5-6cyl-Gas & \multicolumn{1}{|c|}{ Adj. $\mathrm{R}^{2}$} & \multicolumn{1}{l|}{ F-stat } & p-value \\
\hline Overall Model & 0.992 & \multicolumn{1}{|c|}{537.089} & $2.18 \mathrm{E}-08$ \\
\hline & Coefficient & t-stat & p-value \\
\hline Intercept & 30.188 & 18.230 & $3.7 \mathrm{E}-07$ \\
\hline year & -0.0149 & -18.0338 & $3.98 \mathrm{E}-07$ \\
\hline US_CA & 0.0641 & 27.367 & $2.23 \mathrm{E}-08$ \\
\hline
\end{tabular}

\begin{tabular}{|l|r|l|c|}
\hline FWD-6cyl-Flex & Adj. $\mathrm{R}^{2}$ & F-stat & p-value \\
\hline Overall Model & -0.127 & 0.499 & 0.630 \\
\hline & Coefficient & t-stat & p-value \\
\hline Intercept & 0.00933 & & \\
\hline year & & & \\
\hline US_CA & & & \\
\hline $\begin{array}{l}\text { Because none of the coefficients in the model are significant at } \\
\text { the 0.10 level or better, the average of the data was used as the } \\
\text { model: } Y=.009333\end{array}$ \\
\hline
\end{tabular}

\begin{tabular}{|l|r|c|l|}
\hline FWD-8cyl-Gas & \multicolumn{1}{|c|}{ Adj. $\mathrm{R}^{2}$} & F-stat & p-value \\
\hline Overall Model & 0.991 & 479.514 & $3.24 \mathrm{E}-08$ \\
\hline & Coefficient & t-stat & p-value \\
\hline Intercept & 5.077 & 20.766 & $1.51 \mathrm{E}-07$ \\
\hline year & -0.00253 & -20.715 & $1.53 \mathrm{E}-07$ \\
\hline US_CA & 0.00796 & 23.0196 & $7.4 \mathrm{E}-08$ \\
\hline
\end{tabular}


LDT1 Longitudinal

\begin{tabular}{|l|r|c|l|}
\hline 4WD-4cyl-Gas & \multicolumn{1}{|c|}{ Adj. $\mathrm{R}^{2}$} & \multicolumn{1}{l|}{ F-stat } & p-value \\
\hline Overall Model & 0.890 & 37.307 & 0.000185 \\
\hline & Coefficient & t-stat & p-value \\
\hline Intercept & 9.0520 & 5.0858 & 0.00142 \\
\hline year & -0.00452 & -5.0790 & 0.00143 \\
\hline US_CA & 0.0176 & 6.987 & 0.000214 \\
\hline
\end{tabular}

\begin{tabular}{|l|r|c|c|}
\hline 4WD-5-6cyl-Gas & \multicolumn{1}{|c|}{ Adj. $\mathrm{R}^{2}$} & \multicolumn{1}{l|}{ F-stat } & \multicolumn{1}{c|}{-value } \\
\hline Overall Model & 0.799 & 18.870 & 0.00152 \\
\hline & Coefficient & \multicolumn{1}{c|}{ t-stat } & p-value \\
\hline Intercept & 14.859 & 3.737 & 0.00729 \\
\hline year & -0.00741 & -3.730 & 0.00736 \\
\hline US_CA & 0.0274 & 4.881 & 0.00179 \\
\hline
\end{tabular}

\begin{tabular}{|l|r|c|c|}
\hline AWD-10-12cy-Gas & \multicolumn{1}{|c|}{ Adj. $\mathrm{R}^{2}$} & F-stat & p-value \\
\hline Overall Model & 0.687 & 20.723 & 0.00187 \\
\hline & Coefficient & t-stat & p-value \\
\hline Intercept & $8.97 \mathrm{E}-05$ & 15.122 & $3.62 \mathrm{E}-07$ \\
\hline year & & & \\
\hline US_CA & $-3.8 \mathrm{E}-05$ & -4.552 & 0.00187 \\
\hline
\end{tabular}

\begin{tabular}{|l|r|c|c|}
\hline AWD-3-4cyl-Gas & \multicolumn{1}{|c|}{ Adj. $\mathrm{R}^{2}$} & \multicolumn{1}{l|}{ F-stat } & p-value \\
\hline Overall Model & 0.922 & \multicolumn{1}{|c|}{54.516} & $5.39 \mathrm{E}-05$ \\
\hline & Coefficient & t-stat & p-value \\
\hline Intercept & -7.481 & -2.517 & 0.0400 \\
\hline year & 0.00377 & 2.536 & 0.0389 \\
\hline US_CA & 0.0426 & 10.129 & $1.97 \mathrm{E}-05$ \\
\hline
\end{tabular}

\begin{tabular}{|l|r|l|c|}
\hline AWD-5-6cyl-Gas & \multicolumn{1}{|c|}{ Adj. $\mathrm{R}^{2}$} & F-stat & \multicolumn{1}{c|}{$\mathrm{p}$-value } \\
\hline Overall Model & 0.600 & 14.481 & 0.00520 \\
\hline & Coefficient & \multicolumn{1}{c|}{ t-stat } & p-value \\
\hline Intercept & 0.0101 & 2.585 & 0.0323 \\
\hline year & & & \\
\hline US_CA & 0.0230 & 3.805 & 0.00520 \\
\hline
\end{tabular}

\begin{tabular}{|l|r|r|c|}
\hline AWD-8cyl-Gas & \multicolumn{1}{|c|}{ Adj. $\mathrm{R}^{2}$} & \multicolumn{1}{|c|}{ F-stat } & $\mathrm{p}$-value \\
\hline Overall Model & 0.353 & 5.918 & 0.0410 \\
\hline & Coefficient & t-stat & p-value \\
\hline Intercept & -1.469 & -2.428 & 0.0414 \\
\hline year & 0.000736 & 2.433 & 0.0410 \\
\hline US_CA & & & \\
\hline
\end{tabular}




\begin{tabular}{|l|r|r|c|}
\hline RWD-10-12cyl-Gas & \multicolumn{1}{|c|}{ Adj. $\mathrm{R}^{2}$} & \multicolumn{1}{|c|}{ F-stat } & p-value \\
\hline Overall Model & 0.4483 & 4.656 & 0.0518 \\
\hline & Coefficient & t-stat & p-value \\
\hline Intercept & -0.448 & -1.885 & 0.101 \\
\hline year & 0.000225 & 1.897 & 0.0997 \\
\hline US_CA & -0.000800 & -2.39 & 0.0481 \\
\hline
\end{tabular}

\begin{tabular}{|l|r|c|c|}
\hline RWD-3-4cyl-Gas & \multicolumn{1}{|c|}{ Adj. $\mathrm{R}^{2}$} & F-stat & p-value \\
\hline Overall Model & 0.448 & 8.313 & 0.0204 \\
\hline & Coefficient & t-stat & p-value \\
\hline Intercept & 37.392 & 2.894 & 0.0201 \\
\hline year & -0.0186 & -2.883 & 0.0204 \\
\hline US_CA & & & \\
\hline
\end{tabular}

\begin{tabular}{|l|r|l|c|}
\hline RWD-3-4cyl-Flex & Adj. $\mathrm{R}^{2}$ & F-stat & p-value \\
\hline Overall Model & -0.164 & 0.367 & 0.705 \\
\hline & Coefficient & t-stat & p-value \\
\hline Intercept & 0.0180 & & \\
\hline year & & & \\
\hline US_CA & & & \\
\hline $\begin{array}{l}\text { Because none of the coefficients in the model are significant at } \\
\text { the } 0.10 \text { level or better, the average of the data was used as the } \\
\text { model: } Y=0.0180\end{array}$ \\
\hline
\end{tabular}

\begin{tabular}{|l|r|c|l|}
\hline RWD-5-6cyl-Gas & \multicolumn{1}{|c|}{ Adj. $\mathrm{R}^{2}$} & \multicolumn{1}{l|}{ F-stat } & $\mathrm{p}$-value \\
\hline Overall Model & 0.958 & \multicolumn{1}{|c|}{102.872} & $6.46 \mathrm{E}-06$ \\
\hline & Coefficient & t-stat & p-value \\
\hline Intercept & -71.305 & -8.986 & $4.31 \mathrm{E}-05$ \\
\hline year & 0.0359 & 9.0422 & $4.14 \mathrm{E}-05$ \\
\hline US_CA & -0.125 & -11.135 & $1.05 \mathrm{E}-05$ \\
\hline
\end{tabular}

\begin{tabular}{|l|r|c|c|}
\hline RWD-6cyl-Diesel & \multicolumn{1}{|c|}{ Adj. $\mathrm{R}^{2}$} & \multicolumn{1}{|c|}{ F-stat } & $\mathrm{p}$-value \\
\hline Overall Model & 0.434 & 7.891 & 0.0229 \\
\hline & Coefficient & t-stat & p-value \\
\hline Intercept & 0.599 & 2.810 & 0.0228 \\
\hline year & -0.000300 & -2.809 & 0.0229 \\
\hline US_CA & & & \\
\hline
\end{tabular}

\begin{tabular}{|l|r|c|c|}
\hline RWD-6cyl-Flex & \multicolumn{1}{|c|}{ Adj. $\mathrm{R}^{2}$} & \multicolumn{1}{l|}{ F-stat } & p-value \\
\hline Overall Model & 0.585 & 13.667 & 0.00607 \\
\hline & Coefficient & t-stat & p-value \\
\hline Intercept & 23.924 & 3.702 & 0.00602 \\
\hline year & -0.0119 & -3.697 & 0.00607 \\
\hline US_CA & & & \\
\hline
\end{tabular}




\begin{tabular}{|l|r|c|c|}
\hline RWD-8cyl-Gas & \multicolumn{1}{|c|}{ Adj. $\mathrm{R}^{2}$} & F-stat & p-value \\
\hline Overall Model & 0.687 & 20.754 & 0.00186 \\
\hline & Coefficient & t-stat & p-value \\
\hline Intercept & 0.235 & 45.249 & $6.28 \mathrm{E}-11$ \\
\hline year & & & \\
\hline US_CA & 0.0334 & 4.556 & 0.00186 \\
\hline
\end{tabular}

\begin{tabular}{|l|r|c|c|}
\hline RWD-8cyl-Nat Gas & \multicolumn{1}{|c|}{ Adj. $\mathrm{R}^{2}$} & F-stat & $\mathrm{p}$-value \\
\hline Overall Model & 0.299 & 4.844 & 0.0589 \\
\hline & Coefficient & t-stat & p-value \\
\hline Intercept & 0.000641 & 4.943 & 0.00113 \\
\hline Year & & & \\
\hline US_CA & -0.000400 & -2.201 & 0.0589 \\
\hline
\end{tabular}

\begin{tabular}{|l|r|c|c|}
\hline RWD-Rotary-Gas & \multicolumn{1}{|c|}{ Adj. $\mathrm{R}^{2}$} & \multicolumn{1}{l|}{ F-stat } & p-value \\
\hline Overall Model & 0.428 & 7.724 & 0.0240 \\
\hline & Coefficient & t-stat & p-value \\
\hline Intercept & -1.811 & -2.778 & 0.0240 \\
\hline year & 0.000905 & 2.779 & 0.0240 \\
\hline US_CA & & & \\
\hline
\end{tabular}




\section{LDT2 Transverse}

\begin{tabular}{|l|r|c|c|}
\hline 4WD-4cyl-Gas & \multicolumn{1}{|c|}{ Adj. $\mathrm{R}^{2}$} & F-stat & p-value \\
\hline Overall Model & 0.434 & 7.902 & 0.0228 \\
\hline & Coefficient & t-stat & p-value \\
\hline Intercept & -10.829 & -2.810 & 0.0229 \\
\hline year & 0.00542 & 2.811 & 0.0228 \\
\hline US_CA & & & \\
\hline
\end{tabular}

\begin{tabular}{|l|r|c|l|}
\hline 4WD-6cyl-Gas & \multicolumn{1}{|c|}{ Adj. $\mathrm{R}^{2}$} & F-stat & p-value \\
\hline Overall Model & 0.897 & 79.358 & 2E-05 \\
\hline & Coefficient & t-stat & p-value \\
\hline Intercept & -63.0160 & -8.900 & $2.01 \mathrm{E}-05$ \\
\hline year & 0.0315 & 8.908 & $2.00 \mathrm{E}-05$ \\
\hline US_CA & & & \\
\hline
\end{tabular}

\begin{tabular}{|l|r|r|c|}
\hline AWD-3-4cyl-Gas & \multicolumn{1}{|c|}{ Adj. $\mathrm{R}^{2}$} & \multicolumn{1}{l|}{ F-stat } & \multicolumn{1}{c|}{$\mathrm{p}$-value } \\
\hline Overall Model & 0.548 & 6.463 & 0.0257 \\
\hline & Coefficient & \multicolumn{1}{c|}{ t-stat } & \multicolumn{1}{c|}{-value } \\
\hline Intercept & -0.685 & -2.163 & 0.0673 \\
\hline year & 0.000342 & 2.163 & 0.0673 \\
\hline US_CA & 0.00129 & 2.872 & 0.0239 \\
\hline
\end{tabular}

\begin{tabular}{|l|r|c|c|}
\hline AWD-5-6cyl-Gas & \multicolumn{1}{|c|}{ Adj. $\mathrm{R}^{2}$} & F-stat & $\mathrm{p}$-value \\
\hline Overall Model & 0.611 & 15.159 & 0.00460 \\
\hline & Coefficient & t-stat & p-value \\
\hline Intercept & -34.0929 & -3.883 & 0.00465 \\
\hline year & 0.0171 & 3.893 & 0.00459 \\
\hline US_CA & & & \\
\hline
\end{tabular}

\begin{tabular}{|l|r|c|c|}
\hline FWD-3-4cyl-Gas & \multicolumn{1}{|c|}{ Adj. $\mathrm{R}^{2}$} & \multicolumn{1}{|c|}{ F-stat } & p-value \\
\hline Overall Model & 0.619 & 8.320 & 0.0141 \\
\hline & Coefficient & t-stat & p-value \\
\hline Intercept & 6.578 & 2.0834 & 0.0757 \\
\hline year & -0.00326 & -2.0661 & 0.0777 \\
\hline US_CA & -0.0157 & -3.517 & 0.00976 \\
\hline
\end{tabular}

\begin{tabular}{|l|r|c|c|}
\hline FWD-5-6cyl-Gas & \multicolumn{1}{|c|}{ Adj. $\mathrm{R}^{2}$} & \multicolumn{1}{|c|}{ F-stat } & $\mathrm{p}$-value \\
\hline Overall Model & 0.801 & 19.164 & 0.00145 \\
\hline & Coefficient & \multicolumn{1}{c|}{ t-stat } & p-value \\
\hline Intercept & 116.466 & 5.773 & 0.000682 \\
\hline year & -0.0578 & -5.737 & 0.000708 \\
\hline US_CA & -0.0664 & -2.328 & 0.0528 \\
\hline
\end{tabular}




\begin{tabular}{|l|r|c|c|}
\hline FWD-5-6cyl-Flex & \multicolumn{1}{|c|}{ Adj. $\mathrm{R}^{2}$} & \multicolumn{1}{|c|}{ F-stat } & $\mathrm{p}$-value \\
\hline Overall Model & 0.522 & 10.837 & 0.0110 \\
\hline & Coefficient & t-stat & p-value \\
\hline Intercept & 0.0631 & 3.439 & 0.00884 \\
\hline year & & & \\
\hline US_CA & 0.0855 & 3.292 & 0.0110 \\
\hline
\end{tabular}




\section{LDT2 Longitudinal}

\begin{tabular}{|l|r|r|c|}
\hline 4WD-10cyl-Gas & \multicolumn{1}{|l|}{ Adj. $\mathrm{R}^{2}$} & \multicolumn{1}{l|}{ F-stat } & p-value \\
\hline Overall Model & 0.517 & 10.643 & 0.0115 \\
\hline & Coefficient & t-stat & p-value \\
\hline Intercept & 2.0626 & 3.280 & 0.0100 \\
\hline year & -0.00103 & -3.260 & 0.0100 \\
\hline US_CA & & & \\
\hline
\end{tabular}

\begin{tabular}{|l|r|l|l|}
\hline 4WD-10cyl-Propane & \multicolumn{1}{|l|}{ Adj. $\mathrm{R}^{2}$} & F-stat & $\mathrm{p}$-value \\
\hline Overall Model & -0.270 & 0.0435 & 0.958 \\
\hline & Coefficient & t-stat & p-value \\
\hline Intercept & $1.43 \mathrm{E}-06$ & & \\
\hline year & & & \\
\hline US_CA & & & \\
\hline
\end{tabular}

Because none of the coefficients in the model are significant at the 0.10 level or better, the average of the data was used as the model: $\mathrm{Y}=1.43 \mathrm{E}-06$

\begin{tabular}{|l|r|r|l|}
\hline 4WD-3-4cyl-Gas & \multicolumn{1}{|l|}{ Adj. $\mathrm{R}^{2}$} & \multicolumn{1}{l|}{ F-stat } & p-value \\
\hline Overall Model & 0.839 & 24.418 & 0.000698 \\
\hline & Coefficient & t-stat & p-value \\
\hline Intercept & 1.835 & 5.077 & 0.00144 \\
\hline year & -0.000920 & -5.0700 & 0.00145 \\
\hline US_CA & 0.00246 & 4.809 & 0.00195 \\
\hline
\end{tabular}

\begin{tabular}{|c|c|c|c|}
\hline 4WD-6cyl-Diesel & Adj. $R^{2}$ & F-stat & $p$-value \\
\hline \multirow{2}{*}{ Overall Model } & 0.701 & 22.103 & 0.00154 \\
\hline & Coefficient & t-stat & $p$-value \\
\hline Intercept & 0.00529 & 10.876 & 4.52E-06 \\
\hline \multicolumn{4}{|l|}{ year } \\
\hline US_CA & 0.00323 & 4.701 & 0.00154 \\
\hline
\end{tabular}

\begin{tabular}{|l|r|l|l|}
\hline 4WD-6cyl-Flex & Adj. $\mathrm{R}^{2}$ & F-stat & p-value \\
\hline Overall Model & 0.243 & 2.445 & 0.157 \\
\hline & Coefficient & t-stat & p-value \\
\hline Intercept & 0.00779 & & \\
\hline year & & & \\
\hline US_CA & & & \\
\hline Because none of the coefficients in the model are significant at the \\
0.10 level or better, the average of the data was used as the model: \\
$Y=0.00779$ \\
\hline
\end{tabular}




\begin{tabular}{|l|r|r|c|}
\hline 4WD-6cyl-Gas & \multicolumn{1}{|l|}{ Adj. $\mathrm{R}^{2}$} & \multicolumn{1}{l|}{ F-stat } & p-value \\
\hline Overall Model & 0.943 & 74.970 & $1.87 \mathrm{E}-05$ \\
\hline & Coefficient & \multicolumn{1}{l|}{ t-stat } & p-value \\
\hline Intercept & 18.217 & 3.338 & 0.0125 \\
\hline year & -0.00906 & -3.322 & 0.0127 \\
\hline US_CA & 0.0909 & 11.786 & $7.17 \mathrm{E}-06$ \\
\hline
\end{tabular}

\begin{tabular}{|l|r|r|r|}
\hline 4WD-8cyl-Diesel & \multicolumn{1}{|l|}{ Adj. $\mathrm{R}^{2}$} & \multicolumn{1}{l|}{ F-stat } & p-value \\
\hline Overall Model & 0.944 & 77.0178 & $1.71 \mathrm{E}-05$ \\
\hline & Coefficient & \multicolumn{1}{c|}{ t-stat } & p-value \\
\hline Intercept & -10.106 & -10.5006 & $1.55 \mathrm{E}-05$ \\
\hline year & 0.00506 & 10.526 & $1.52 \mathrm{E}-05$ \\
\hline US_CA & 0.00895 & 6.576 & 0.000311 \\
\hline
\end{tabular}

\begin{tabular}{|l|r|r|c|}
\hline 4WD-8cyl-Flex & \multicolumn{1}{|l|}{ Adj. $\mathrm{R}^{2}$} & \multicolumn{1}{l|}{ F-stat } & $\mathrm{p}$-value \\
\hline Overall Model & 0.500 & 5.492 & 0.0368 \\
\hline & Coefficient & t-stat & p-value \\
\hline Intercept & -11.245 & -2.387 & 0.0484 \\
\hline year & 0.00562 & 2.387 & 0.0484 \\
\hline US_CA & 0.0153 & 2.299 & 0.0551 \\
\hline
\end{tabular}

\begin{tabular}{|l|r|r|c|}
\hline 4WD-8cyl-Gas & \multicolumn{1}{|l|}{ Adj. $\mathrm{R}^{2}$} & \multicolumn{1}{l|}{ F-stat } & p-value \\
\hline Overall Model & 0.980 & 223.569 & 4.54E-07 \\
\hline & Coefficient & t-stat & p-value \\
\hline Intercept & 24.416 & 7.978 & $9.27 \mathrm{E}-05$ \\
\hline year & -0.0121 & -7.926 & $9.67 \mathrm{E}-05$ \\
\hline US_CA & 0.0848 & 19.604 & $2.24 \mathrm{E}-07$ \\
\hline
\end{tabular}

\begin{tabular}{|l|r|r|c|}
\hline AWD-4cyl-Gas & \multicolumn{1}{|l|}{ Adj. $\mathrm{R}^{2}$} & \multicolumn{1}{l|}{ F-stat } & p-value \\
\hline Overall Model & 0.563 & 12.603 & 0.00751 \\
\hline & Coefficient & t-stat & p-value \\
\hline Intercept & -0.674 & -3.548 & 0.00753 \\
\hline year & 0.000337 & 3.550 & 0.00751 \\
\hline US_CA & & & \\
\hline
\end{tabular}

\begin{tabular}{|l|r|r|c|}
\hline AWD-6cyl-Flex & \multicolumn{1}{|l|}{ Adj. $\mathrm{R}^{2}$} & \multicolumn{1}{|l|}{ F-stat } & p-value \\
\hline Overall Model & 0.424 & 7.628 & 0.0246 \\
\hline & Coefficient & t-stat & p-value \\
\hline Intercept & -1.107 & -2.76 & 0.0247 \\
\hline year & 0.000554 & 2.762 & 0.0246 \\
\hline US_CA & & & \\
\hline
\end{tabular}




\begin{tabular}{|l|r|l|l|}
\hline AWD-6cyl-Gas & \multicolumn{1}{|l|}{ Adj. $\mathrm{R}^{2}$} & \multicolumn{1}{l|}{ F-stat } & p-value \\
\hline Overall Model & 0.930 & 61.0218 & $3.72 \mathrm{E}-05$ \\
\hline & Coefficient & \multicolumn{1}{l|}{ t-stat } & p-value \\
\hline Intercept & -8.296 & -9.981 & $2.17 \mathrm{E}-05$ \\
\hline year & 0.00416 & 10.0184 & $2.11 \mathrm{E}-05$ \\
\hline US_CA & -0.00547 & -4.656 & 0.00233 \\
\hline
\end{tabular}

\begin{tabular}{|l|r|r|c|}
\hline AWD-8cyl-Gas & \multicolumn{1}{|l|}{ Adj. $\mathrm{R}^{2}$} & \multicolumn{1}{l|}{ F-stat } & p-value \\
\hline Overall Model & 0.726 & 12.899 & 0.00449 \\
\hline & Coefficient & \multicolumn{1}{|l|}{ t-stat } & p-value \\
\hline Intercept & -14.500 & -4.564 & 0.00259 \\
\hline year & 0.00727 & 4.578 & 0.00255 \\
\hline US_CA & -0.00988 & -2.200 & 0.0637 \\
\hline
\end{tabular}

\begin{tabular}{|l|r|r|l|}
\hline RWD-10cyl-Gas & \multicolumn{1}{|l|}{ Adj. $\mathrm{R}^{2}$} & \multicolumn{1}{l|}{ F-stat } & p-value \\
\hline Overall Model & 0.938 & 69.262 & $2.44 \mathrm{E}-05$ \\
\hline & Coefficient & \multicolumn{1}{l|}{ t-stat } & p-value \\
\hline Intercept & 2.108 & 5.0819 & 0.00143 \\
\hline year & -0.00105 & -5.0563 & 0.00147 \\
\hline US_CA & -0.00623 & -10.628 & $1.43 \mathrm{E}-05$ \\
\hline
\end{tabular}

\begin{tabular}{|c|c|c|c|}
\hline RWD-10cyl-Propane & Adj. $R^{2}$ & F-stat & $p$-value \\
\hline Overall Model & -0.173 & 0.336 & 0.726 \\
\hline & Coefficient & t-stat & $p$-value \\
\hline Intercept & 8.96E-06 & & \\
\hline year & & & \\
\hline US_CA & & & \\
\hline
\end{tabular}

Because none of the coefficients in the model are significant at the 0.10 level or better, the average of the data was used as the model: $\mathrm{Y}=8.96 \mathrm{E}-06$

\begin{tabular}{|l|r|r|c|}
\hline RWD-4cyl-Diesel & \multicolumn{1}{|l|}{ Adj. $\mathrm{R}^{2}$} & \multicolumn{1}{|l|}{-stat } & p-value \\
\hline Overall Model & 0.198 & 3.218 & 0.111 \\
\hline & Coefficient & t-stat & p-value \\
\hline Intercept & -0.0241 & -1.793 & 0.111 \\
\hline year & $1.2 \mathrm{E}-05$ & 1.794 & 0.111 \\
\hline US_CA & & & \\
\hline
\end{tabular}

\begin{tabular}{|l|r|r|l|}
\hline RWD-4cyl-Gas & \multicolumn{1}{|l|}{ Adj. $\mathrm{R}^{2}$} & \multicolumn{1}{l|}{ F-stat } & p-value \\
\hline Overall Model & 0.836 & 23.979 & 0.000737 \\
\hline & Coefficient & t-stat & p-value \\
\hline Intercept & 8.872 & 5.367 & 0.00105 \\
\hline year & -0.00442 & -5.355 & 0.00106 \\
\hline US_CA & -0.0103 & -4.392 & 0.00319 \\
\hline
\end{tabular}




\begin{tabular}{|l|r|l|l|}
\hline RWD-5-6cyl-Diesel & Adj. $\mathrm{R}^{2}$ & F-stat & p-value \\
\hline Overall Model & -0.220 & 0.190 & 0.831 \\
\hline & Coefficient & t-stat & p-value \\
\hline Intercept & 0.00284 & & \\
\hline year & & & \\
\hline US_CA & & & \\
\hline $\begin{array}{l}\text { Because none of the coefficients in the model are significant at } \\
\text { the 0.10 level or better, the average of the data was used as the } \\
\text { model: } Y=0.00284\end{array}$ \\
\hline
\end{tabular}

\begin{tabular}{|l|r|r|l|}
\hline RWD-5-6cyl-Gas & \multicolumn{1}{|l|}{ Adj. $\mathrm{R}^{2}$} & \multicolumn{1}{l|}{ F-stat } & $\mathrm{p}$-value \\
\hline Overall Model & 0.895 & 39.219 & 0.000157 \\
\hline & Coefficient & \multicolumn{1}{c|}{ t-stat } & p-value \\
\hline Intercept & 29.317 & 4.985 & 0.00159 \\
\hline year & -0.0145 & -4.947 & 0.00166 \\
\hline US_CA & -0.0610 & -7.346 & 0.000156 \\
\hline
\end{tabular}

\begin{tabular}{|l|r|l|c|}
\hline RWD-6cyl-Flex & \multicolumn{1}{|c|}{ Adj. $\mathrm{R}^{2}$} & F-stat & p-value \\
\hline Overall Model & 0.631 & 16.359 & 0.00371 \\
\hline & Coefficient & t-stat & p-value \\
\hline Intercept & -10.464 & -4.0421 & 0.00373 \\
\hline year & 0.00523 & 4.0446 & 0.00370 \\
\hline US_CA & & & \\
\hline
\end{tabular}

\begin{tabular}{|l|r|l|l|}
\hline RWD-8cyl-Diesel & Adj. $\mathrm{R}^{2}$ & F-stat & $\mathrm{p}$-value \\
\hline Overall Model & -0.173 & 0.338 & 0.724 \\
\hline & Coefficient & t-stat & $\mathrm{p}$-value \\
\hline Intercept & 0.0129 & & \\
\hline year & & & \\
\hline US_CA & & & \\
\hline $\begin{array}{l}\text { Because none of the coefficients in the model are significant at } \\
\text { the 0.10 level or better, the average of the data was used as the } \\
\text { model: } \mathrm{Y}=0.0129\end{array}$ \\
\hline
\end{tabular}

\begin{tabular}{|l|r|r|c|}
\hline RWD-8cyl-Flex & \multicolumn{1}{|c|}{ Adj. $\mathrm{R}^{2}$} & \multicolumn{1}{l|}{ F-stat } & \multicolumn{1}{c|}{-value } \\
\hline Overall Model & 0.548 & 6.447 & 0.0258 \\
\hline & Coefficient & t-stat & \multicolumn{1}{c|}{-value } \\
\hline Intercept & -7.877 & -2.767 & 0.0278 \\
\hline year & 0.00394 & 2.767 & 0.0278 \\
\hline US_CA & 0.00921 & 2.288 & 0.0559 \\
\hline
\end{tabular}




\begin{tabular}{|l|r|r|l|}
\hline RWD-8cyl-Gas & \multicolumn{1}{|c|}{ Adj. $\mathrm{R}^{2}$} & \multicolumn{1}{|c|}{ F-stat } & $\mathrm{p}$-value \\
\hline Overall Model & 0.896 & \multicolumn{1}{|c|}{39.671} & 0.000152 \\
\hline & Coefficient & t-stat & p-value \\
\hline Intercept & -18.635 & -1.816 & 0.112 \\
\hline year & 0.00949 & 1.850 & 0.107 \\
\hline US_CA & -0.126 & -8.713 & $5.26 \mathrm{E}-05$ \\
\hline
\end{tabular}

\begin{tabular}{|l|r|c|l|}
\hline RWD-8cyl-Nat Gas & \multicolumn{1}{|c|}{ Adj. $\mathrm{R}^{2}$} & F-stat & p-value \\
\hline Overall Model & 0.891 & 74.220 & $2.55 \mathrm{E}-05$ \\
\hline & Coefficient & t-stat & p-value \\
\hline Intercept & 0.000678 & 18.446 & $7.68 \mathrm{E}-08$ \\
\hline year & & & \\
\hline US_CA & -0.000450 & -8.615 & $2.55 \mathrm{E}-05$ \\
\hline
\end{tabular}




\section{Appendix V}

\section{Linear Regression Results-Tuned}

The regression models used were often reasonable predictors of future segment shares. However, the forecasting of future vehicle sales at the level required for this project is not necessarily suited for mathematical models. Thus, CAR was forced to adjust many of the models to better reflect factors that could not, by their very nature be modeled. To this end, CAR relied upon discussion with industry experts, and CAR internal industry expertise, to mold the results to better represent a reasonable estimate of the U.S. and California market for 2009. The following is a description of the changes made, and a brief description of the extent of the changes. The last to columns present the CAR adjusted forecast-CAR2009-and the regression prediction-REG2009. The CAR adjusted forecast is represented in the report as the final forecast.

\section{Passenger Vehicle-Transverse}

1. FWD/3-4cyl/Gas: Reduced due to increase in FWD3-4cyl/Gas-Elec HEV. The U.S. forecast was decreased from 57.7 percent to 53.8 percent. The California forecast was reduced from 65.3 percent 55.8 percent. California had a larger reduction than the U.S. market due largely to the expected higher share of HEVs in California.

2. FWD/5-6cyl/Gas: The regression over-emphasizes the downward trend of V6 engines. However, the increase in HEV technology will continue to put pressure on this segment. The U.S. forecast was increased slightly from 27.0 percent to 27.6. The California segment was reduced from 20.6 to 19.9

3. FWD/3-4cyl/Gas-Elec HEV: We believe the regression results greatly underestimate the HEV share for 2009. Given announced product plans, and likely other additions to the market, CAR estimates this segment will see substantial growth by 2009 . The U.S. estimate is 6 percent, while California segment is forecast to grow to 12 percent of the total transverse segment. ${ }^{21}$ However, this forecast does not necessarily suggest that CAR believes HEV technology will be a widespread success. In reality, the five year trend is strong for this technology, but even given the percentages forecasted, we believe it will still be very much in the proof of technology phase.

4. FWD/5-6cyl/Gas-Elec HEV: Because this is an entirely new segment-the first entry began sales in fourth quarter of 2004-there is no model to forecast an estimate. CAR believes that there will be other entries into this segment; however CAR does not expect it to be as high volume as the 3-4 cylinder segment. We forecast a 1.6 percent share for the U.S. market, and a 2.0 percent share for California.

5. AWD/8cyl/Gas and FWD/8cyl/Gas: Because this segment is very small, it is heavily influenced by single product introductions-and reductions. The only AWD 8 cylinder vehicle offered during recent years has been pulled from the market. Conversely the regression results forecast of 0.0 percent for the FWD 8 cylinder segment does not take into account the introduction of a redesigned FWD Cadillac Deville and two other GM offerings. Given this information, CAR

\footnotetext{
${ }^{21}$ CAR notes forecasts for higher percent of HEV sales in California than the rest of the country. Initial sales of such vehicles have been higher (on a percent basis) than the US as a whole. We believe due to higher local gas prices, increased awareness of the general buying public, and other factors, this trend will continue.
} 
has reduced the AWD/8cyl/Gas forecast to 0.0 percent, and increased the FWD/8cyl/Gas by a similar amount.

\begin{tabular}{|c|c|c|c|c|c|c|}
\hline \multicolumn{7}{|c|}{$\begin{array}{c}\text { Table IV.1 United States PCLDT1 Registrations, Transverse Layout } \\
2000-2003 \text { Actual and } 2009 \text { Forecasted } \\
\text { (percent of segment) }\end{array}$} \\
\hline Vehicle Summary & 2000 & 2001 & 2002 & 2003 & CAR2009 & REG2009 \\
\hline FWD/3-4cyl/Gas & $52.7 \%$ & $53.6 \%$ & $54.2 \%$ & $54.6 \%$ & $53.8 \%$ & $57.7 \%$ \\
\hline FWD/5-6cyl/Gas & $40.6 \%$ & $39.1 \%$ & $37.4 \%$ & $35.5 \%$ & $27.6 \%$ & $27.0 \%$ \\
\hline FWD/8cyl/Gas & $2.3 \%$ & $2.1 \%$ & $1.8 \%$ & $1.5 \%$ & $0.1 \%$ & $0.0 \%$ \\
\hline FWD/4cyl/Diesel & $0.3 \%$ & $0.3 \%$ & $0.4 \%$ & $0.4 \%$ & $0.8 \%$ & $0.8 \%$ \\
\hline FWD/6cyl/Flexible & $1.5 \%$ & $0.8 \%$ & $0.9 \%$ & $1.5 \%$ & $0.9 \%$ & $0.9 \%$ \\
\hline FWD/4cyl/Nat Gas & $0.0 \%$ & $0.0 \%$ & $0.0 \%$ & $0.0 \%$ & $0.0 \%$ & $0.0 \%$ \\
\hline $\begin{array}{l}\text { FWD/3-4cyl/Gas-Elec } \\
\mathrm{HEV}\end{array}$ & $0.1 \%$ & $0.2 \%$ & $0.5 \%$ & $0.6 \%$ & $6.0 \%$ & $2.3 \%$ \\
\hline FWD5/6Gas-Elec HEV & $\mathrm{N} / \mathrm{A}$ & $\mathrm{N} / \mathrm{A}$ & $\mathrm{N} / \mathrm{A}$ & $\mathrm{N} / \mathrm{A}$ & $1.6 \%$ & $\mathrm{~N} / \mathrm{A}$ \\
\hline AWD/4cyl/Gas & $0.3 \%$ & $0.3 \%$ & $0.6 \%$ & $1.1 \%$ & $2.0 \%$ & $2.0 \%$ \\
\hline AWD/5-6cyl/Gas & $0.8 \%$ & $1.1 \%$ & $1.5 \%$ & $1.7 \%$ & $3.0 \%$ & $3.0 \%$ \\
\hline AWD/8cyl/Gas & $0.0 \%$ & $0.0 \%$ & $0.0 \%$ & $0.0 \%$ & $0.0 \%$ & $0.1 \%$ \\
\hline 4WD+FWD/4cyl/Gas & $1.2 \%$ & $1.2 \%$ & $1.6 \%$ & $1.7 \%$ & $2.2 \%$ & $2.2 \%$ \\
\hline 4WD+FWD/6cyl/Gas & $0.2 \%$ & $1.2 \%$ & $1.0 \%$ & $1.3 \%$ & $2.0 \%$ & $2.7 \%$ \\
\hline Total US PCLDT1 Tran & $100.0 \%$ & $100.0 \%$ & $100.0 \%$ & $100.0 \%$ & $100.0 \%$ & $98.7 \%$ \\
\hline
\end{tabular}

\begin{tabular}{|c|c|c|c|c|c|c|}
\hline \multicolumn{7}{|c|}{$\begin{array}{c}\text { Table IV.2 California PCLDT1Registrations, Transverse Layout } \\
2000-2003 \text { Actual and } 2009 \text { Forecasted } \\
\text { (percent of segment) }\end{array}$} \\
\hline Vehicle Summary & 2000 & 2001 & 2002 & 2003 & CAR2009 & REG2009 \\
\hline FWD/3-4cyl/Gas & $60.2 \%$ & $61.4 \%$ & $61.2 \%$ & $61.7 \%$ & $55.8 \%$ & $65.3 \%$ \\
\hline FWD/5-6cyl/Gas & $33.3 \%$ & $32.8 \%$ & $31.0 \%$ & $29.6 \%$ & $19.9 \%$ & $20.6 \%$ \\
\hline FWD/8cyl/Gas & $1.5 \%$ & $1.3 \%$ & $0.9 \%$ & $0.8 \%$ & $0.1 \%$ & $0.0 \%$ \\
\hline FWD/4cyl/Diesel & $0.0 \%$ & $0.1 \%$ & $0.3 \%$ & $0.3 \%$ & $0.6 \%$ & $0.6 \%$ \\
\hline FWD/6cyl/Flex & $2.1 \%$ & $0.5 \%$ & $0.8 \%$ & $1.1 \%$ & $0.9 \%$ & $0.9 \%$ \\
\hline FWD/4cyl/Nat Gas & $0.1 \%$ & $0.1 \%$ & $0.1 \%$ & $0.1 \%$ & $0.1 \%$ & $0.1 \%$ \\
\hline $\begin{array}{l}\text { FWD/3-4cyl/Gas-Elec } \\
\text { HEV }\end{array}$ & $0.2 \%$ & $0.7 \%$ & $1.0 \%$ & $1.3 \%$ & $12.0 \%$ & $12.0 \%$ \\
\hline FWD/5-6cyl/Gas/HEV & $\mathrm{N} / \mathrm{A}$ & $\mathrm{N} / \mathrm{A}$ & $\mathrm{N} / \mathrm{A}$ & $\mathrm{N} / \mathrm{A}$ & $2.0 \%$ & N/A\% \\
\hline AWD/3-4cyl/Gas & $0.4 \%$ & $0.4 \%$ & $0.6 \%$ & $0.8 \%$ & $2.0 \%$ & $2.0 \%$ \\
\hline AWD/5-6cyl/Gas & $0.8 \%$ & $1.1 \%$ & $1.5 \%$ & $1.4 \%$ & $3.0 \%$ & $3.0 \%$ \\
\hline AWD/8cyl/Gas & $0.0 \%$ & $0.0 \%$ & $0.0 \%$ & $0.0 \%$ & $0.0 \%$ & $0.1 \%$ \\
\hline 4WD+FWD/4cyl/Gas & $1.2 \%$ & $1.0 \%$ & $1.4 \%$ & $1.5 \%$ & $2.2 \%$ & $2.2 \%$ \\
\hline 4WD+FWD/6cyl/Gas & $0.1 \%$ & $0.6 \%$ & $0.5 \%$ & $0.5 \%$ & $1.3 \%$ & $2.3 \%$ \\
\hline Total US PCLDT1 Tran & $100.0 \%$ & $100.0 \%$ & $100.0 \%$ & $100.0 \%$ & $99.9 \%$ & $109.1 \%$ \\
\hline
\end{tabular}


LDT2-Transverse

1. FWD/4cyl/Gas and FWD/6cyl/Gas: The linear regression model greatly exaggerates the decline in these sectors. CAR believes these segments will stabilize due largely to the increase in the passenger car based SUVs and CUVS. We also expect California to trend slightly higher for both of these segmentsand conversely lower in the four-wheel and all-wheel drive segments.

2. FWD/6cyl/Flex: As noted previously, the flex fuel segment is highly dependent upon company response to many factors, and is thus highly unpredictable-and certainly not reasonable to be forecast by regression models. CAR has used an estimate of 5 percent for this segment for both the U.S. and California in 2009.

3. Trans/FWD/3-4cyl/HEV and Trans/5-6cyl/Gas-Elec HEV: Since there were no salable vehicles in these two segments during our historical time frame, modeling of any type is not applicable. Based on industry sources and CAR estimates, we believe there will be several entrants into this segment in the coming years. However, a significant challenge is presented by the differentiation between front-wheel drive and four (or all)-wheel drive. Several of the announced entrants appear likely to offer both FWD and 4WD (or AWD). CAR believes these products will account for 8 percent (FWD only) and 12 percent (FWD and 4WDor AWD) of transverse LDT2s registered in both the US and California by 2009.

4. AWD/4cyl/Gas and AWD/5-6cyl/Gas: CAR believes the regression models present reasonable estimates for 2009. However, the regression models must be tempered somewhat by the introduction of four-wheel drive HEV entrants. CAR has adjusted downward slightly the regression model to account for HEV technology in the AWD/5-6cyl/Gas segment.

5. 4WD+FWD/6cyl/Gas: The regression model overestimates the continued growth for this sector, thus, CAR has reduced the estimates for both U.S. and California. This reduction in the growth rate is due to the number of new entrants being slowed greatly in the coming years indicating a mature segment. 


\begin{tabular}{|c|c|c|c|c|c|c|}
\hline \multicolumn{7}{|c|}{$\begin{array}{c}\text { Table IV.3 U.S. LDT2 Registrations, Transverse Layout } \\
2000-2003 \text { Actual and } 2009 \text { Forecasted } \\
\text { (percent of segment) }\end{array}$} \\
\hline Vehicle Summary & 2000 & 2001 & 2002 & 2003 & CAR2009 & REG2009 \\
\hline FWD/4cyl/Gas & $3.7 \%$ & $3.9 \%$ & $3.7 \%$ & $3.2 \%$ & $2.8 \%$ & $1.3 \%$ \\
\hline FWD/6cyl/Gas & $75.2 \%$ & $64.8 \%$ & $59.5 \%$ & $58.6 \%$ & $44.7 \%$ & $20.0 \%$ \\
\hline FWD/6cyl/Flex & $15.1 \%$ & $15.9 \%$ & $16.6 \%$ & $10.0 \%$ & $5.0 \%$ & $14.9 \%$ \\
\hline Trans/FWD/3-4cyl/HEV & $\mathrm{N} / \mathrm{A}$ & $\mathrm{N} / \mathrm{A}$ & $\mathrm{N} / \mathrm{A}$ & $\mathrm{N} / \mathrm{A}$ & $4.0 \%$ & \\
\hline Trans/FWD/5/6-cyl/HEV & $\mathrm{N} / \mathrm{A}$ & $\mathrm{N} / \mathrm{A}$ & $\mathrm{N} / \mathrm{A}$ & $\mathrm{N} / \mathrm{A}$ & $4.0 \%$ & \\
\hline $\begin{array}{l}\text { Trans/4WD/3-4cyl/HEV } \\
\text { (includes AWD) }\end{array}$ & N/A & N/A & N/A & N/A & $2.0 \%$ & \\
\hline $\begin{array}{l}\text { Trans/4WD /5- } \\
\text { 6cyl/HEV(includes AWD) }\end{array}$ & N/A & N/A & N/A & N/A & $2.0 \%$ & \\
\hline AWD/4cyl/Gas & $0.0 \%$ & $0.2 \%$ & $0.2 \%$ & $0.2 \%$ & $1.0 \%$ & $0.4 \%$ \\
\hline AWD/5-6cyl/Gas & $4.9 \%$ & $8.4 \%$ & $12.6 \%$ & $14.8 \%$ & $15.0 \%$ & $22.4 \%$ \\
\hline 4WD+FWD/4cyl/Gas & $0.0 \%$ & $0.0 \%$ & $0.0 \%$ & $2.5 \%$ & $3.9 \%$ & $4.9 \%$ \\
\hline 4WD+FWD/6cyl/Gas & $1.2 \%$ & $6.8 \%$ & $7.3 \%$ & $10.7 \%$ & $15.6 \%$ & $31.0 \%$ \\
\hline Total US LDT2 Tran & $100.0 \%$ & $100.0 \%$ & $100.0 \%$ & $100.0 \%$ & $100.0 \%$ & $94.9 \%$ \\
\hline
\end{tabular}

\begin{tabular}{|c|c|c|c|c|c|c|}
\hline \multicolumn{7}{|c|}{$\begin{array}{c}\text { Table IV.4 California LDT2 Registrations, Transverse Layout } \\
\text { 2000-2003 Actual and } 2009 \text { Forecasted } \\
\text { (percent of segment) }\end{array}$} \\
\hline Vehicle Summary & 2000 & 2001 & 2002 & 2003 & CAR2009 & REG2009 \\
\hline FWD/3-4cyl/Gas & $4.3 \%$ & $5.9 \%$ & $5.3 \%$ & $4.8 \%$ & $2.8 \%$ & 2.8 \\
\hline FWD/5-6cyl/Gas & $86.7 \%$ & $68.2 \%$ & $64.2 \%$ & $60.8 \%$ & $44.7 \%$ & 26.7 \\
\hline FWD/5-6cyl/Flex & $1.7 \%$ & $9.7 \%$ & $12.0 \%$ & $7.9 \%$ & $5.0 \%$ & 6.3 \\
\hline Trans/FWD/3-4cyl/HEV & N/A & N/A & N/A & N/A & $4.0 \%$ & \\
\hline Trans/FWD/5-6cyl/HEV & $\mathrm{N} / \mathrm{A}$ & $\mathrm{N} / \mathrm{A}$ & $\mathrm{N} / \mathrm{A}$ & $\mathrm{N} / \mathrm{A}$ & $4.0 \%$ & \\
\hline $\begin{array}{l}\text { Trans/4WD/3-4cyl/HEV } \\
\text { (includes AWD) }\end{array}$ & $\mathrm{N} / \mathrm{A}$ & $\mathrm{N} / \mathrm{A}$ & $\mathrm{N} / \mathrm{A}$ & N/A & $2.0 \%$ & \\
\hline $\begin{array}{l}\text { Trans/4WD /5- } \\
\text { 6cyl/HEV(includes AWD) }\end{array}$ & N/A & N/A & $\mathrm{N} / \mathrm{A}$ & $\mathrm{N} / \mathrm{A}$ & $2.0 \%$ & \\
\hline AWD/4cyl/Gas & $0.0 \%$ & $0.0 \%$ & $0.0 \%$ & $0.0 \%$ & $1.0 \%$ & 0.3 \\
\hline AWD/5-6cyl/Gas & $6.4 \%$ & $7.9 \%$ & $9.2 \%$ & $10.0 \%$ & $15.0 \%$ & 22.4 \\
\hline 4WD+FWD/4cyl/Gas & $0.0 \%$ & $0.0 \%$ & $0.0 \%$ & $2.9 \%$ & $3.9 \%$ & 4.9 \\
\hline 4WD+FWD/6cyl/Gas & $0.9 \%$ & $8.3 \%$ & $9.3 \%$ & $13.6 \%$ & $15.6 \%$ & 31.0 \\
\hline Total CA LDT2 Tran & $100.0 \%$ & $100.0 \%$ & $100.0 \%$ & $100.0 \%$ & $100.0 \%$ & $94.4 \%$ \\
\hline
\end{tabular}


Passenger Vehicle-Longitudinal

1. RWD/4cyl/Gas: The linear regression model greatly exaggerates the decline in this segment. CAR believes this segment will remain relatively stable through 2009. There is potential for substitution of 4 cylinder vehicles with new entrants in the 6 cylinder segments. CAR forecasts a 11.6 percent share for the U.S and 13.0 percent of California

2. RWD/6cyl/Gas: The regression models exaggerate the growth of this sector for both the U.S. and California markets. CAR believes there will be continued growth in this segment; however, due to increased product offerings in the allwheel and four-wheel drive the growth will not come near the regression model. CAR has limited this segment to 41.0 percent for the U.S. market, and 53.1 percent for California.

3. RWD/6cyl/Diesel: Since there were no salable vehicles in these two segments during our historical time frame, modeling of any type is not applicable. However, there are pending entrants into this segment that may present initial share, and thus CAR estimates a small share for the diesel engine in both the U.S. and California markets.

4. AWD segments: CAR believes the AWD/4cyl/Gas segment will remain stable as it now appears to be a mature segment, with entrants leaving and entering in relatively equal numbers. There are new entrants into the AWD/6cyl/Gas segment, and as such should lead to a slight increase for both markets. CAR believes the AWD/8cyl/Gas segment will see growth in the coming five years. Several manufacturers are either entering, or increasing their focus on, this segment.

5. HEV RWD segments: There is currently one HEV RWD vehicle announced. This is expected to be a low volume entry, with relatively higher sales in California. We expect others, but not likely within this forecast period.

\begin{tabular}{|c|c|c|c|c|c|c|}
\hline \multicolumn{7}{|c|}{$\begin{array}{c}\text { Table IV.5 United States PCLDT1Registrations, Longitudinal Layout } \\
2000-2003 \text { Actual and } 2009 \text { Forecasted } \\
\text { (percent of segment) }\end{array}$} \\
\hline Vehicle Summary & 2000 & 2001 & 2002 & 2003 & CAR2009 & REG2009 \\
\hline RWD/4cyl/Gas & $14.2 \%$ & $9.4 \%$ & $10.1 \%$ & $12.1 \%$ & $11.6 \%$ & $0.0 \%$ \\
\hline RWD/5-6cyl/Gas & $26.8 \%$ & $34.0 \%$ & $36.2 \%$ & $37.8 \%$ & $41.0 \%$ & $60.7 \%$ \\
\hline RWD/8cyl/Gas & $25.6 \%$ & $27.8 \%$ & $28.4 \%$ & $26.5 \%$ & $25.8 \%$ & $26.8 \%$ \\
\hline RWD/10-12cyl/Gas & $0.2 \%$ & $0.2 \%$ & $0.2 \%$ & $0.3 \%$ & $0.4 \%$ & $0.4 \%$ \\
\hline RWD/4cyl/Flex & $4.3 \%$ & $4.0 \%$ & $3.0 \%$ & $0.1 \%$ & $1.8 \%$ & $1.8 \%$ \\
\hline RWD/6cyl/Flex & $6.0 \%$ & $1.8 \%$ & $1.6 \%$ & $2.7 \%$ & $0.2 \%$ & $0.0 \%$ \\
\hline RWD/6cyl/Diesel & $0.0 \%$ & $0.0 \%$ & $0.0 \%$ & $0.0 \%$ & $0.3 \%$ & $\mathrm{~N} / \mathrm{A}$ \\
\hline RWD/8cyl/Nat Gas & $0.0 \%$ & $0.0 \%$ & $0.0 \%$ & $0.0 \%$ & $0.0 \%$ & $0.0 \%$ \\
\hline $\begin{array}{l}\text { RWD/Rotary } \\
\text { Engine/Gas }\end{array}$ & $0.0 \%$ & $0.0 \%$ & $0.0 \%$ & $0.5 \%$ & $0.4 \%$ & $0.4 \%$ \\
\hline AWD/4cyl/Gas & $8.6 \%$ & $10.2 \%$ & $11.0 \%$ & $10.7 \%$ & $10.7 \%$ & $12.8 \%$ \\
\hline AWD/6cyl/Gas & $4.5 \%$ & $4.1 \%$ & $2.4 \%$ & $2.8 \%$ & $3.6 \%$ & $3.1 \%$ \\
\hline AWD/8cyl/Gas & $0.4 \%$ & $0.3 \%$ & $0.3 \%$ & $0.7 \%$ & $2.7 \%$ & $0.9 \%$ \\
\hline AWD/10-12cyl/Gas & $0.0 \%$ & $0.0 \%$ & $0.0 \%$ & $0.0 \%$ & $0.1 \%$ & $0.4 \%$ \\
\hline 4WD+RWD/4cyl/Gas & $4.0 \%$ & $3.0 \%$ & $2.5 \%$ & $1.5 \%$ & $0.4 \%$ & $0.0 \%$ \\
\hline 4WD+RWD/5-6cyl/Gas & $5.6 \%$ & $5.0 \%$ & $4.3 \%$ & $4.3 \%$ & $1.0 \%$ & $0.0 \%$ \\
\hline $\begin{array}{l}\text { Total US PCLDT1 } \\
\text { Long }\end{array}$ & $100.0 \%$ & $100.0 \%$ & $100.0 \%$ & $100.0 \%$ & $100.0 \%$ & $107.3 \%$ \\
\hline
\end{tabular}




\begin{tabular}{|l|l|r|r|r|r|}
\hline \multicolumn{7}{|c|}{ Table IV.6 California PCLDT1Registrations, Longitudinal Layout } \\
$\mathbf{2 0 0 0 - 2 0 0 3}$ Actual and 2009 Forecasted \\
(percent of segment )
\end{tabular}

LDT2-Longitudinal

The regression models did not present reasonable forecasts for several of the longitudinal LDT2 segments. More than any, the longitudinal LDT2 segment, is derived by interactions among the offerings. While there have been some share trend changes in recent years, it is relatively stable, with variation within the sector driven more by corporate policy - the increased use of flex fueled vehicles-than by substitution.

1. RWD/4cyl/Gas: The decline in this segment has been driven by the reduced product offerings and consumer demand. The model forecast a decline to zero for this segment. However, it is likely that there will continue to be some offerings in the coming decade. The forecast indicates limited, but continued product offerings by at least one company.

2. RWD/6cyl/Gas: In terms of actual numbers, sales in this segment have decreased, but not by as much as may be suggested in the percentages. The period between 1999 and 2003 saw a great increase in RWD/6cyl/Flex offerings. Such a switch is driven, not by consumer demand, but instead, corporate strategy.

3. RWD/8cyl/Gas: This segment was steady-to slightly falling-in the U.S. and growing in the Californian market. CAR believes that segment fluctuation in the U.S. can be at least partially attributed to the increase in the RWD/8cyl/Flex segment. The forecast shows a reduction in this non-market driven variation for this segment. Conversely the California market showed growth for this segment during this period-with a reduction in Flex fueled vehicles. CAR chose to limit the regression forecast, in part due to the availably of Hybrid technology in this segment by 2009

4. RWD Diesel: CAR believes the model slightly underestimates RWD diesel market share for the U.S. market in 2009. Thus changes have been made to reflect this upward trend. The model gives a reasonable approximation for the California market. 
5. Flex Fuel offerings: As noted previously, the flex fuel segments are driven by factors far beyond statistical modeling and thus changes were made where necessary.

6. 4WD Gas: Several 4WD+RWD/Gas segments were also altered. These changes were largely due to product. Each of the segments experience product withdrawals, or entries that biased the regression models, and thus the forecast cushions the final results to take into account these product changes.

7. Long/4WD/8cyl/HEV/Gas: Since there were no salable vehicles in these two segments during our historical time frame, modeling of any type is not applicable. There is one announced product for this segment. However there are conflicting reports as to other entrants. CAR believes that it is highly likely there will be at least one additional entrant to this segment by 2009. It is also unclear whether these will be RWD, 4WD or AWD. Due to this uncertainty, CAR has applied all to the 4WD segment.

\begin{tabular}{|c|c|c|c|c|c|c|}
\hline \multicolumn{7}{|c|}{$\begin{array}{c}\text { Table IV.7 U.S. LDT2 Registrations, Longitudinal Layout } \\
\text { 2000-2003 Actual and 2009 Forecasted } \\
\text { (percent of segment) }\end{array}$} \\
\hline Vehicle Summary & 2000 & 2001 & 2002 & 2003 & CAR2009 & REG2009 \\
\hline RWD/4cyl/Gas & $1.5 \%$ & $1.0 \%$ & $0.7 \%$ & $0.5 \%$ & $0.1 \%$ & $0.0 \%$ \\
\hline RWD/6cyl/Gas & $18.0 \%$ & $17.2 \%$ & $16.6 \%$ & $13.9 \%$ & $11.6 \%$ & $5.1 \%$ \\
\hline RWD/8cyl/Gas & $22.8 \%$ & $23.2 \%$ & $21.1 \%$ & $21.2 \%$ & $19.6 \%$ & 20.7 \\
\hline RWD/10cyl/Gas & $0.6 \%$ & $0.5 \%$ & $0.3 \%$ & $0.2 \%$ & $0.0 \%$ & $0.0 \%$ \\
\hline RWD/4cyl/Diesel & $0.0 \%$ & $0.0 \%$ & $0.0 \%$ & $0.0 \%$ & $0.5 \%$ & $0.0 \%$ \\
\hline RWD/6cyl/Diesel & $0.3 \%$ & $0.3 \%$ & $0.2 \%$ & $0.4 \%$ & $1.0 \%$ & $0.3 \%$ \\
\hline RWD/8cyl/Diesel & $1.4 \%$ & $1.4 \%$ & $1.1 \%$ & $1.0 \%$ & $1.5 \%$ & $1.3 \%$ \\
\hline RWD/6cyl/Flex & $0.2 \%$ & $0.1 \%$ & $0.6 \%$ & $1.6 \%$ & $2.0 \%$ & $4.8 \%$ \\
\hline RWD/8cyl/Flex & $0.0 \%$ & $0.4 \%$ & $2.3 \%$ & $2.3 \%$ & $2.0 \%$ & $4.2 \%$ \\
\hline RWD/8cyl/Nat Gas & $0.0 \%$ & $0.0 \%$ & $0.0 \%$ & $0.0 \%$ & $0.0 \%$ & $0.0 \%$ \\
\hline RWD/10cyl/Propane & $0.0 \%$ & $0.0 \%$ & $0.0 \%$ & $0.0 \%$ & $0.0 \%$ & $0.0 \%$ \\
\hline AWD/4cyl/Gas & $0.0 \%$ & $0.0 \%$ & $0.0 \%$ & $0.2 \%$ & $0.3 \%$ & $0.3 \%$ \\
\hline AWD/6cyl/Gas & $2.2 \%$ & $2.6 \%$ & $2.8 \%$ & $3.3 \%$ & $5.9 \%$ & $5.9 \%$ \\
\hline AWD/8cyl/Gas & $2.7 \%$ & $2.8 \%$ & $3.2 \%$ & $5.2 \%$ & $9.1 \%$ & $9.1 \%$ \\
\hline AWD/6cyl/Flex & $0.0 \%$ & $0.0 \%$ & $0.1 \%$ & $0.4 \%$ & $0.1 \%$ & $0.6 \%$ \\
\hline 4WD+RWD/4cyl/Gas & $0.6 \%$ & $0.4 \%$ & $0.3 \%$ & $0.3 \%$ & $0.1 \%$ & $0.0 \%$ \\
\hline 4WD+RWD/5-6cyl/Gas & $18.3 \%$ & $19.0 \%$ & $19.1 \%$ & $15.5 \%$ & $13.0 \%$ & $10.8 \%$ \\
\hline 4WD+RWD/8cyl/Gas & $25.8 \%$ & $25.0 \%$ & $21.8 \%$ & $22.2 \%$ & $20.0 \%$ & $14.7 \%$ \\
\hline 4WD+RWD/10cyl/Gas & $1.1 \%$ & $0.9 \%$ & $0.7 \%$ & $0.5 \%$ & $0.3 \%$ & $0.0 \%$ \\
\hline 4WD+RWD/6cyl/Diesel & $0.9 \%$ & $0.8 \%$ & $0.7 \%$ & $1.1 \%$ & $1.7 \%$ & $0.9 \%$ \\
\hline 4WD+RWD/8cyl/Diesel & $2.7 \%$ & $3.6 \%$ & $3.8 \%$ & $4.1 \%$ & $7.4 \%$ & $7.4 \%$ \\
\hline 4WD+RWD/6cyl/Flex & $1.1 \%$ & $0.1 \%$ & $1.0 \%$ & $2.5 \%$ & $0.8 \%$ & $0.8 \%$ \\
\hline 4WD+RWD/8cyl/Flex & $0.0 \%$ & $0.6 \%$ & $3.5 \%$ & $3.7 \%$ & $2.0 \%$ & $6.1 \%$ \\
\hline 4WD+RWD/10cyl/Propane & $0.0 \%$ & $0.0 \%$ & $0.0 \%$ & $0.0 \%$ & $0.0 \%$ & $0.0 \%$ \\
\hline Long/4WD/8cyl/HEV/Gas & N/A & N/A & N/A & N/A & $1.0 \%$ & N/A \\
\hline Total US LDT2 Long & $100.0 \%$ & $100.0 \%$ & $100.0 \%$ & $100.0 \%$ & $100.0 \%$ & $93 \%$ \\
\hline
\end{tabular}




\begin{tabular}{|c|c|c|c|c|c|c|}
\hline \multicolumn{7}{|c|}{$\begin{array}{c}\text { Table IV.8 California LDT2 Registrations, Longitudinal Layout } \\
2000-2003 \text { Actual and } 2009 \text { Forecasted } \\
\text { (percent of segment) }\end{array}$} \\
\hline Vehicle Summary & 2000 & 2001 & 2002 & 2003 & CAR2009 & REG2009 \\
\hline RWD/4cyl/Gas & $3.1 \%$ & $1.8 \%$ & $1.3 \%$ & $1.0 \%$ & $0.2 \%$ & $0.0 \%$ \\
\hline RWD/5-6cyl/Gas & $25.4 \%$ & $23.5 \%$ & $21.7 \%$ & $17.7 \%$ & $13.5 \%$ & $11.2 \%$ \\
\hline RWD/8cyl/Gas & $32.2 \%$ & $35.8 \%$ & $37.2 \%$ & $38.5 \%$ & $38.7 \%$ & $42.3 \%$ \\
\hline RWD/10cyl/Gas & $1.2 \%$ & $1.2 \%$ & $1.0 \%$ & $0.7 \%$ & $0.2 \%$ & $0.2 \%$ \\
\hline RWD/4cyl/Diesel & $0.0 \%$ & $0.0 \%$ & $0.0 \%$ & $0.0 \%$ & $0.1 \%$ & $0.0 \%$ \\
\hline RWD/5-6cyl/Diesel & $0.3 \%$ & $0.2 \%$ & $0.2 \%$ & $0.3 \%$ & $0.3 \%$ & $0.3 \%$ \\
\hline RWD/8cyl/Diesel & $1.2 \%$ & $1.3 \%$ & $1.3 \%$ & $1.5 \%$ & $1.3 \%$ & $1.3 \%$ \\
\hline RWD/6cyl/Flex & $0.0 \%$ & $0.0 \%$ & $1.0 \%$ & $2.9 \%$ & $1.2 \%$ & $4.8 \%$ \\
\hline RWD/8cyl/Flex & $0.0 \%$ & $0.0 \%$ & $0.0 \%$ & $0.4 \%$ & $0.5 \%$ & $3.2 \%$ \\
\hline RWD/8cyl/Nat Gas & $0.1 \%$ & $0.1 \%$ & $0.1 \%$ & $0.1 \%$ & $0.1 \%$ & $0.1 \%$ \\
\hline RWD/10cyl/Propane & $0.0 \%$ & $0.0 \%$ & $0.0 \%$ & $0.0 \%$ & $0.0 \%$ & $0.0 \%$ \\
\hline AWD/4cyl/Gas & $0.0 \%$ & $0.0 \%$ & $0.0 \%$ & $0.1 \%$ & $0.3 \%$ & $0.3 \%$ \\
\hline AWD/6cyl/Gas & $2.6 \%$ & $3.0 \%$ & $3.5 \%$ & $4.3 \%$ & $6.4 \%$ & $6.4 \%$ \\
\hline AWD/8cyl/Gas & $3.3 \%$ & $3.6 \%$ & $4.5 \%$ & $6.8 \%$ & $10.1 \%$ & $10.1 \%$ \\
\hline AWD/6cyl/Flex & $0.0 \%$ & $0.0 \%$ & $0.0 \%$ & $0.1 \%$ & $0.1 \%$ & $0.5 \%$ \\
\hline 4WD+RWD/4cyl/Gas & $0.3 \%$ & $0.2 \%$ & $0.2 \%$ & $0.2 \%$ & $0.0 \%$ & $0.0 \%$ \\
\hline 4WD+RWD/6cyl/Gas & $10.0 \%$ & $9.2 \%$ & $8.6 \%$ & $5.7 \%$ & $4.7 \%$ & $1.7 \%$ \\
\hline 4WD+RWD/8cyl/Gas & $16.8 \%$ & $16.3 \%$ & $14.9 \%$ & $13.8 \%$ & $12.0 \%$ & $6.2 \%$ \\
\hline 4WD+RWD/10cyl/Gas & $1.1 \%$ & $0.9 \%$ & $0.7 \%$ & $0.6 \%$ & $0.3 \%$ & $0.0 \%$ \\
\hline 4WD+RWD/6cyl/Diesel & $0.6 \%$ & $0.5 \%$ & $0.4 \%$ & $0.5 \%$ & $0.9 \%$ & $0.5 \%$ \\
\hline 4WD+RWD/8cyl/Diesel & $1.6 \%$ & $2.5 \%$ & $3.0 \%$ & $3.6 \%$ & $5.5 \%$ & $6.5 \%$ \\
\hline 4WD+RWD/6cyl/Flex & $0.2 \%$ & $0.0 \%$ & $0.3 \%$ & $1.0 \%$ & $0.5 \%$ & $0.8 \%$ \\
\hline 4WD+RWD/8cyl/Flex & $0.0 \%$ & $0.0 \%$ & $0.0 \%$ & $0.2 \%$ & $1.0 \%$ & $4.5 \%$ \\
\hline 4WD+RWD/10cyl/Propane & $0.0 \%$ & $0.0 \%$ & $0.0 \%$ & $0.0 \%$ & $0.1 \%$ & $0.0 \%$ \\
\hline Long/4WD/8cyl/HEV/Gas & & & & & $2.0 \%$ & $\mathrm{~N} / \mathrm{A}$ \\
\hline Total CA LDT2 Long & $100.0 \%$ & $100.0 \%$ & $100.0 \%$ & $100.0 \%$ & $100.0 \%$ & $100.9 \%$ \\
\hline
\end{tabular}




\section{Appendix VI \\ List of Acronyms}

2WD

Two Wheel Drive

4WD Four Wheel Drive

AMT

AT.

Automated Manual Transmission

AWD Automatic Transmission

BAS All Wheel Drive

B.O.M Belt-Alternator Starter

B.O.P Bill of Materials

CARB Bill of Process

CAR California Air Resource Board

CIDI

CNC

CUV.

CVT

Compression Ignition Direct Injection Computer Numerically Controlled

DC Crossover Utility Vehicle

$\mathrm{DOHC}$ Continuously Variable Transmission

DSC

ECM

ERG

FWD

GDI. Dual Clutch

GHG

$\mathrm{HCCl}$

HEV

Dual Overhead Camshafts

14

ICE .. Double Sided Clutch

Engine Control Module

.Exhaust Gas Recirculation Front Wheel Drive Gasoline Direct Injection Greenhouse Gas

IMA

ISG

LDT

NAICS

NOx

$\mathrm{OHV}$

PCV

PM

PV

RWD

$\mathrm{SI}$

SSC

SUV

V6.

V8

VMT

Homogeneous Charge Compression Ignition Hybrid Electric Vehicle Inline 4 Cylinder Engine Internal Combustion Engine Integrated Motor Assist (Honda) Integrated Starter Generator Light Duty Trucks North American Industrial Classification System Oxides of Nitrogen Overhead Valve

Positive Crankcase Ventilation Particulate Matter

Passenger Vehicles Rear Wheel Drive Spark Ignited Single Sided Clutch Sport Utility Vehicle 6 Cylinder V Configuration Engine 8 Cylinder V Configuration Engine Vehicle Miles Traveled 